This document was prepared in conjunction with work accomplished under Contract No. DE-AC09-96SR18500 with the U. S. Department of Energy.

\title{
DISCLAIMER
}

This report was prepared as an account of work sponsored by an agency of the United States Government. Neither the United States Government nor any agency thereof, nor any of their employees, nor any of their contractors, subcontractors or their employees, makes any warranty, express or implied, or assumes any legal liability or responsibility for the accuracy, completeness, or any third party's use or the results of such use of any information, apparatus, product, or process disclosed, or represents that its use would not infringe privately owned rights. Reference herein to any specific commercial product, process, or service by trade name, trademark, manufacturer, or otherwise, does not necessarily constitute or imply its endorsement, recommendation, or favoring by the United States Government or any agency thereof or its contractors or subcontractors. The views and opinions of authors expressed herein do not necessarily state or reflect those of the United States Government or any agency thereof. 


\section{DWPF HYDROGEN GENERATION STUDY- FORM OF NOBLE METAL SRAT TESTING}

David C. Koopman

July 2005

Immobilization Technology Section Savannah River National Laboratory Aiken, SC 29808

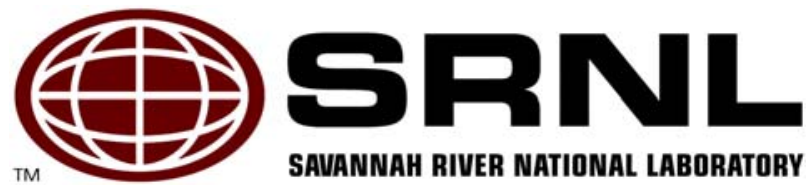




\section{DISCLAIMER}

This report was prepared by Westinghouse Savannah River Company (WSRC) for the United States Department of Energy under Contract No. DE-AC09-96SR18500 and is an account of work performed under that contract. Neither the United States Department of Energy, nor WSRC, nor any of their employees makes any warranty, expressed or implied, or assumes any legal liability or responsibility for the accuracy, completeness, or usefulness, of any information, apparatus, or product or process disclosed herein or represents that its use will not infringe privately owned rights. Reference herein to any specific commercial product, process, or service by trademark, name, manufacturer or otherwise does not necessarily constitute or imply endorsement, recommendation, or favoring of same by WSRC or by the United States Government or any agency thereof. The views and opinions of the authors expressed herein do not necessarily state or reflect those of the United States Government or any agency thereof.

\section{Printed in the United States of America}

Prepared For U.S. Department of Energy 
WSRC-TR-2005-00286

Revision 0

Key Words: SRAT, Hydrogen, Noble Metals, DWPF

Retention: permanent

\section{DWPF HYDROGEN GENERATION STUDY- FORM OF NOBLE METAL SRAT TESTING}

David C. Koopman

July 2005

Immobilization Technology Section Savannah River National Laboratory Aiken, SC 29808

Prepared for the U.S. Department of Energy Under Contract Number DEAC09-96SR18500

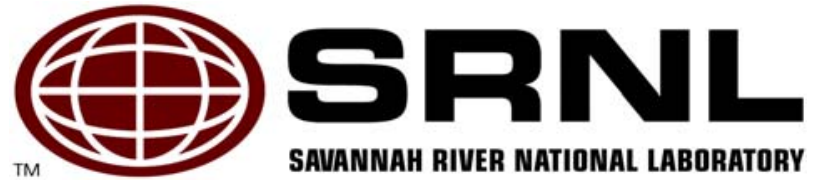




\section{REVIEWS AND APPROVALS}

\section{AUTHOR:}

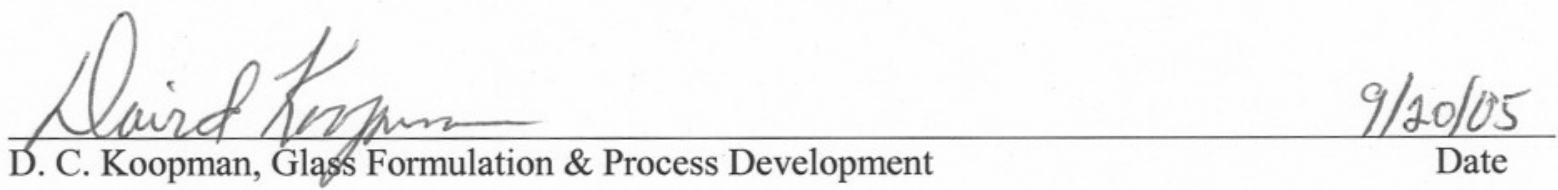

\section{TECHNICAL REVIEWER:}

Sannichis 21 Sept 05

\section{APPROVERS:}

En brotzahut

E. W. Holtzscheiter, Manager, Immobilization Technology Section $9-26-05$ Date Sharan fotauc

S. L. Marra, Manager, Glass Formulation \& Process Development

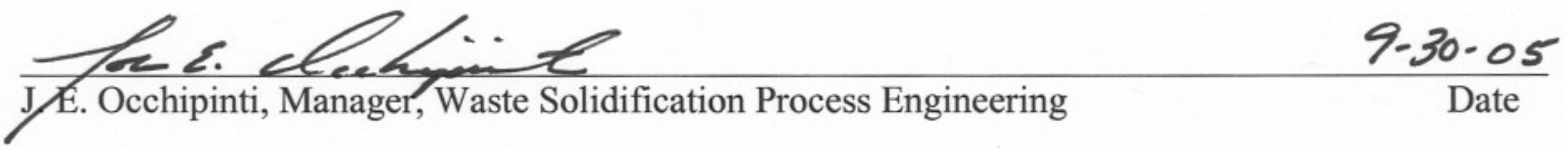




\section{EXECUTIVE SUMMARY}

The Defense Waste Processing Facility, DWPF, has requested that the Savannah River National Laboratory, SRNL, investigate the factors that contribute to hydrogen generation to determine if current conservatism in setting the DWPF processing window can be reduced. A phased program has been undertaken to increase understanding of the factors that influence hydrogen generation in the DWPF Chemical Process Cell, CPC. The hydrogen generation in the CPC is primarily due to noble metal catalyzed decomposition of formic acid with a minor contribution from radiolytic processes. Noble metals have historically been added as trim chemicals to process simulations. The present study investigated the potential conservatism that might be present from adding the catalytic species as trim chemicals to the final sludge simulant versus co-precipitating the noble metals into the insoluble sludge solids matrix.

Two sludge simulants were obtained, one with co-precipitated noble metals and one without noble metals. Co-precipitated noble metals were expected to better match real waste behavior than using trimmed noble metals during CPC simulations. Portions of both sludge simulants were held at $97^{\circ} \mathrm{C}$ for about eight hours to qualitatively simulate the effects of long term storage on particle morphology and speciation. The two original and two heat-treated sludge simulants were then used as feeds to Sludge Receipt and Adjustment Tank, SRAT, process simulations. Testing was done at relatively high acid stoichiometries, $\sim 175 \%$, and without mercury in order to ensure significant hydrogen generation. Hydrogen generation rates were monitored during processing to assess the impact of the form of noble metals. The following observations were made on the data:

- Co-precipitated noble metal simulant processed similarly to trimmed noble metal simulant in most respects, such as nitrite to nitrate conversion, formate destruction, and $\mathrm{pH}$, but differently with respect to hydrogen generation.

- The peak hydrogen generation rate occurred three to five hours later for the regular and heat-treated co-precipitated noble metal slurries than for the slurries with trimmed noble metals.

- The peak hydrogen generation rate was lower during processing of the co-precipitated noble metal simulant relative to the trimmed noble metal simulant data.

- Trimmed noble metals appeared to be conservative relative to co-precipitated noble metals under the conditions of these tests as long as the peak hydrogen generation rate occurred early in the SRAT boiling period.

- If the peak hydrogen generation rate with trimmed noble metals is near or above the DWPF limit, and if the peak occurs late in the SRAT cycle, then a potential SME cycle hydrogen generation rate issue could be anticipated when using co-precipitated noble metals, since the peak is expected to be delayed relative to trimmed noble metals.

- The peak hydrogen generation rate increased from about 1.3 to about $3.7 \mathrm{lbs} \mathrm{H}_{2} / \mathrm{hr}$ on the range of $170-190 \%$ stoichiometry, or about $0.1 \mathrm{lbs} . \mathrm{H}_{2} / \mathrm{hr}$ per \% change in the stoichiometric factor at DWPF scale.

- The peak generation rate was slightly higher during processing of the heat-treated coprecipitated noble metal simulant relative to the trimmed noble metal heat-treated simulant, but this probably due to somewhat more excess acid being added to the co-precipitated noble metal test than intended.

- The variations in the peak hydrogen generation rate appeared to track the quantity of dissolved rhodium in the SRAT product. 
- A noble metal apparently activated and then de-activated during the final hour of formic acid addition. The associated peak generation rate was $<3 \%$ of the maximum rate seen in each test. Palladium may have been responsible based on literature data.

- Planned comparisons between heat-treated and un-heat-treated simulants were complicated by the significantly altered base equivalents following heat-treatment. This necessitated making small adjustments to the stoichiometric acid factor to attempt to match the excess acid contents of the various cases.

The overall conclusion for the work completed to date is that co-precipitated noble metals were more difficult to activate, and were probably less active then trimmed noble metals under the conditions tested. The use of heat-treatment to simulate aging did not change the ease of activation of the noble metals. The relative ranking of the heat-treated trimmed and co-precipitated noble metal simulants was ambiguous with respect to peak hydrogen generation rate.

Therefore, further studies are recommended as part of the form of noble metal testing to better understand the conservatism associated with trimmed noble metals on hydrogen generation, particularly with respect to the impact of heat-treatment on the results. These include:

- Evaluating noble metal conservatism in simulant tests against Shielded Cells hydrogen generation data.

- Obtaining additional data on noble metal solubility as hydrogen generation rate changes.

- Performing follow-up tests with heat-treated simulants to clarify the impact it had on trimmed versus noble metal simulants.

These tests are intended to better define the correlation of noble metal dissolution with hydrogen generation, to ensure that simulant results continue to bound real waste processing, and to obtain more information about the effect of heat-treatment on simulant processing. Simulants that are more representative of real waste are desired for these studies, particularly with respect to base equivalents, total inorganic carbon, and rheology. 


\section{TABLE OF CONTENTS}

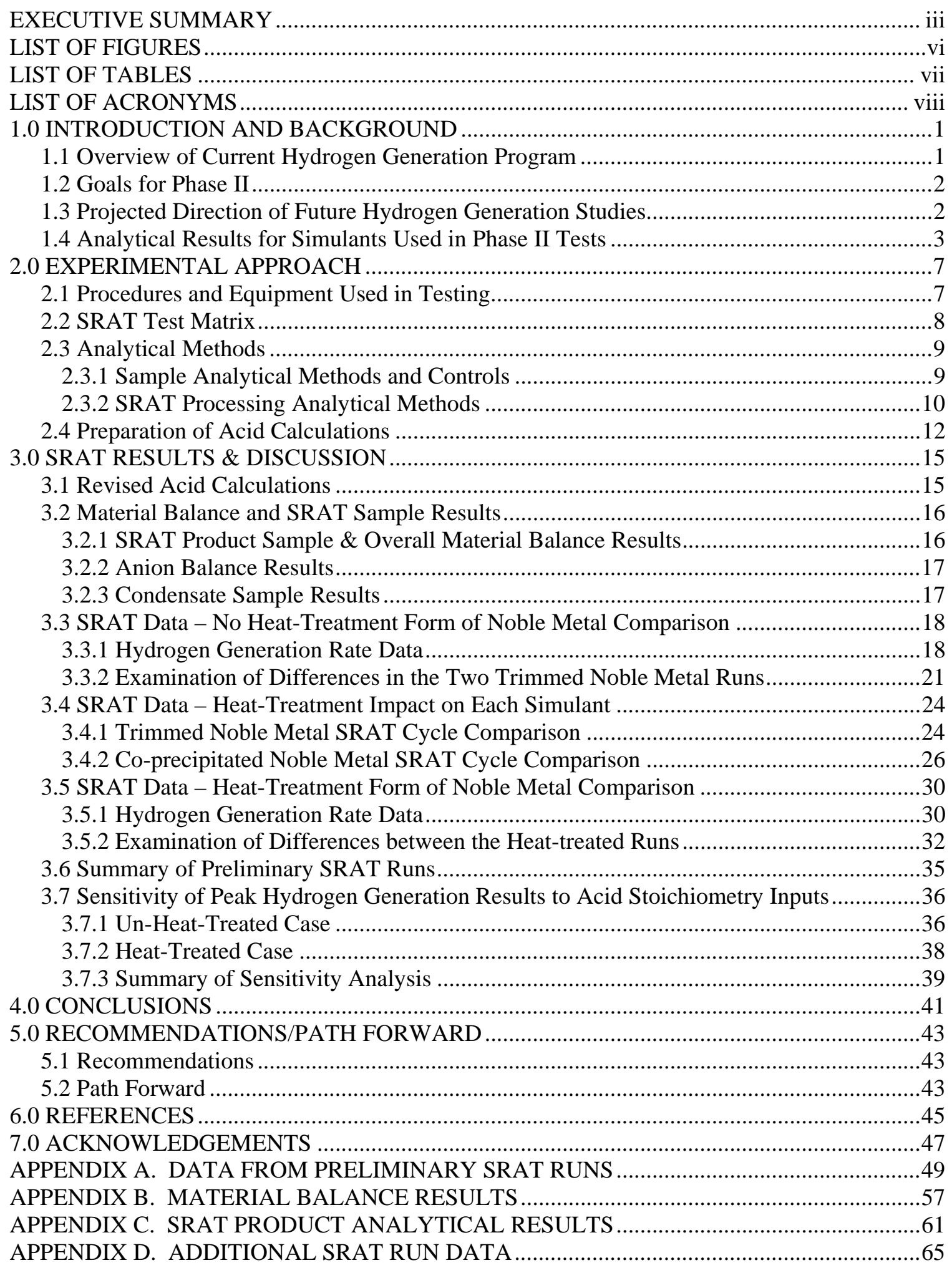




\section{LIST OF FIGURES}

Figure 1. Schematic of SRAT Equipment Set-Up........................................................................ 7

Figure 2. Hydrogen Generation Near the End of Acid Addition..................................................... 19

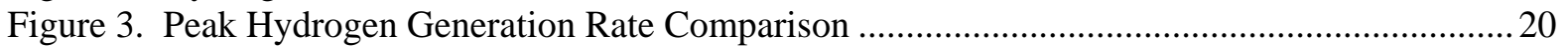

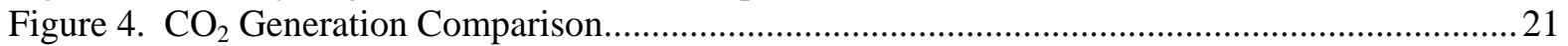

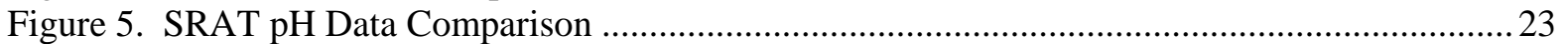

Figure 6. Comparison of SRAT $\mathrm{H}_{2}$ Data in Runs Trimmed to 100\% Noble Metals............................ 25

Figure 7. SRAT pH Data for 100\% Trimmed Noble Metals.........................................................26

Figure 8. Comparison of SRAT $\mathrm{H}_{2}$ Data in Runs with Co-Precipitated Noble Metals .......................2 27

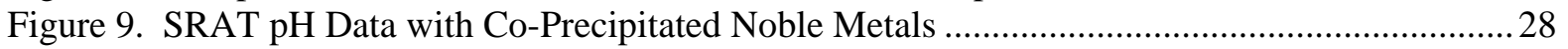

Figure 10. SRAT $\mathrm{CO}_{2}$ Data with Co-precipitated Noble Metals...................................................29

Figure 11. Onset of Hydrogen Generation - Heat-treated Case ....................................................... 31

Figure 12. Hydrogen Generation During the Heat-Treated Simulant Tests ....................................... 32

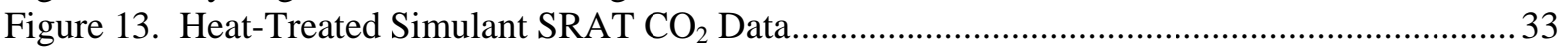

Figure 14. Heat-Treatment Impact on $\mathrm{CO}_{2}$ with Trimmed Noble Metals ......................................... 34

Figure 15. Heat-Treatment Impact on $\mathrm{CO}_{2}$ with Co-Precipitated Noble Metals................................ 35

Figure 16. Hydrogen Generation at Two Stoichiometries with Co-precipitated Simulant ................. 37

Figure 17. Onset of Hydrogen Generation in Co-ppt Testing ........................................................5 51

Figure 18. Impact of Stoichiometry on Hydrogen Generation (trimmed noble metals)......................55

Figure 19. Early Hydrogen Generation in Trimmed Noble Metal Testing ........................................53

Figure 20. Preliminary Run Carbon Dioxide Data .......................................................................... 54

Figure 21. Preliminary SRAT Run pH Data ..................................................................................5 55

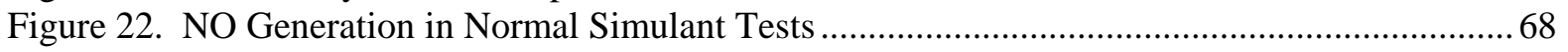

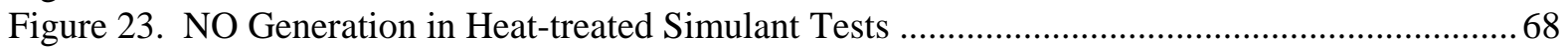

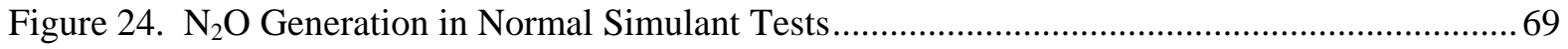

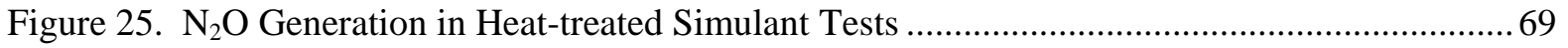




\section{LIST OF TABLES}

Table 1. Major Calcined Elemental Composition in the Starting Sludges .......................................... 4

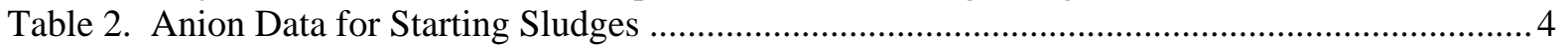

Table 3. Wt. \% Solids, Density, and pH Data for Starting Sludges ................................................ 4

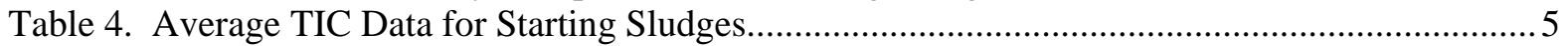

Table 5. Base Equivalents Measurements on Starting Slurries .................................................... 5

Table 6. Pre-Run Stoichiometric Acid and Redox Calculations ...................................................... 13

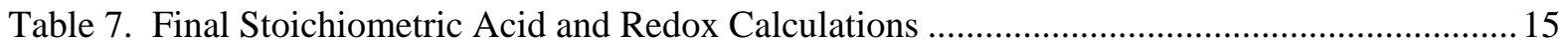

Table 8. SRAT Product Supernate Noble Metal Concentrations ....................................................... 16

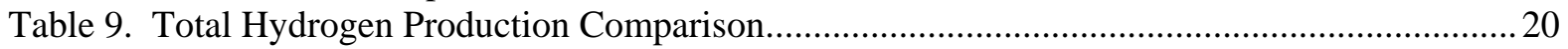

Table 10. SRAT Product Rh Dissolution Levels........................................................................ 30

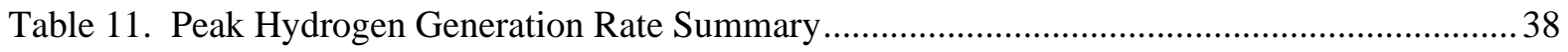

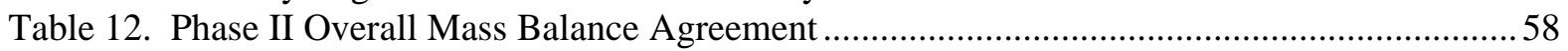

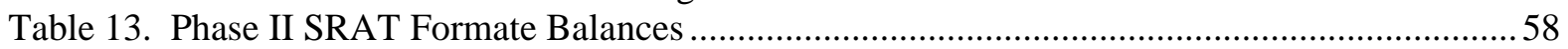

Table 14. Phase II SRAT Nitrate Balance Calculations ....................................................................5 59

Table 15. Calcined Elementals in the Phase II SRAT Products .....................................................62 62

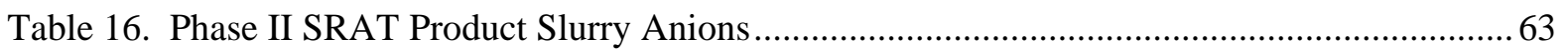

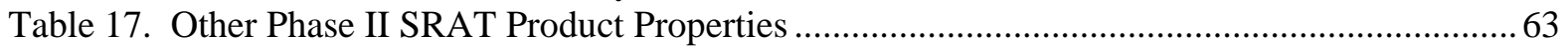

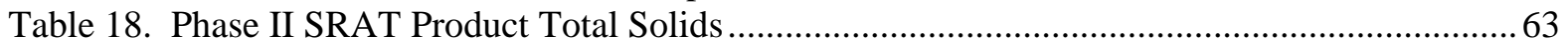

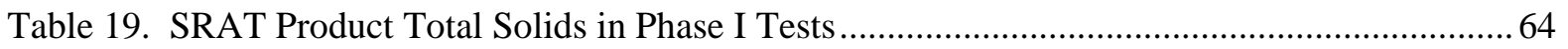

Table 20. MWWT Analyses - Co-precipitated Noble Metal Tests.....................................................6 66

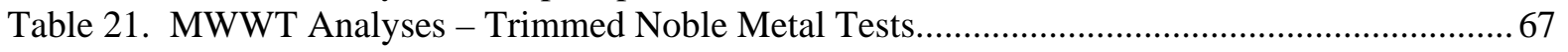

Table 22. Elemental Composition of MWWT Condensate Samples …............................................ 70

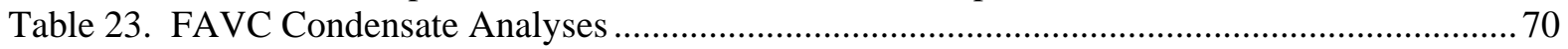




\section{LIST OF ACRONYMS}

\begin{tabular}{|c|c|}
\hline ACTL & Aiken County Technology Laboratory \\
\hline ADS & Analytical Development Section \\
\hline ASP & Analytical Study Plan \\
\hline CNM & Co-precipitated Noble Metal simulant \& SRAT test \\
\hline CNM2 & Co-precipitated Noble Metal simulant SRAT test \#2 \\
\hline CNM-HT & Co-precipitated Noble Metal, heat-treated simulant SRAT test \\
\hline CPC & Chemical Process Cell \\
\hline DWPF & Defense Waste Processing Facility \\
\hline FAVC & Formic Acid Vent Condenser \\
\hline FIC & Flow Indicating Controller \\
\hline FITC & Flow Indicating and Totalizing Controller \\
\hline GC & Gas Chromatograph \\
\hline GPD & Glass Formulation and Process Development group \\
\hline HT & Heat-treated \\
\hline IC & Ion Chromatography \\
\hline ICP-AES & Inductively Coupled Plasma-Atomic Emission Spectroscopy \\
\hline ICP-MS & Inductively Coupled Plasma-Mass Spectroscopy \\
\hline ITS & Immobilization Technology Section \\
\hline LEL & Lower Explosive Limit \\
\hline MKS & Product line of gas mass flow measurement and flow controller devices \\
\hline MWWT & Mercury Water Wash Tank \\
\hline pph & pounds per hour \\
\hline QA & Quality Assurance \\
\hline SB3 & Sludge Batch 3 \\
\hline SB4 & Sludge Batch 4 \\
\hline SLM & Std. liters per minute \\
\hline SME & Slurry Mix Evaporator vessel \\
\hline SMECT & Slurry Mix Evaporator Condensate Tank \\
\hline SRAT & Sludge Receipt and Adjustment Tank \\
\hline SRS & Savannah River Site \\
\hline SRNL & Savannah River National Laboratory \\
\hline TIC & Total Inorganic Carbon \\
\hline TNM-100 & Trimmed Noble Metal simulant SRAT test; $100 \%$ noble metal concentration \\
\hline TNM-100-2 & Trimmed Noble Metal simulant SRAT test \#2; 100\% noble metal concentration \\
\hline TNM-65 & Trimmed Noble Metal simulant SRAT test at 65\% noble metal concentration \\
\hline TNM-100-HT & Trimmed Noble Metal, heat-treated simulant SRAT test at $100 \%$ noble metal conc. \\
\hline TR & Technical Report \\
\hline TT\&QAP & Task Technical and Quality Assurance Plan \\
\hline TTR & Task technical request \\
\hline WSRC & Westinghouse Savannah River Company \\
\hline
\end{tabular}




\subsection{INTRODUCTION AND BACKGROUND}

\subsection{Overview of Current Hydrogen Generation Program}

The Defense Waste Processing Facility, DWPF, requested that the Savannah River National Laboratory, SRNL, investigate the factors that contribute to hydrogen generation to determine if current conservatism in setting the DWPF processing window can be reduced. Noble metal catalyzed hydrogen generation in simulation work constrains the allowable acid addition operating window in DWPF. This constraint potentially impacts washing strategies during sludge batch preparation. It can also influence decisions related to the addition of secondary waste streams to a sludge batch. A phased program has been undertaken to increase understanding of the factors that influence hydrogen generation in the DWPF Chemical Process Cell, CPC. The main emphasis has been on Sludge Receipt and Adjustment Tank, SRAT, reactions. Slurry Mix Evaporator, SME, hydrogen generation potential is also being evaluated during lab-scale testing. The hydrogen generation in the CPC is primarily due to noble metal catalyzed decomposition of formic acid with a minor contribution from radiolytic hydrogen generation.

Work commenced upon receipt of the HLW/DWPF/TTR-04-0028. The form of noble metal impact on hydrogen generation was selected from the overall phased program for study in FY05. A task technical and quality assurance plan, TT\&QAP, was prepared, Fellinger (2004). This plan expanded on the earlier work done in FY04. An analytical study plan, ASP, was prepared, Koopman (2004b). The FY04-FY05 program is summarized below.

Phase I included the following activities and was divided into three parts:

Part 1 Issue the $\mathrm{H}_{2}$ generation literature review covering work through 2002, i.e. through Sludge Batch 2 (this report has been issued, Koopman, 2004a). Analyze some 1998 data found during the review. Update the review to cover Sludge Batch 3, SB3, and Sludge Batch 4, SB4, hydrogen generation data collected to date. The additional tasks are reported in Koopman (2005b).

Part 2 Document recent FY04 scoping tests performed with different forms of $\mathrm{Hg}$. This report has been issued, Koopman (2005a).

Part 3 Obtain a SB3 simulant from the Simulant Development Program, Eibling (2005), without noble metals. Modify a SB3 recipe from the Simulant Development Program to include noble metals. These two simulants, with and without co-precipitated noble metals, were used to test the impact of the form of noble metals on hydrogen generation. Simulant preparation is reported in Koopman (2005c).

Phase II includes the following activities and was divided into two parts:

Part 1 Perform SRAT cycles to determine any impact of the form of noble metals on $\mathrm{H}_{2}$ generation in the SRAT. This is reported on here.

Part 2 Conduct follow-up form of noble metal work, including an assessment to determine if similar hydrogen production is achieved using simulants in the Shielded Cells equipment setup that was used in the Sludge Batch 3 qualification effort. 


\subsection{Goals for Phase II}

The primary goal of Phase II, Part 1 of the hydrogen generation program was to perform an initial evaluation of the impact, if any, of using co-precipitated noble metals in process simulations compared to using trimmed noble metals. Previous simulant studies of the DWPF SRAT have trimmed the noble metals into the available sludge simulant at the desired target compositions for Pd, Rh, and Ru. Noble metals in real waste were co-precipitated with the other sludge species in the high level waste tanks. Atoms or small crystallites of the noble metals should have been integrated into the general insoluble solids matrix. Chemical activation of noble metals in real waste is potentially subject to rate-limiting phenomena during CPC operations that might inhibit hydrogen generating reactions compared to simulant testing with trimmed noble metals.

The noble metals in Savannah River Site, SRS, tank farm wastes were not only co-precipitated with the other insoluble solids, but they have also been in storage for several decades. Long term storage could have altered the morphology and speciation of the insoluble material in the tanks. This phenomenon is referred to as aging. A decision was made to investigate aging effects on co-precipitated noble metals as a secondary goal of Phase II, Part 1 of the program. Aging would be simulated qualitatively by applying a heat-treatment to some of the co-precipitated simulant slurry prior to using it in CPC simulations. The heat-treatment methodology has been under separate study in a program developing alternative methods of simulant production and preparation, Eibling (2005).

There were two follow-up objectives for Phase II based on changes made since the Phase I SRAT testing was completed. It was observed in the Phase I, Part 2 SRAT simulations that when reflux was initiated there was a marked decline in hydrogen generation rate. The species responsible for this decline are worth identifying, if possible, since they could potentially be used to help control hydrogen generation. Investigation of this issue continued in Phase II. Targeted samples were pulled to investigate this. The lab-scale SRAT equipment had also been modified following Phase I SRAT simulations. It was desired to assess the impacts of these modifications on SRAT processing in general, and on hydrogen generation in this and future phases.

Although the CPC includes both the SRAT and the SME cycles, proposed experiments for Phase II were limited to the SRAT cycle. Peak hydrogen generation rates generally occur in the SRAT cycle when the rates are near the DWPF limits, although this is not always the case. SRAT tests were to be extended if hydrogen generation was both significant and increasing at the end of the twelve-hour SRAT reflux period to evaluate potential SME hydrogen generation behavior. Hydrogen generation rates had always peaked and were decreasing by the end of the SRAT cycle in the seven form of noble metal SRAT simulations described in this report.

\subsection{Projected Direction of Future Hydrogen Generation Studies}

The benefit of an improved understanding of hydrogen generation is the potential to reduce conservatism in defining the DWPF processing region for each sludge batch. Future phases of the hydrogen generation program beyond Phase II have various other factors to consider that have already been identified, Koopman (2004a), plus any new factors that might arise, e.g. the impact of adding new streams to the SRAT. The list of previously identified factors potentially impacting hydrogen generation that need further study included:

- the role of silver, which was reported to be able to form amalgams with the noble metals

- the role of sludge composition, and of nitrite ion in particular, which experiments have shown has a complex role in hydrogen generation 
- the role of washing in general, since the species that may be gradually poisoning the noble metal catalysts are presumably soluble, but have not been identified

- the impact of secondary waste streams (such as canyon streams or salt processing streams) on the acid requirement and the amount of excess acid

In addition to these factors, there are still some open questions regarding the relative roles of the three noble metals, Pd, Rh, and Ru. Work by C. W. Hsu (1992) with early flowsheets showed significant roles for both $\mathrm{Rh}$ and $\mathrm{Ru}$. Scoping work with the nitric acid sludge-only flowsheet has not shown a significant role for Ru. Koopman (2005b) has more details. Previously reviewed literature studies, Koopman (2004a), indicate that Pd should be the easiest noble metal to activate, and that it may be the most active of the three. It was noted in the review, however, that Pd in SRS sludge waste is typically present in lower concentrations than either $\mathrm{Rh}$ or $\mathrm{Ru}$.

\subsection{Analytical Results for Simulants Used in Phase II Tests}

Two versions of Sludge Batch 3 simulant were prepared at the Aiken County Technology Laboratory, ACTL, Koopman (2005c). One ACTL simulant included co-precipitated noble metals and the other did not. There was enough of each simulant to do four SRAT simulations of about $2400 \mathrm{~g}$ each. About onefourth of each simulant was heat-treated to simulate tank farm aging. This produced changes in some of the analytical properties. As a consequence, the un-heat-treated and heat-treated versions of each simulant were treated as different simulants, giving a total of four simulants that would be used in the Phase II, Part 1 testing.

The sludge simulants had to be analyzed before the SRAT experiments could be performed. The simulants were given the following short-hand names similar to those of the SRAT runs in which they were used:

$\begin{array}{ll}\text { TNM } & \text { trimmed noble metals required } \\ \text { TNM-HT } & \text { trimmed noble metals required and heat-treated } \\ \text { CNM } & \text { co-precipitated noble metals included } \\ \text { CNM-HT } & \text { co-precipitated noble metals included and heat-treated }\end{array}$

SRAT run names used a similar nomenclature along with numbers denoting the percentage of the target noble metals that were trimmed. The tables in this section primarily summarize data needed for the stoichiometric acid calculation for the SRAT cycle, section 2.4. Additional compositional details for the four simulants can be found in Koopman (2005c).

Calcined wt. \%'s at $1100^{\circ} \mathrm{C}$ are given in Table 1 for the major elements. CNM and CNM-HT were identical in elemental composition, since they came from the same starting material. Manganese was required for the pre-run SRAT acid calculation, section 2.4. 
Table 1. Major Calcined Elemental Composition in the Starting Sludges

\begin{tabular}{|l|c|c|c|}
\hline & TNM & TNM-HT & CNM \\
\hline $\mathrm{Al}$ & 9.23 & 8.93 & 8.13 \\
\hline $\mathrm{Ca}$ & 2.29 & 2.45 & 2.08 \\
\hline $\mathrm{Cr}$ & 0.21 & 0.20 & 0.22 \\
\hline $\mathrm{Fe}$ & 24.6 & 23.7 & 24.6 \\
\hline $\mathrm{K}$ & 0.27 & 0.32 & 0.28 \\
\hline $\mathrm{Mg}$ & 2.1 & 2.1 & 1.8 \\
\hline $\mathrm{Mn}$ & 5.2 & 5.2 & 5.1 \\
\hline $\mathrm{Na}$ & 18.9 & 18.1 & 19.8 \\
\hline $\mathrm{Ni}$ & 1.4 & 1.3 & 1.3 \\
\hline $\mathrm{P}$ & 0.52 & 0.57 & n.a. \\
\hline $\mathrm{S}$ & 0.20 & 0.22 & 0.38 \\
\hline $\mathrm{Si}$ & 0.56 & 0.98 & 0.51 \\
\hline $\mathrm{Sr}$ & 0.51 & 0.52 & 0.49 \\
\hline
\end{tabular}

n.a. $=$ not analyzed

Sludge anion results for nitrite and nitrate are given in Table 2. These were needed for the stoichiometric acid calculation to perform preliminary redox balancing of the nitric and formic acid additions.

Table 2. Anion Data for Starting Sludges

\begin{tabular}{|l|c|c|c|c||}
\hline Mg/kg slurry & TNM & TNM-HT & CNM & CNM-HT \\
\hline Nitrite & 14,200 & 16,800 & 14,000 & 15,700 \\
\hline Nitrate & 10,100 & 12,000 & 10,900 & 11,000 \\
\hline
\end{tabular}

Average results for solids are given in Table 3, along with density and $\mathrm{pH}$.

Table 3. Wt. \% Solids, Density, and pH Data for Starting Sludges

\begin{tabular}{|l|c|c|c|c|}
\hline & TNM & TNM-HT & CNM & CNM-HT \\
\hline Wt. \% TS & 18.55 & 18.89 & 18.31 & 18.65 \\
\hline Wt. \% IS & 11.59 & 12.09 & 11.05 & 11.71 \\
\hline Wt. \% SS & 6.96 & 6.80 & 7.27 & 6.93 \\
\hline Wt. \% CS & 14.05 & 14.28 & 13.95 & 14.06 \\
\hline Density, g/mL & 1.13 & 1.10 & 1.14 & 1.12 \\
\hline pH & 11.7 & 11.8 & 12.0 & Not obtained \\
\hline
\end{tabular}

TS=total solids, IS=insoluble solids, $S S=$ soluble solids, $C S=$ calcined solids

Total and calcined solids, along with density, were required for the stoichiometric acid calculation (calcined solids was needed to convert the manganese wt. \% to moles Mn per kg slurry).

Considerable total inorganic carbon, TIC, data was obtained as described in Koopman (2005c). This was averaged later to determine the best estimate of TIC for each simulant run. Table 4 has the average values obtained from the analyses. 
WSRC-TR-2005-00286

Revision 0

Table 4. Average TIC Data for Starting Sludges

\begin{tabular}{|l|c|c|c|c|}
\hline \hline mg C/kg slurry & TNM & TNM-HT & CNM & CNM-HT \\
\hline Average & 2210 & 1940 & 2440 & 2470 \\
\hline
\end{tabular}

Early base equivalent molarities were obtained by auto-titrator. Measurement switched to a manual titration technique after the auto-titrator failed in the middle of the Phase II test program.

Table 5. Base Equivalents Measurements on Starting Slurries

\begin{tabular}{|l|c|c|c|c|}
\hline M at pH 7 & TNM & TNM-HT & CNM & CNM-HT \\
\hline Auto-titrator & 0.815 & - & 0.821 & 0.690 \\
\hline Manual Titration & $\sim 0.78$ & 0.69 & 0.77 & 0.65 \\
\hline
\end{tabular}

The heat-treated, noble metal free simulant, TNM-HT, had not been prepared when the auto-titrator failed. 
WSRC-TR-2005-00286

Revision 0

This page intentionally left blank. 


\subsection{EXPERIMENTAL APPROACH}

The tasks performed to accomplish this work are described in the following sections:

2.1 Procedures and Equipment Used in Testing

2.2 SRAT Test Matrix

2.3 Analytical Methods

2.4 Preliminary SRAT Acid Calculations

\subsection{Procedures and Equipment Used in Testing}

Hydrogen generation testing was performed at ACTL. Tests used 3-L kettles with glassware fabricated to functionally replicate the DWPF CPC processing vessels. The 3-L glass kettle was used to replicate the SRAT, and it was connected to the SRAT Condenser, the Mercury Water Wash Tank, MWWT, the Slurry Mix Evaporator Condensate Tank, SMECT, and the Formic Acid Vent Condenser, FAVC. A process flow diagram of the experimental setup is given in Figure 1.

Figure 1. Schematic of SRAT Equipment Set-Up

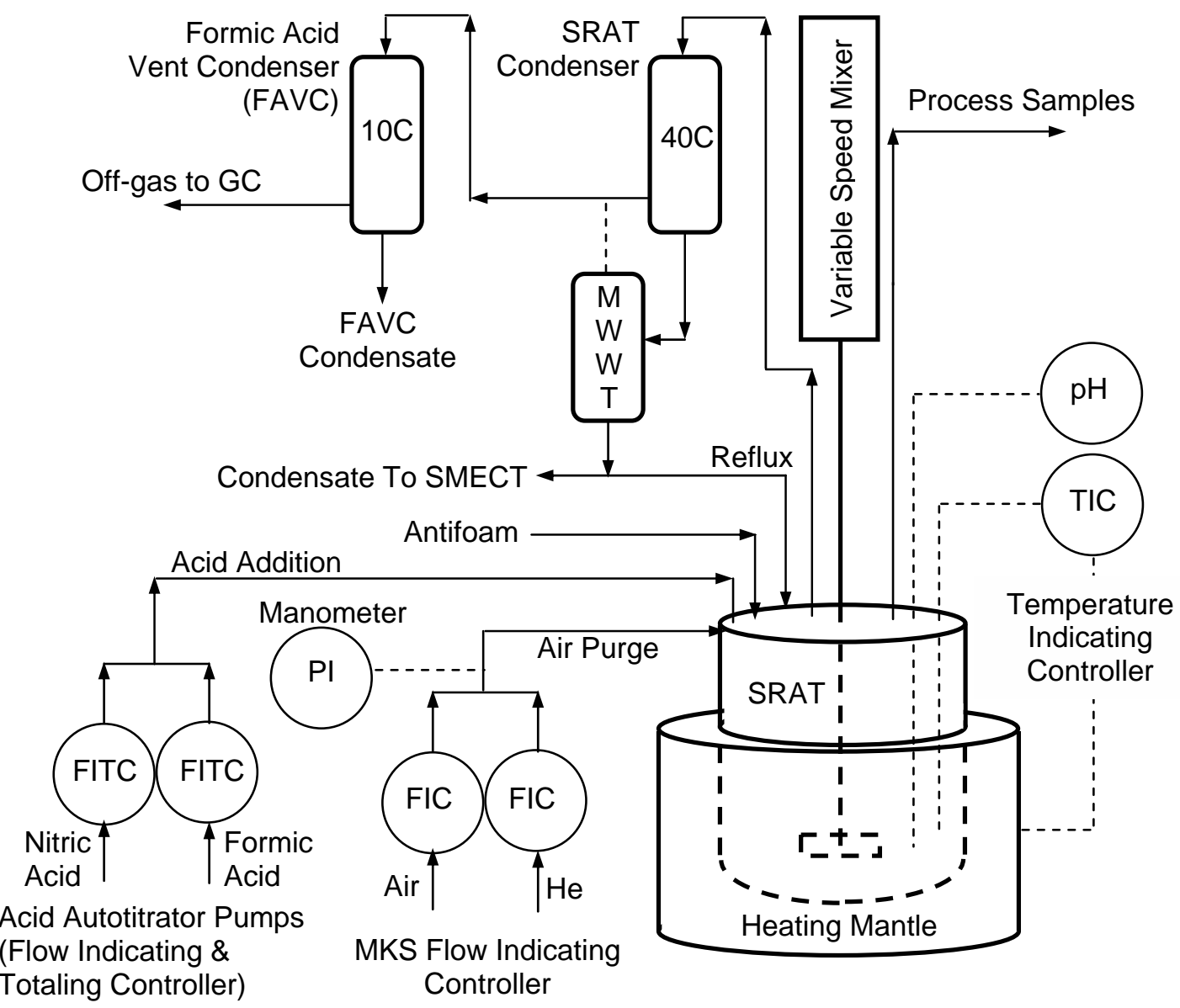


The SRNL Conduct of R\&D manual, WSRC-IM-97-00024, was used to perform a pre-check of the work to be performed. Potential issues with hydrogen concentrations in excess of one volume percent, i.e. $25 \%$ of the lower explosive limit, LEL, were identified and determined to not be a serious concern at this scale. Nevertheless, logic was incorporated into the run plans to increase the air purge when hydrogen exceeded 1.5-2 volume \% to avoid operating near the lower explosive limit of $\sim 4 \%$ hydrogen in air. The Environmental Evaluation Checklist for ACTL was reviewed to ensure that waste types and volumes were within the planned limits for the facility.

The seven SRAT tests had technically reviewed run plans. The seven run plan document numbers are given at the end of the References in section 6.0. Runs were performed in accordance with Procedure ITS-0094, Laboratory Scale Chemical Process Cell Simulations, in the L29 Manual. The test equipment was visually monitored for foaming, air entrainment, slurry rheology changes, loss of heat transfer capabilities, and off-gas carryover. Observations were recorded in laboratory notebooks.

Concentrated nitric acid, $10.53 \mathrm{M}$, and formic acid, 23.6M, were used to acidify the sludge and perform neutralization and reduction reactions during processing. The volume of each acid to add to a given run was determined using the current DWPF acid addition strategy. Additional acid calculation details are given in section 2.4 .

Simulant was introduced into the CPC simulation equipment at ACTL. The 3-L SRAT was used instead of the 4-L SRAT which has been used in other CPC testing to better control internal refluxing of $\mathrm{NO}_{2}$ condensation products inside the SRAT. The test scale was approximately 1/10,800 relative to a 6000 gallon charge of fresh sludge in DWPF. Fully trimmed simulant was heated from room temperature to $93^{\circ} \mathrm{C}$. A $200 \mathrm{ppm} 747$ antifoam addition was made at $40^{\circ} \mathrm{C}$ during heat-up. Nitric acid, $10.53 \mathrm{M}$, was added at $93^{\circ} \mathrm{C}$ ( $\sim$ two hour duration). A $100 \mathrm{ppm} 747$ antifoam addition was made. This was followed by formic acid addition, $23.6 \mathrm{M}$, at $93^{\circ} \mathrm{C}$ ( five hour duration). A $500 \mathrm{ppm} 747$ antifoam addition was made following formic acid addition. The SRAT was taken to boiling to complete dewatering. This took about two hours. The SRAT was then switched to reflux. Refluxing was performed for twelve hours. The heating mantle was turned off at the end of reflux. Data collection continued until the SRAT contents had cooled to $50^{\circ} \mathrm{C}$. The SRAT contents were allowed to cool to room temperature. Foaming was observed when the $100 \mathrm{ppm}$ addition following nitric acid was delayed.

SRAT simulations started with about $2400 \mathrm{~g}$ of fully trimmed sludge at $17.95 \mathrm{wt}$ \% total solids. Air purges, acid addition rates, and boil-up rates were controlled at prototypical levels equivalent to 230 standard cubic feet per minute, scfm, of air, two gallons/minute acid additions, and $5000 \mathrm{lbs} / \mathrm{hour}$ of steam to the heating coils. All testing had a MWWT that started with about $50 \mathrm{~g}$ of de-ionized water in it. The SRAT condenser and FAVC were controlled at $40^{\circ} \mathrm{C}$ and $10^{\circ} \mathrm{C}$, respectively. Each simulation started with a freshly cleaned set of glassware. The SRAT rig was leak checked before and retested after each simulation.

Sample mass data were taken to support material balance calculations for each test. All materials added or removed from the SRAT were weighed and recorded (with the exception of the air purge and off-gas). SRAT hardware was scraped down using spatulas to maximize the recovery of SRAT product slurry in determining the final product mass. Overall mass balances were prepared. These were used to support calculations of formate loss and nitrite to nitrate conversion.

\subsection{SRAT Test Matrix}

The experimental SRAT cycle test matrix for the form of noble metal testing included two comparisons to meet the main goals for Phase II, Part 1 in section 1.2. The first comparison was between matching 
SRAT runs using the co-precipitated noble metal simulant and the other simulant after trimming it with similar concentrations of noble metals. Nearly identical acid additions were used in these tests. If hydrogen generation results were nearly identical for the co-precipitated noble metal SRAT and the 100\% trimmed noble metal SRAT cycles, then this would indicate no significant difference between trimmed and co-precipitated noble metals. A supporting run would be made trimmed at $65 \%$ of the nominal noble metal concentrations to show the sensitivity of the $100 \%$ trimmed noble metal results to the concentrations of the noble metals and to cover potential analytical uncertainties in the measured concentrations of the co-precipitated noble metals, Koopman (2005c).

The second comparison was to assess the impact of tank farm aging on the comparison of co-precipitated to trimmed noble metals. The effect of aging was simulated by heat-treating a simulant for about 7.5 hours at $97^{\circ} \mathrm{C}$. The comparison involved a SRAT run using heat-treated simulant with co-precipitated noble metals, plus a SRAT run using heat-treated, noble metal-free simulant trimmed with noble metals. The trimmed run was made using $100 \%$ of the recipe noble metal predictions since data from the first planned comparison indicated that this was a suitable choice. These runs could be compared to their unheat-treated counterparts as well as to each other.

In order to complete the hydrogen generation rate comparisons, two preliminary and five main SRAT runs were completed. Each was given a shorthand name as described below. The naming convention was similar to that used for the simulants. CNM stands for co-precipitated noble metals, while TNM stands for trimmed noble metals. HT stands for heat-treated.

CNM this preliminary run used CNM simulant

CNM2 this run was like run CNM, but it was given less acid

CNM-HT this run used CNM simulant that had been heat-treated (HT)

TNM-100 this preliminary run used TNM simulant trimmed to $100 \%$ of the recipe prediction

TNM-100-2 this run was like run TNM-100, but it was given less acid

TNM-65 this run used TNM simulant trimmed to $65 \%$ of the recipe prediction, and it had an acid addition similar to TNM-100-2

TNM-100-HT this run used TNM simulant that had been heat-treated, then trimmed to $100 \%$ of the recipe prediction for noble metals

The two preliminary runs, CNM and TNM-100, provided an improved basis for the acid calculation inputs used in the main tests. The results from these two runs ensured that the SRAT product would be reasonably well balanced for redox in the five main tests. This allowed for control of the relative amount of formic acid added in the main tests which was the source of hydrogen. CNM2, TNM-100-2, and TNM-65 formed a set for comparison purposes (no heat-treatment case). Similarly, CNM-HT and TNM100-HT formed a second set for comparison purposes (heat-treated case).

\subsection{Analytical Methods}

\subsubsection{Sample Analytical Methods and Controls}

Sample analyses for this phase of the hydrogen generation testing followed the directions in the ASP, Koopman (2004a). Sample request forms were submitted along with the samples to be analyzed. 
Analyses followed the guidelines and methods of sample control stated in the Analytical Study Plan, ASP. A unique lab identification number was assigned to each sample for tracking purposes. Analyses were performed using approved analytical and quality assurance, QA, procedures. Samples were analyzed by the SRNL-Mobile Lab and by the Analytical Development Section, ADS.

The Mobile Lab performed analyses on the SRAT product slurries to determine the chemical composition, total and dissolved solids, density, and $\mathrm{pH}$. The chemical composition was determined in duplicate by calcining the samples at $1100^{\circ} \mathrm{C}$ and then dissolving the product using $\mathrm{Na}_{2} \mathrm{O}_{2} / \mathrm{NaOH}$ fusion and lithium metaborate fusion with acid uptake of the fusions. The preparations were then analyzed using inductively coupled plasma - atomic emission spectroscopy, ICP-AES, to measure the cations present.

SRAT product samples were prepared for anion analyses using weighted dilutions, followed by filtrations to remove solids, and were then analyzed by ion chromatography, IC. Samples of the condensate collected during dewatering through the MWWT and in the FAVC were also submitted for IC analysis. Density and $\mathrm{pH}$ measurements of these samples were also performed. The total solids were measured on two aliquots of each slurry sample by drying the slurry at $115^{\circ} \mathrm{C}$. The dissolved solids were measured similarly on two supernate aliquots obtained from filtered slurry. The insoluble and soluble solids fractions were calculated from the total and dissolved solids results.

ADS tracked noble metal dissolution in the SRAT product by inductively coupled plasma-mass spectroscopy, ICP-MS. Supernate was separated from the SRAT product slurry by centrifuging. Fresh solids continued to form, so the samples were dissolved by aqua regia prior to ICP-MS analysis.

Samples of nitric acid and formic acid were measured at ACTL to determine density under temperature controlled conditions. These values were used to determine the molarity using standard correlations.

\subsubsection{SRAT Processing Analytical Methods}

SRAT cycle processing data were taken at 20 minute intervals during all of the test runs. This included temperature, pressure, $\mathrm{pH}$, agitator rpm and torque, and heating mantle power input. New slurry $\mathrm{pH}$ probes were calibrated with $\mathrm{pH} 4$ and 10 buffers before each simulation, then checked in $\mathrm{pH} 7$ buffer, and then checked in $\mathrm{pH} \mathrm{4,} \mathrm{7,} \mathrm{and} 10$ buffers after each simulation. More frequent $\mathrm{pH}$ data were taken during acid addition to track $\mathrm{pH}$ as a function of the volume of acid added. These data were used to produce process titration curves.

Acid addition volumes were tracked using a totalizing dispenser. This is a positive displacement pump frequently used with automatic titrators. It delivers a steady flowrate, while simultaneously recording the total volume dispensed. The potential for a low addition exists if a significant air bubble gets into the system. The acids being dispensed were routinely weighed before and after addition to confirm that the correct amount had been added.

Off-gas composition was monitored by Immobilization Technology Section, ITS, personnel during each SRAT simulation using either an Agilent 3000A Micro gas chromatograph, GC, or an Agilent M200H Series Micro GC. These GC's have two separation columns. The first column was calibrated for molecular hydrogen, $\mathrm{H}_{2}$, helium, He, molecular oxygen, $\mathrm{O}_{2}$, molecular nitrogen, $\mathrm{N}_{2}$, and nitric oxide, NO. The second column was calibrated for carbon dioxide, $\mathrm{CO}_{2}$, and nitrous oxide, $\mathrm{N}_{2} \mathrm{O}$. Monitoring these species provides insight into the reactions occurring during processing and can be used to determine whether a flammable mixture has formed. Argon was the carrier gas within the GC. Two standard calibration gases were available and were used to check the accuracy of the GC's before and after each SRAT simulation. These had maximum concentrations of $66.44 \% \mathrm{~N}_{2}, 20.96 \% \mathrm{O}_{2}, 20.00 \% \mathrm{CO}_{2}, 10.05 \%$ $\mathrm{NO}, 2.53 \% \mathrm{~N}_{2} \mathrm{O}, 0.998 \% \mathrm{H}_{2}$, and $0.499 \% \mathrm{He}$. Sampling frequency was once every three minutes. 
Off-gas compositions can be converted into flow rates. A helium internal standard flow was used for this purpose. The nominal DWPF-scaled air purge was converted to $99.5 \%$ air and $0.5 \%$ helium by volume. The individual volumetric flow rates of air and helium into the SRAT were controlled by a pair of MKS flow controllers. These flow controllers are routinely calibrated for accuracy. Field checks of the controllers from the two rigs against each other indicated that they were performing within $5 \%$ of the indicated flows for both the air pair and the helium pair. This accuracy was suitable when using a 0-1 std. liter per minute (SLM) controller for the air flow, but was marginal when using a 0-5 SLM controller (TNM-100-2 and TNM-100-HT). The scaled, prototypical air purge was about 0.6 SLM, and deviations exceeding \pm 0.02 SLM were seen with the 0-5 SLM controllers. The 0-5 SLM controllers were used in order to provide additional dilution flow when the hydrogen volume percent exceeded 1.5-2\%.

The computation of the DWPF-scale hydrogen flow from the MKS and GC data was performed as follows:

$$
\begin{gathered}
\text { DWPF - scale } \mathrm{H}_{2} \text { flow, } \mathrm{lb} / \mathrm{hr}=(\text { He flow, sccm }) *\left(\frac{\text { vol\% } \mathrm{H}_{2}}{\text { vol\% } \mathrm{He}}\right) *\left(\frac{1 \mathrm{gram}-\text { mole }}{22,415 \mathrm{std} . \mathrm{cm}^{3}}\right) * \\
\left(\frac{2.016 \mathrm{~g} \mathrm{H}_{2}}{\text { gram }- \text { mole }}\right) *\left(\frac{60 \text { minutes }}{\text { hour }}\right) *\left(\frac{1 \mathrm{lb}}{453.6 \mathrm{~g}}\right) *\left(\frac{6000 \text { gallons }}{\text { sludgevolume, } L}\right) *\left(\frac{3.7854 \mathrm{~L}}{\text { gallon }}\right)
\end{gathered}
$$

The ratio of hydrogen to helium percent (vol\%) is less sensitive to variations in the injected volume of gas sample into the GC column than the raw volume percents of the gases. This mitigated one potential source of error. Calibration gases were at elevated pressure, so they could assist the injection pump in moving gas into the column. It has been observed that room air and bottled air at $1 \mathrm{~atm}$ are only about 90-92\% oxygen and nitrogen following calibration. Room air should be somewhat higher in these two gases, $\sim 97-98 \%$, varying due to the humidity. Since the results for vol\% $\mathrm{H}_{2}$ and vol\% He both depended on the injected sample volume in the same manner, the vol\% ratio was essentially insensitive to this source of error. The other quantities in the calculation were conversion factors except for the sludge volume and helium flow. Sludge was batched by mass, and the sludge density was determined analytically with errors typically less than $2 \%$. Therefore, the accuracy of this calculation was limited primarily by how well the GC stayed in calibration during a SRAT run and the accuracy of the MKS He flow controller.

A set of samples was taken to monitor the MWWT and FAVC anions during each SRAT simulation. The onset of reflux was observed to have a significant impact on reducing hydrogen generation temporarily in Phase I, Koopman (2005a). Changes were made to make the experimental equipment more prototypical of DWPF chemistry. These were anticipated to have some mitigating impact on this effect. The dewatering mass removed from the MWWT was divided roughly into a first quarter, second quarter, and final half as it was removed. The contents of the MWWT were also collected at the end of reflux and analyzed. Barely enough mass was collected in the FAVC for a sample over the course of a typical SRAT simulation at this scale. These samples were analyzed by the methods in section 2.3.1. The purpose of these samples was to help evaluate the fate of anions in the rigs, the sensitivity of the formate loss and nitrite to nitrate conversion factors to the process equipment, and the impact of the equipment changes on the hydrogen generation rate at the onset of reflux per the secondary objectives in section 1.2.

Samples were taken of the SRAT products from all seven tests. These were characterized per section 2.3.1 for elements, anions, wt. \% solids, $\mathrm{pH}$, and density. SRAT product slurries were centrifuged following the five main tests. Samples of the supernate phase were taken. Insoluble solids formed in the 
supernate phase after separation. Consequently these samples required an aqua regia dissolution to identify species that were dissolved during processing. The samples were then analyzed for noble metal content in order to determine the extent to which the noble metals were dissolved in the SRAT product and to evaluate any impact due to the form of noble metals and/or the heat-treatment.

The end of acid addition was chosen as the common reference point for graphs of various measurements versus time. This choice divides the SRAT cycle into negative times for acid addition at $93^{\circ} \mathrm{C}$ and positive times for boiling. Significant hydrogen generation generally follows acid addition, since the formic acid is the source of the hydrogen.

\subsection{Preparation of Acid Calculations}

Tight control of the acid added relative to the stoichiometric acid calculation was desired to permit the desired comparisons in hydrogen generation rate to be made. This is not always possible due to analytical uncertainties and changing sludge properties. This was illustrated when two preliminary runs were performed using a nominal stoichiometric factor of $185 \%$ in the acid calculation. Improved TIC measurements indicated one run was closer to $183 \%$ and the other run was closer to $191 \%$. The $8 \%$ difference in excess acid was responsible for significant additional hydrogen generation, see section 3.7.1 or Appendix A. This obscured any difference in noble metal activity.

The sludge analytical data in section 1.4 included inputs to the stoichiometric acid calculation. In addition to that information, it was necessary to set either the redox target or the ratio of formic acid to total acid, set the projected formate loss, set the projected conversion of nitrite to nitrate, set the projected destruction of nitrite, and set a target for either the SRAT product solids content or dewater mass.

The iron glass redox target for tests CNM, CNM2, CNM-HT, and TNM-100 was $0.20 \mathrm{Fe}^{+2} / \Sigma \mathrm{Fe}$. It was not possible to simultaneously control the iron glass redox target and the fraction of the total acid that was formic acid in the comparison runs. TNM-65 and TNM-100-2 had redox targets of 0.195 and a slightly higher ratio of formic acid to total acid than the run they would be compared to, CNM2. This was a compromise when faced with two constraints that could not be satisfied simultaneously. Similarly, TNM100-HT had a lower redox target of 0.181 and a slightly higher fraction of formic acid than its comparison run, CNM-HT. The trimmed noble metal runs, TNM-100-2, TNM-65, and TNM-100-HT, had less formic acid added than the corresponding co-precipitated noble metal runs, CNM2 and CNM-HT. Therefore, if the trimmed noble metal run tests produced more hydrogen than the co-precipitated noble metal run tests, the result could not be blamed on the presence of additional formic acid.

The projected formate loss, the projected conversion of nitrite to nitrate, and the projected destruction of nitrite for the two preliminary runs CNM and TNM-100 were based on a Clemson Environmental Technology Laboratory, CETL, SB3 simulant SRAT run in the modified SRAT equipment, Baich (2004b). These anion factors are summarized in the first pair of columns in Table 6. Also given are the percent oxalate lost, which was assumed to be $10 \%$ throughout Phase II, and which has a negligible effect on redox at the low concentrations present in the starting simulants. The projected redox, fraction of total acid that was added as formic acid, and the actual formic, nitric, and total acid additions per liter of SRAT receipt slurry are presented as well. 
Table 6. Pre-Run Stoichiometric Acid and Redox Calculations

\begin{tabular}{|l|c|c|c|c|c|c|c||}
\hline Quantity: & CNM & $\begin{array}{c}\text { TNM- } \\
100\end{array}$ & CNM2 & $\begin{array}{c}\text { TNM- } \\
100-2\end{array}$ & $\begin{array}{c}\text { TNM- } \\
65\end{array}$ & $\begin{array}{c}\text { CNM- } \\
\text { HT }\end{array}$ & $\begin{array}{c}\text { TNM- } \\
100-H T\end{array}$ \\
\hline \% $\mathrm{NO}_{2}^{-}$Destroyed & 100 & 100 & 100 & 100 & 100 & 100 & 100 \\
\hline \% $\mathrm{NO}_{2}^{-}$Converted to $\mathrm{NO}_{3}^{-}$ & 30 & 30 & 18 & 18 & 18 & 18 & 13 \\
\hline \% Formate Lost & 13 & 13 & 20 & 20 & 20 & 20 & 23.4 \\
\hline \% Oxalate Lost & 10 & 10 & 10 & 10 & 10 & 10 & 10 \\
\hline Projected Redox & 0.200 & 0.200 & 0.200 & 0.195 & 0.195 & 0.200 & 0.181 \\
\hline $\begin{array}{l}\text { Fraction } \mathrm{HCOOH} \text { in Total } \\
\text { Acid }\end{array}$ & 0.8185 & 0.8141 & 0.8302 & 0.8318 & 0.8323 & 0.8348 & 0.8400 \\
\hline Moles $\mathrm{HNO}_{3} / \mathrm{L}$ slurry & 0.571 & 0.586 & 0.491 & 0.468 & 0.461 & 0.457 & 0.409 \\
\hline Moles $\mathrm{HCOOH}_{\text {L slurry }}$ & 2.577 & 2.568 & 2.398 & 2.313 & 2.288 & 2.308 & 2.143 \\
\hline Moles Total Acid/L slurry & 3.148 & 3.154 & 2.889 & 2.781 & 2.749 & 2.765 & 2.552 \\
\hline
\end{tabular}

The two preliminary tests, CNM and TNM-100, were run first. Assumed inputs for the three un-heattreated runs, CNM2, TNM-100-2, and TNM-65 were updated based on the preliminary results from CNM and TNM-100. This was also true for the first heat-treated simulant run, CNM-HT. The assumed inputs for the second heat-treated simulant run, TNM-100-HT, were based on the preliminary results from first heat-treated run, CNM-HT.

The addition strategy for CNM and TNM-100 assumed that the two simulants were closer in composition than was indicated by later analytical results, particularly TIC, as discussed in Koopman (2005c). It was desired to bound the co-precipitated noble metal result from above in hydrogen generation rate in TNM100. Essentially identical acid additions in terms of mole acid per liter slurry were made to these two runs with essentially equal fractions of formic acid. Subsequent additional sludge analytical work, however, indicated that the simulants with and without co-precipitated noble metals needed separate stoichiometric acid calculations due to real compositional variations. Valuable information was obtained in the two preliminary runs and has been brought into the discussion of results where appropriate. The emphasis of the SRAT results section of this report, section 3.0, is on the five SRAT runs that were made after the two preliminary runs.

Runs CNM2, TNM-100-2, and TNM-65 followed the preliminary runs. These were all made with simulants that had not been heat-treated. The stoichiometric acid factor was $172 \%$ with $100 \%$ trimmed noble metals, $170 \%$ with $65 \%$ trimmed noble metals, and $171 \%$ with the co-precipitated noble metals. The stoichiometric factors for the two runs with trimmed noble metals were biased up and down slightly to produce a visible difference in the hydrogen generation rate profiles of these two runs with which to potentially bracket the behavior of the co-precipitated noble metals.

The final two runs, CNM-HT and TNM-100-HT, used the two heat-treated simulants and were run at $176 \%$ stoichiometry. It was desired to compare these two runs to each other, but also to compare CNMHT to CNM2 if possible, and also to compare TNM-100-HT to TNM-100-2 if possible. Although the stoichiometric factor increased from about $170-172 \%$ to $176 \%$, both of the heat-treated simulant runs received less total acid than their un-heat-treated counterparts. The net effect of changes in the inputs to the acid calculations caused by heat-treatment caused this to occur. 
WSRC-TR-2005-00286

Revision 0

This page intentionally left blank. 


\subsection{SRAT RESULTS \& DISCUSSION}

The experimental results relevant to the interpretation of hydrogen generation data are given in this section. The organization is as follows:

3.1 Revised Acid Calculations

3.2 Material Balance and SRAT Product Results

3.3 SRAT Data - No Heat-Treatment Form of Noble Metal Comparison

3.4 SRAT Data - Effect of Heat-Treatment on Both Simulants

3.5 SRAT Data - Heat-Treatment Form of Noble Metal Comparison

3.6 Preliminary SRAT Run Summary

3.7 Sensitivity of Peak Hydrogen Generation Results to Acid Stoichiometry Inputs

A direct comparison of peak hydrogen generation rate was not meaningful for the two preliminary runs. The data were most useful in ensuring that the five main tests gave the desired results and in the interpretation of the sensitivity of the peak hydrogen generation rates to uncertainties in the inputs to the stoichiometric acid calculation. A brief summary is given in section 3.6, but most of the data were put in Appendix A.

\subsection{Revised Acid Calculations}

Table 6 was revisited following the analysis of data from the runs. This was done to assess the potential impact of pre-run assumptions concerning formate loss and nitrite to nitrate conversion on the data. Nitrite was destroyed in all seven tests. The acid-strike method for oxalate determination was not used on the SRAT products, so the relatively insignificant oxalate loss term was not re-evaluated. Nitrite to nitrate conversion and formate loss were recalculated from the standpoint of the usage in the stoichiometric acid and redox calculation, see Appendix B. (These species mass balances intentionally ignore nitrate, nitrite, and formate lost to the MWWT and FAVC to better match the DWPF acid calculation.)

Table 7. Final Stoichiometric Acid and Redox Calculations

\begin{tabular}{|l|c|c|c|c|c|c|c||}
\hline Factor: & CNM & $\begin{array}{c}\text { TNM- } \\
100\end{array}$ & CNM2 & $\begin{array}{c}\text { TNM- } \\
100-2\end{array}$ & $\begin{array}{c}\text { TNM- } \\
65\end{array}$ & $\begin{array}{c}\text { CNM- } \\
\text { HT }\end{array}$ & $\begin{array}{c}\text { TNM- } \\
100-H T\end{array}$ \\
\hline \% $\mathrm{NO}_{2}^{-}$Destroyed & 100 & 100 & 100 & 100 & 100 & 100 & 100 \\
\hline$\% \mathrm{NO}_{2}^{-}$Converted to $\mathrm{NO}_{3}^{-}$ & 16 & 13 & 4 & 4 & 10 & 13 & -8 \\
\hline \% HCOO- Lost & 22 & 27 & 24 & 26 & 24 & 23 & 33 \\
\hline \% Oxalate Ion Lost & - & - & - & - & - & - & - \\
\hline Projected Redox & 0.167 & 0.135 & 0.210 & 0.192 & 0.192 & 0.193 & 0.178 \\
\hline $\begin{array}{l}\text { Fraction } \mathrm{HCOOH} \text { in Total } \\
\text { Acid }\end{array}$ & 0.8185 & 0.8141 & 0.8302 & 0.8318 & 0.8323 & 0.8348 & 0.8400 \\
\hline Moles $\mathrm{HNO}_{3} / \mathrm{L}$ slurry & 0.571 & 0.586 & 0.491 & 0.468 & 0.461 & 0.457 & 0.409 \\
\hline Moles $\mathrm{HCOOH}_{\text {L slurry }}$ & 2.577 & 2.568 & 2.398 & 2.313 & 2.288 & 2.308 & 2.143 \\
\hline Moles Total Acid/L slurry & 3.148 & 3.154 & 2.889 & 2.781 & 2.749 & 2.765 & 2.552 \\
\hline
\end{tabular}

The largest changes between pre-run and post-run calculations were in the first two preliminary runs, CNM and TNM-100. This led to noticeably lower projected redox targets in Table 7 compared to Table 6. Revised redox projections for the five main SRAT tests were generally no more than 0.005-0.010 
different from the pre-run targets based on analytical results following the runs. TNM-100-HT, however, had unexpected formate loss and low nitrite to nitrate conversion leading to a somewhat more oxidizing SRAT product. This could lead to a slightly reduced peak hydrogen generation rate versus a duplicate run with a 0.2 redox. These tests benefited from the incorporation of preliminary run results into the acid calculations. A more complete balance of formate and nitrate including condensate streams is given in Appendix B. Formate loss in the five main tests was in the range of $22-27 \%$ seen in the two preliminary runs, except for TNM-100-HT. The TNM-100-HT SRAT product sample was re-analyzed, and then resampled and re-analyzed without significantly altering the results.

\subsection{Material Balance and SRAT Sample Results}

Analyses on the SRAT product samples are given in detail in Appendix C. Analyses of condensate samples removed from the SRAT are given in detail in Appendix D. These were combined with mass input and output from the SRAT run to construct overall material balances, plus balances on formate and nitrate ions. The material balance results are given in Appendix B. The significant findings from this part of the data analysis are given below.

Off-gas data not covered in the discussions on hydrogen generation in sections 3.3 to 3.5 are given in Appendix A and D. Off-gas data during acid addition showed only minor variations between the runs. The onset of reflux was followed by fresh releases of small quantities of $\mathrm{NO}$ and $\mathrm{N}_{2} \mathrm{O}$.

\subsubsection{SRAT Product Sample \& Overall Material Balance Results}

SRAT product elemental and anion results were generally as expected and relatively consistent in the set of runs as desired, Appendix C. One additional analysis was introduced in this phase of the hydrogen generation program. Samples of the five primary SRAT run product slurries were separated to obtain supernate samples. The supernate was analyzed for dissolved noble metals by ICP-MS. This was done to evaluate any impact from using co-precipitated noble metals that might not have shown up in the off-gas data. The results are given in Table 8.

Table 8. SRAT Product Supernate Noble Metal Concentrations

\begin{tabular}{|l|c|r|c|}
\hline \hline & Pd, ppb & Rh, ppb & Ru, ppb \\
\hline CNM2 & 479 & 206 & 4084 \\
\hline CNM-HT & 551 & $\mathbf{1 8 0 5}$ & 8559 \\
\hline TNM-100-2 & 1260 & 133 & 4185 \\
\hline TNM-65 & 1251 & 157 & 3514 \\
\hline TNM-100-HT & 682 & 82 & 5550 \\
\hline
\end{tabular}

Note that dissolved rhodium was nearly an order of magnitude greater in the run with heat-treated, coprecipitated noble metal simulant, CNM-HT, than in the other four runs. Much smaller ranges of variations were seen in the data for palladium and ruthenium. The high values for $\mathrm{Rh}$ and $\mathrm{Ru}$ in CNMHT may be significant to the explanation of the off-gas results obtained.

There was one major finding specific to the overall material balance. This was found in the wt. \% total solids of the SRAT products produced in all of the tests using the new simulants made at ACTL. The loss in solids during processing relative to that predicted in the SRNL acid calculation plus dewatering calculation was about twice as large as in runs using CETL simulants. The difference between predicted and measured total solids averaged $2.6 \mathrm{wt}$ \%. For comparison the difference in Phase I, Part 2 was $1.46 \%$. This increased loss of solids occurred while total mass was controlled as well as in previous simulant runs. The leading hypothesis to explain the solids loss is that the precipitated hydroxide solids 
in the ACTL simulants are more readily converted by acid into other species plus water than the solids in the traditional simulants. This explains both observations, that solids were lost, while total mass was maintained at expected levels.

\subsubsection{Anion Balance Results}

Balances on formate ion showed general consistency between all of the runs except TNM-100-HT, Table 7. The difference in the result for TNM-100-HT might be real or due entirely to analytical uncertainties in the calculation. This run also had the lowest conversion of nitrite to nitrate. That implies that it had the highest conversion of nitrite to gaseous oxides of nitrogen, which would have an associated loss of formate to carbon dioxide. The two unusual findings are mutually consistent, which lends them more validity. (The full nitrate balance, accounting for the condensate streams, Table 14, indicated that there was a small nitrite to nitrate conversion, but that it was smaller than nitrate losses to the condensate streams.) It was not clear why the heat-treated simulant with trimmed noble metals would have behaved differently compared to the two runs with un-heat-treated simulant and trimmed noble metals.

Formate losses were higher than in Phase I, Part 2 (the impact of mercury study), Koopman (2005a). Phase I, Part 2 formate losses averaged about $17 \%$ versus $24 \%$ here. There was some impact to formate loss due to the relatively high stoichiometries of the Phase II runs which led to additional formate destruction. Nitrite to nitrate conversions were much lower than in Phase I, Part 2. Phase I conversions averaged about 55\% versus $9 \%$ here. The changed conversions were primarily attributed to the modifications made to the processing equipment following Phase I, Part 2, see Baich (2004b). The SRAT condenser and MWWT were modified to better match DWPF-scale equipment. This included vertical down flow tubes in the condenser, a reduced volume MWWT, elimination of off-gas passing through the MWWT, and a submerged condensate feed to the MWWT from the SRAT condenser.

\subsubsection{Condensate Sample Results}

A large drop in hydrogen generation accompanied the start of reflux in Phase I, Part 2 data, Koopman (2005a). Condensate samples were taken in Phase II to study this phenomenon. The modified test equipment changed the way that dewatering occurred during SRAT simulations in Phase II. The $\sim 93^{\circ} \mathrm{C}$ air purge during acid addition picked up moisture. Prior to routinely insulating the SRAT during acid addition, most of this moisture was condensed inside the SRAT (internally refluxed). With the insulated SRAT, most of this moisture collected in the MWWT during acid addition in Phase II. The amount collected approached $50 \%$ of the targeted dewatering mass for a SRAT simulation.

The MWWT collected an acidic condensate stream $(\mathrm{pH}<3)$ throughout the SRAT cycle, once the slurry itself became acidic during acid addition. Nitrite was not detected in the MWWT samples, however its presence was inferred from the release of $\mathrm{NO}$ and $\mathrm{N}_{2} \mathrm{O}$ following the start of reflux in the SRAT. These are nitrite ion decomposition products. If the nitrite were in the SRAT already, then there would be little reason for a spike in these two gases to occur immediately after starting reflux. It is possible that the nitrite in the MWWT samples did not survive long enough to be detected by IC several days later. Quenching smaller samples in caustic might stabilize them long enough to check for nitrite.

The nature of acidity in the MWWT samples was changing during processing. It was initially due to nitric acid, but this began changing over to formic acid as nitrite destruction went to completion in the SRAT. By the end of the SRAT cycle, the MWWT contents were primarily acidic due to formic acid. The transition was occurring as the SRAT went to reflux. This was the time when a sharp drop in hydrogen generation had been seen. Such drops were still seen in Phase II, but they were much less pronounced than in the previous testing. A revised sampling approach is recommended to better define the SRAT Condenser condensate composition close to the start of reflux. 
The FAVC samples were composites over the entire SRAT cycle. They were far more acidic than any of the MWWT samples that were obtained ( $\mathrm{pH} \sim 1$ ). The IC data indicate that this was due to nitric acid rather than formic acid. The FAVC sampling frequency could be modified from once at the end of the run, to once following formic acid addition and again at the end of the run. This could be used to see if significant nitrate reaches the FAVC during SRAT boiling, or if it comes primarily during nitrite destruction during formic acid addition. The complicating factor is that the total amount collected during a 3-L simulation is small, and individual, potentially nitrate-rich, droplets can remain on the condenser tube walls for extended periods of time.

\subsection{SRAT Data - No Heat-Treatment Form of Noble Metal Comparison}

Three SRAT simulations were completed at $\sim 171 \%$ of the stoichiometric acid requirement using the simulants with and without co-precipitated noble metals. Tests CNM2, TNM-100-2, and TNM-65 were used to compare the effect of co-precipitation of noble metals on the activation rate and catalytic activity of the noble metals responsible for hydrogen generation in the SRAT. These tests were designed to meet the primary goal of the form of noble metal testing in section 1.2.

All three SRAT cycles were characterized by significant reductions in the apparent viscosity of the slurry during acid addition. All three SRAT cycles began to produce foam with only the initial $200 \mathrm{ppm}$ of antifoam present once formic acid addition was started. It was necessary to add the $100 \mathrm{ppm}$ of additional antifoam that DWPF adds before formic acid addition to control the foam that was formed. There were no foaming issues during boiling.

\subsubsection{Hydrogen Generation Rate Data}

Interesting phenomena were observed near the end of formic acid addition. These are shown in Figure 2 which plots the DWPF-scale hydrogen generation rate in pounds per hour, pph, as a function of processing time relative to the end of formic acid addition. 
Figure 2. Hydrogen Generation Near the End of Acid Addition

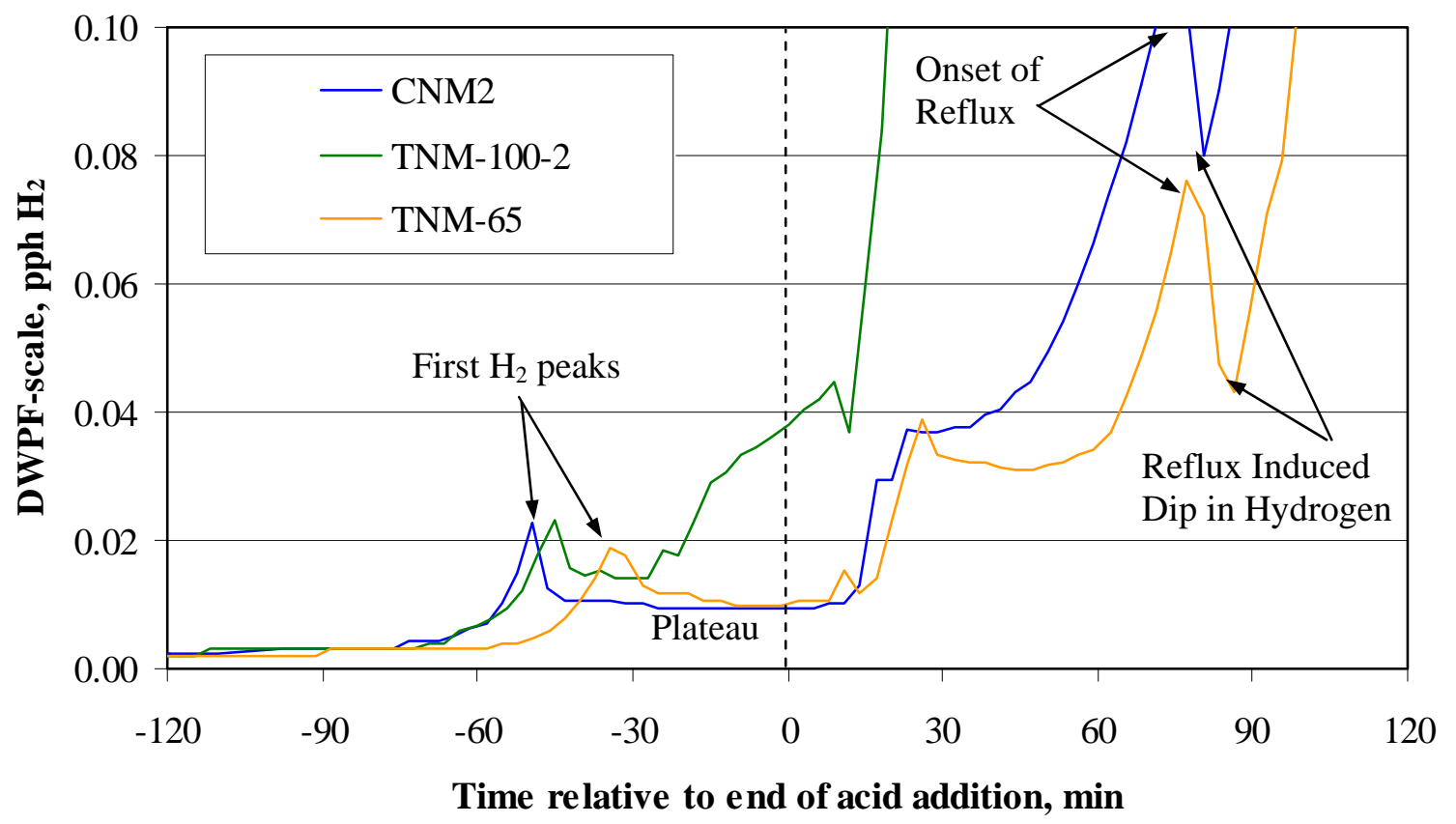

There was a small peak in hydrogen generation about 45 minutes prior to the end of formic acid addition in all three runs. The occurrence of this peak was almost simultaneous for CNM2 and TNM-100-2, and it was of nearly identical magnitude. The peak for TNM-65 came later and was smaller, which would be expected given the lower noble metal concentrations. This peak may be due to palladium, which the literature reviewed in Koopman (2004a) reported to have the shortest induction time of the three noble metals in SRS waste. The data obtained in this study cannot distinguish the individual effects of the three different noble metals. It appears that this initial peak in hydrogen generation was not impacted by differences between co-precipitated and trimmed noble metals. These peaks were $<3 \%$ the magnitude of the primary hydrogen generation rate peaks for the respective runs.

The hydrogen generation rate behavior following these initial peaks, however, began to show more differences between CNM2 and TNM-100-2. The TNM-100-2 hydrogen dropped to a plateau for about fifteen minutes and then took off very quickly. CNM2 dropped to a plateau that lasted for an hour. During this period, TNM-65 essentially caught up to CNM2. Both of these two runs then activated further at about 15 minutes after acid addition, i.e. roughly at the onset of boiling. Figure 3 shows the entire hydrogen generation rate profiles for these three tests. The DWPF design basis allows no more than $0.65 \mathrm{lbs} / \mathrm{hr}$ of hydrogen generation to ensure that the vent system remains below 25\% of the LEL for hydrogen in air. The hydrogen generation rate axis scaling was chosen to highlight this value. 
WSRC-TR-2005-00286

Revision 0

Figure 3. Peak Hydrogen Generation Rate Comparison

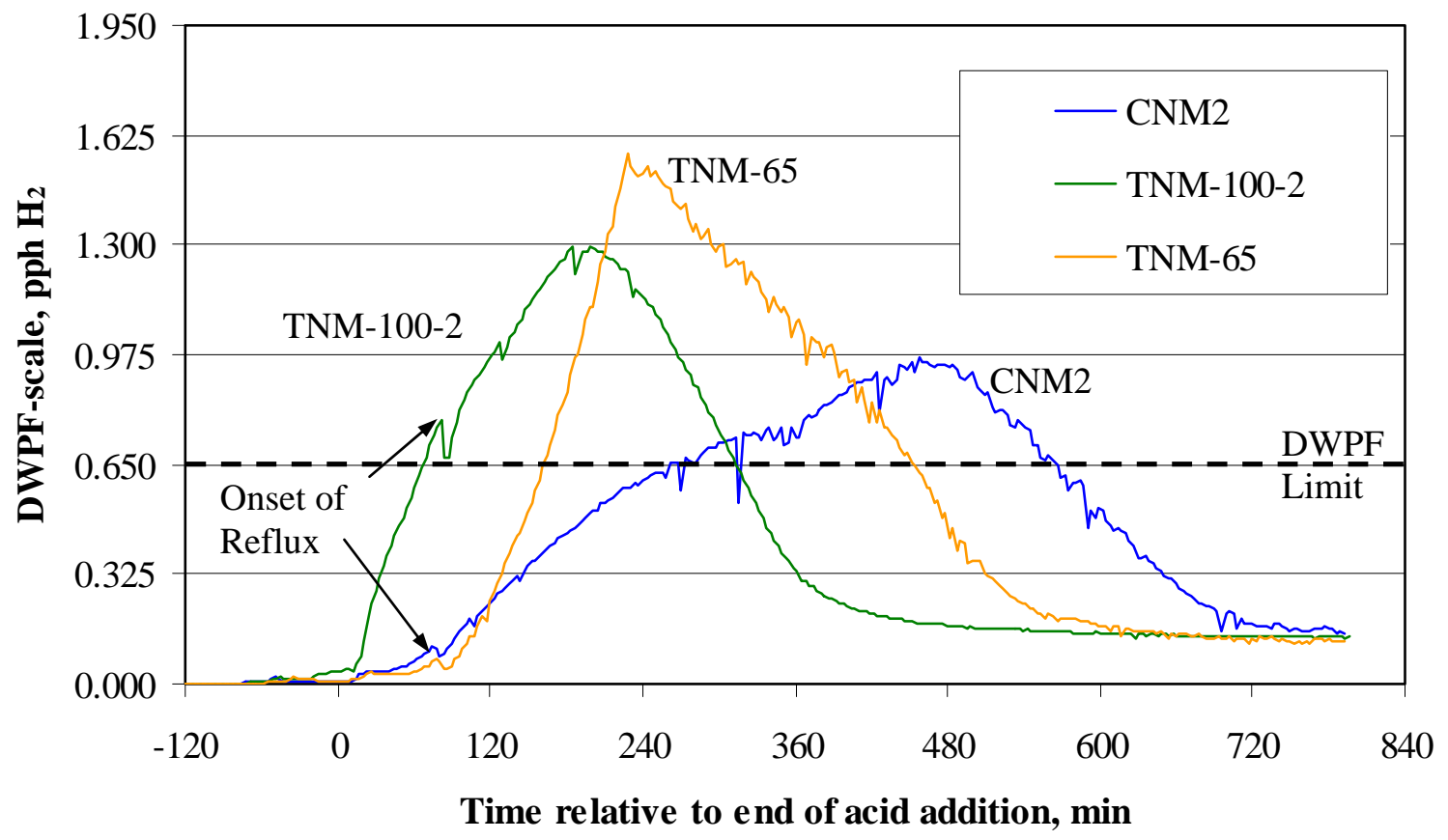

The occurrence of the overall peak hydrogen generation rate was delayed for the co-precipitated noble metal run relative to the trimmed noble metal runs by approximately four hours. The two trimmed noble metal runs also had peak hydrogen generation rates that were $30-50 \%$ greater than in the co-precipitated noble metal run. The onset of reflux, marked in Figure 2 and Figure 3, had much less impact on hydrogen generation than in the Phase I study. This is attributed to the modified experimental equipment.

The rate of decline in hydrogen generation rate following the peak was similar in all three runs. Complete deactivation of the noble metals was not indicated. Instead, it appeared that the noble metals changed into a less active state that could support about $0.15 \mathrm{lbs} / \mathrm{hr}$ of hydrogen generation.

Bench-scale hydrogen flow rates were calculated per section 2.1. These were integrated over the duration of the SRAT cycle to determine the total hydrogen mass produced in the three tests, Table 9.

Table 9. Total Hydrogen Production Comparison

\begin{tabular}{||l|c|c|c||}
\hline & CNM2 & TNM-100-2 & TNM-65 \\
\hline Hydrogen Produced, g & 0.276 & 0.261 & 0.302 \\
\hline
\end{tabular}

The results are fairly similar, indicating that approximately the same quantity of excess acid was converted to hydrogen in all three cases. CNM2 actually produced more total hydrogen than TNM-100-2, even though its peak generation rate was lower. This is another confirmation that these two runs were generally similar overall, though different in detail.

Data given later in section 3.0 showed that the co-precipitated noble metal simulant hydrogen generation rate peaked later than the trimmed noble metal simulant in every test. Using trimmed noble metal data to predict the timing of the hydrogen generation rate peak in the SRAT cycle cannot be recommended at this time. The reason is that a hydrogen generation rate that is acceptable in the SRAT cycle is not necessarily 
acceptable in the SME cycle. Co-precipitated noble metals could have their peak rate in the SME cycle if corresponding concentrations of trimmed noble metals peak late in the SRAT cycle. This would not be conservative relative to DWPF if real waste noble metals behave like co-precipitated noble metals in simulants.

\subsubsection{Examination of Differences in the Two Trimmed Noble Metal Runs}

The run with trimmed noble metals at $65 \%$ concentration peaked later but at a higher rate than the run with trimmed noble metals at $100 \%$. It also produced slightly more total hydrogen. The higher peak rate was unexpected. Consequently, the data for these two runs were given considerable scrutiny. A small correction to the data has already been made for a slight bias in one of the air purge flow controllers.

Carbon dioxide data can often give insight into hydrogen generation. Hydrogen generation produces $\mathrm{CO}_{2}$ as a co-product. Consequently, phenomena seen in hydrogen generation can be mirrored in the $\mathrm{CO}_{2}$ data. Carbon dioxide data shown in Figure 4 indicate that the TNM-100-2 and TNM-65 were apparently nearly identical until near the end of acid addition. $\mathrm{CO}_{2}$ data during acid addition for CNM2 were omitted for clarity, although they were generally similar to the data for the two runs with trimmed noble metals. $\mathrm{CO}_{2}$ data during acid addition were dominated by non-hydrogen producing reactions, e.g. carbonate destruction and nitrite destruction.

Figure 4. $\mathrm{CO}_{2}$ Generation Comparison

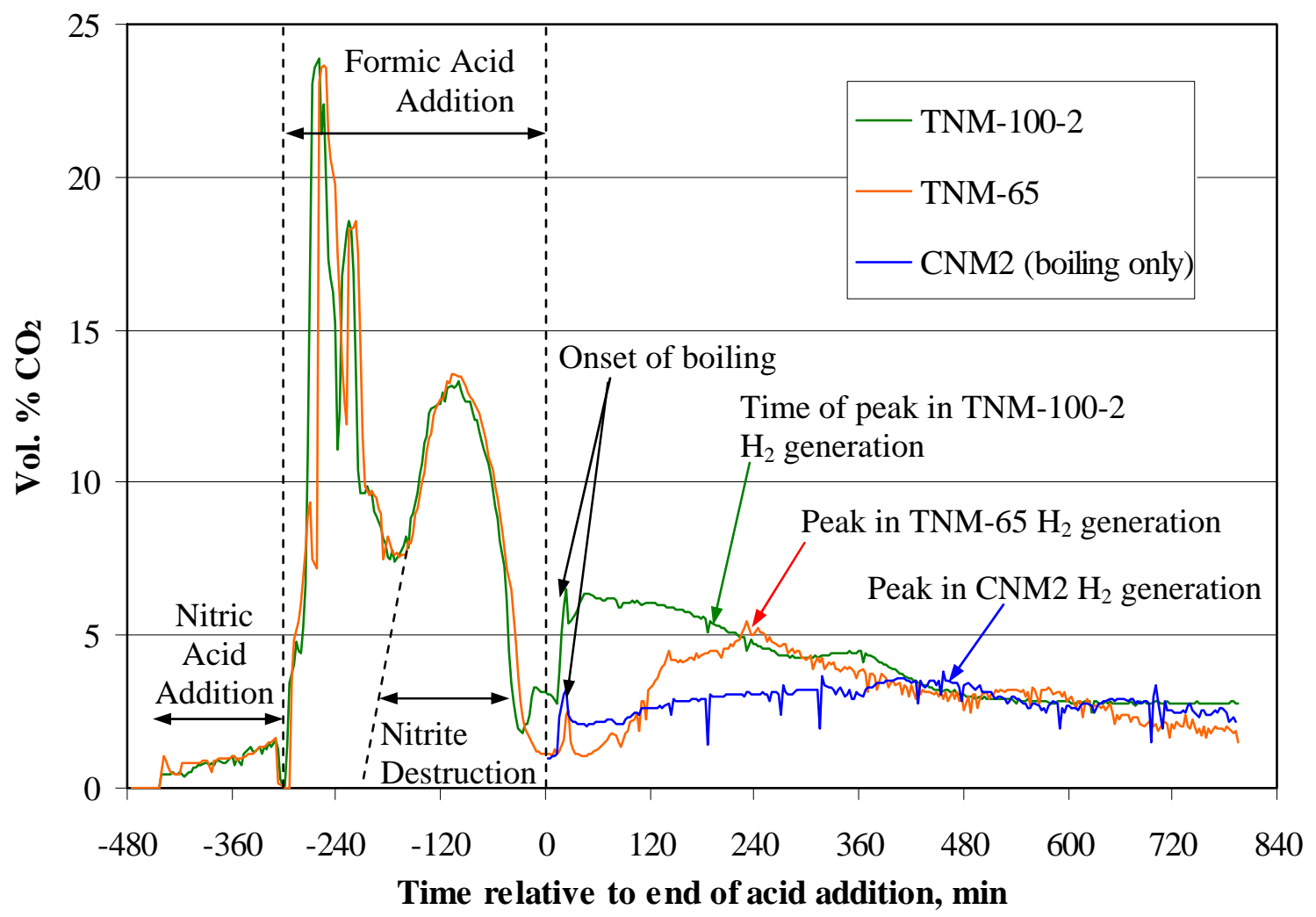

The $\mathrm{CO}_{2}$ peak after acid addition in Figure 4 and the hydrogen peak in Figure 3 did not occur at the same time for TNM-100-2. The locations of the peak hydrogen generation rates from Figure 3 are marked by arrows in Figure 4. The TNM-100-2 $\mathrm{CO}_{2}$ peak developed much more quickly after acid addition and peaked higher than TNM-65. If hydrogen had tracked $\mathrm{CO}_{2}$ shortly after boiling like it generally does 
later, then the TNM-100-2 peak hydrogen generation rate would have been higher than in TNM-65. It had been anticipated that the peak hydrogen and peak $\mathrm{CO}_{2}$ during boiling would both be higher with $100 \%$ noble metals. These data indicate that the catalytic chemistry following acid addition was more complicated than just the production of hydrogen. This may relate to the precise extent of nitrite destruction or the state of noble metal reduction at this time.

The similarities in the $\mathrm{CO}_{2}$ data from -450 to -30 minutes and from 240 minutes to 720 minutes, however, can be taken to mean that the impact of a 35\% reduction in trimmed noble metals was not overly significant to the SRAT chemistry in general. Conversely, the data from 0 to 420 minutes indicate that the co-precipitated noble metal test showed lower reactivity with respect to $\mathrm{CO}_{2}$ formation initially, but that it eventually became indistinguishable from the two tests with trimmed noble metals. Formate material balance data appear to support this, see Table 13, page 58 for further details. TNM-100-2 had a slightly greater formate loss than either CNM2 or TNM-65 (which were comparable), though the results are within the uncertainties of the calculation. These data seem to indicate that the co-precipitated noble metals, or at least the one(s) responsible for significant hydrogen generation, were being activated more slowly than the trimmed noble metals.

Reflux may also have played a role in differentiating TNM-100-2 from TNM-65. TNM-100-2 was producing significant hydrogen at the onset of reflux, while TNM-65 was barely beginning its ramp to its peak rate. The inhibiting species in reflux may have had more of an impact on TNM-100-2 hydrogen generation, because it was more active at the start of reflux.

The $\mathrm{pH}$ profiles of these runs suggested another potential contributing factor for the greater hydrogen generation rate in the run with $65 \%$ noble metals, Figure 5 . Note that the sludges in all three tests were very thick initially, and mixing was an issue. This may explain the unusual $\mathrm{pH}$ behavior seen at the very start of nitric acid addition, -480 to -360 minutes. Locally high acid concentrations apparently dissolved base species faster than they were neutralized. The slurries thinned out significantly once the $\mathrm{pH}$ fell below about 6.0-6.5. 
Figure 5. SRAT pH Data Comparison

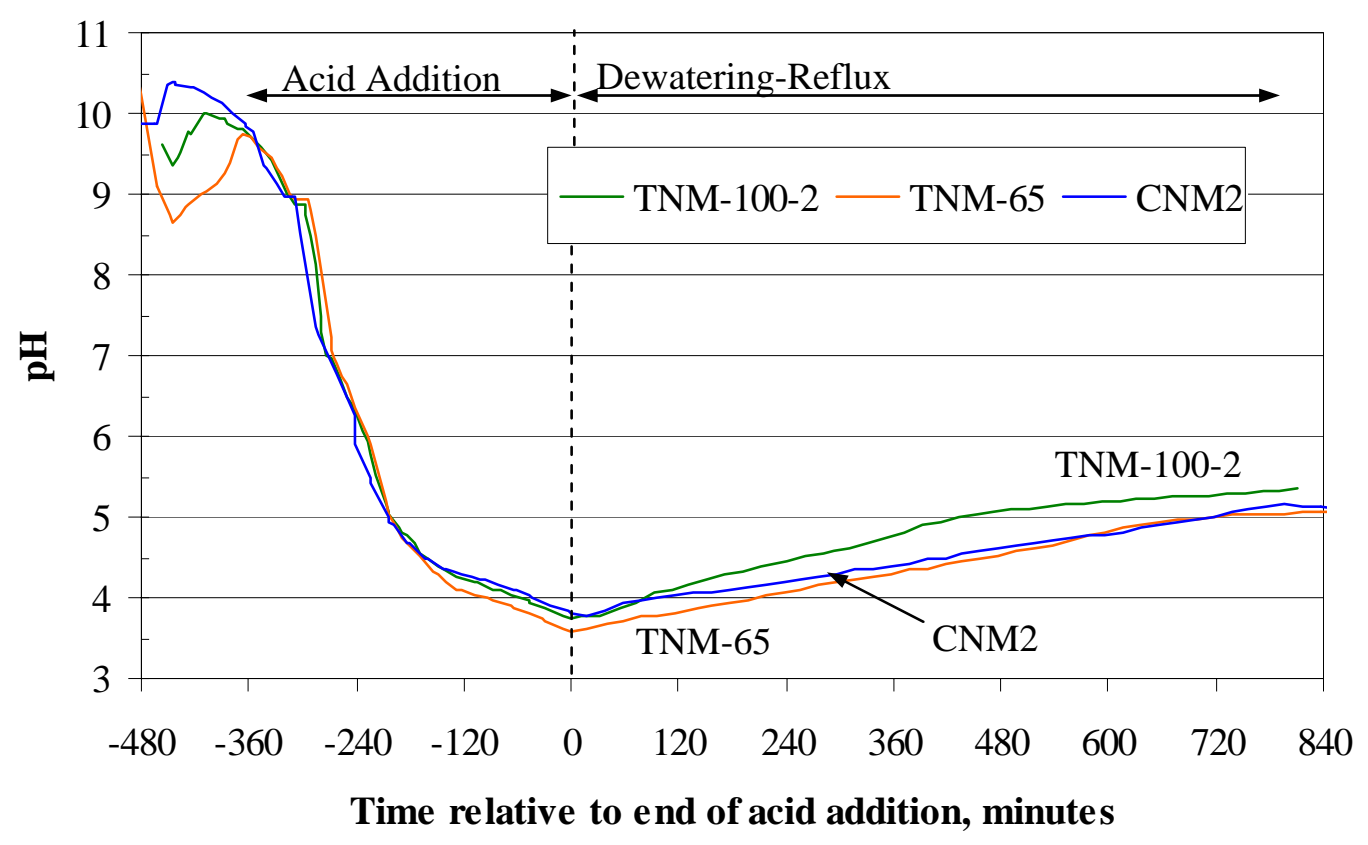

It appears that the run with $65 \%$ trimmed noble metals was slightly more acidic at the end of acid addition than the other two runs (at adjusted processing time equal zero). Although great care was taken to batch the sludge and to regulate mixing and acid addition identically in the three runs, it is possible that environmental factors and random errors are the explanation for the difference that led to the lower $\mathrm{pH}$ at $65 \%$ noble metals relative to $100 \%$ rather than changes in chemistry. Lower $\mathrm{pH}$ implies more formic acid and less sodium formate. The reviewed literature indicated that formic acid is converted more readily to hydrogen than formate ion, Koopman (2004a). An alternative explanation, however, would be that TNM100-2 noble metals were more active in consuming formic acid prior to the end of acid addition due to their higher concentration, and this increased acid consumption led to the higher $\mathrm{pH}$ at the end of acid addition. The higher $\mathrm{pH}$ led to more sodium formate relative to formic acid and to less hydrogen at the time of the peak generation rate.

Some of the work at the University of Georgia, see the review in Koopman (2004a), as well as the 1998 data obtained by Boley and Lambert and analyzed in Koopman (2005b), point to a non-metallic phase of rhodium as potentially being more active, e.g. a rhodium complex in solution. The distribution of Rh species between various oxidation states and between the supernate and insoluble solids during SRAT processing has not been quantified. Samples of the SRAT product supernate were submitted to ADS. The dissolved Rh result for TNM-65, Table 8, was higher than for TNM-100-2, even though it started with only $65 \%$ as much rhodium. These two samples were prepared together and run on the ICP-MS together, so relative comparisons should be good. What these data cannot show are the concentrations of $\mathrm{Rh}$ in solution at the time of peak hydrogen generation. If complexed Rh supernate concentrations were higher in TNM-65 than in TNM-100-2, then this could easily explain the higher peak hydrogen generation rate seen in that run. Future test programs could sample the SRAT near the hydrogen generation peak to check for dissolved Rh. Nitrite ion concentration was below the detection limit in all of the SRAT products. That does not preclude some nitrite ion being present and complexed with $\mathrm{Rh}$ at concentrations this low. 
A shift to a later time for peak hydrogen generation was found during a review of SB3 hydrogen data, Koopman (2005b). During the SB3 acid window study, a drop from 170\% to 155\% of stoichiometry produced an eight hour delay in the peak hydrogen generation rate, but almost no change in the magnitude. The relevance to TNM-100-2 and TNM-65 hydrogen data is that in both cases a change was made to the system that would have been expected to lead to a reduced peak hydrogen generation rate, but instead produced a shift of the peak to a later time. The changes were to noble metal concentration in one case and to excess acid concentration in the other.

Consequently, there is a possibility that changes to either acid stoichiometry or noble metal concentration could produce similar end results in the hydrogen generation rate profile during the SRAT cycle. This would be consistent with hydrogen generation kinetics being driven by a term containing a product of the noble metal concentration (rate constant term) with the excess acid concentration, potentially raised to some power other than one. Such a correlation was tested statistically during the review of SB3 data, and it was found to explain much of the observed variation in hydrogen generation rate data, Koopman (2005b).

\subsection{SRAT Data - Heat-Treatment Impact on Each Simulant}

Portions of the two simulants that were the basis for the SRAT runs in section 3.3 were subjected to heattreatment as described in Koopman (2005c). Tests CNM-HT and TNM-100-HT were designed to compare the effect of co-precipitation of noble metals versus trimmed noble metals in the context of the heat-treated simulants. These tests were used to meet the secondary goals of the form of noble metal testing in section 1.2. These included comparisons between trimmed noble metal SRAT runs before and after heat-treatment, comparisons between co-precipitated noble metal SRAT runs before and after heattreatment, and comparisons between trimmed and co-precipitated noble metals after heat-treatment.

Analyses following heat-treatment indicated a significant drop in base equivalents at $\mathrm{pH} 7$ of approximately $0.12 \mathrm{M}$, as well as nitrite concentrations that were more than $10 \%$ higher. There was a net reduction in the stoichiometric acid requirement. It was decided to partially off-set this reduction by raising the stoichiometric factor from $\sim 171 \%$ to $176 \%$. The rationale was to try to keep the moles of excess acid or acid not consumed in reactions with base, carbonate, nitrite, and Mn approximately constant. This required an element of engineering judgment to accomplish. In spite of the higher stoichiometric factor, the two runs with the heat-treated simulants both received less total acid than the three runs based on the original simulants discussed in section 3.3.

Both SRAT cycles were characterized by reductions in the apparent viscosity of the slurry during acid addition. Both SRAT cycles began to produce foam with only the initial $200 \mathrm{ppm}$ of antifoam present once formic acid addition was started. It was necessary to add the $100 \mathrm{ppm}$ of additional antifoam that DWPF adds before formic acid addition to control the foam that was formed. There were no foaming issues during boiling.

\subsubsection{Trimmed Noble Metal SRAT Cycle Comparison}

The first comparison involving a test with heat-treated simulant was made between the two runs based on trimmed noble metals at $100 \%$ of the target concentrations. TNM-100-2 used the original simulant at $172 \%$ stoichiometry, or 2.781 moles total acid/L sludge, while TNM-100-HT used heat-treated simulant at $176 \%$ stoichiometry, or 2.552 moles total acid/L sludge. Figure 6 compares these two runs containing nominal SB3 levels of noble metals. 
Figure 6. Comparison of SRAT $\mathrm{H}_{2}$ Data in Runs Trimmed to $100 \%$ Noble Metals

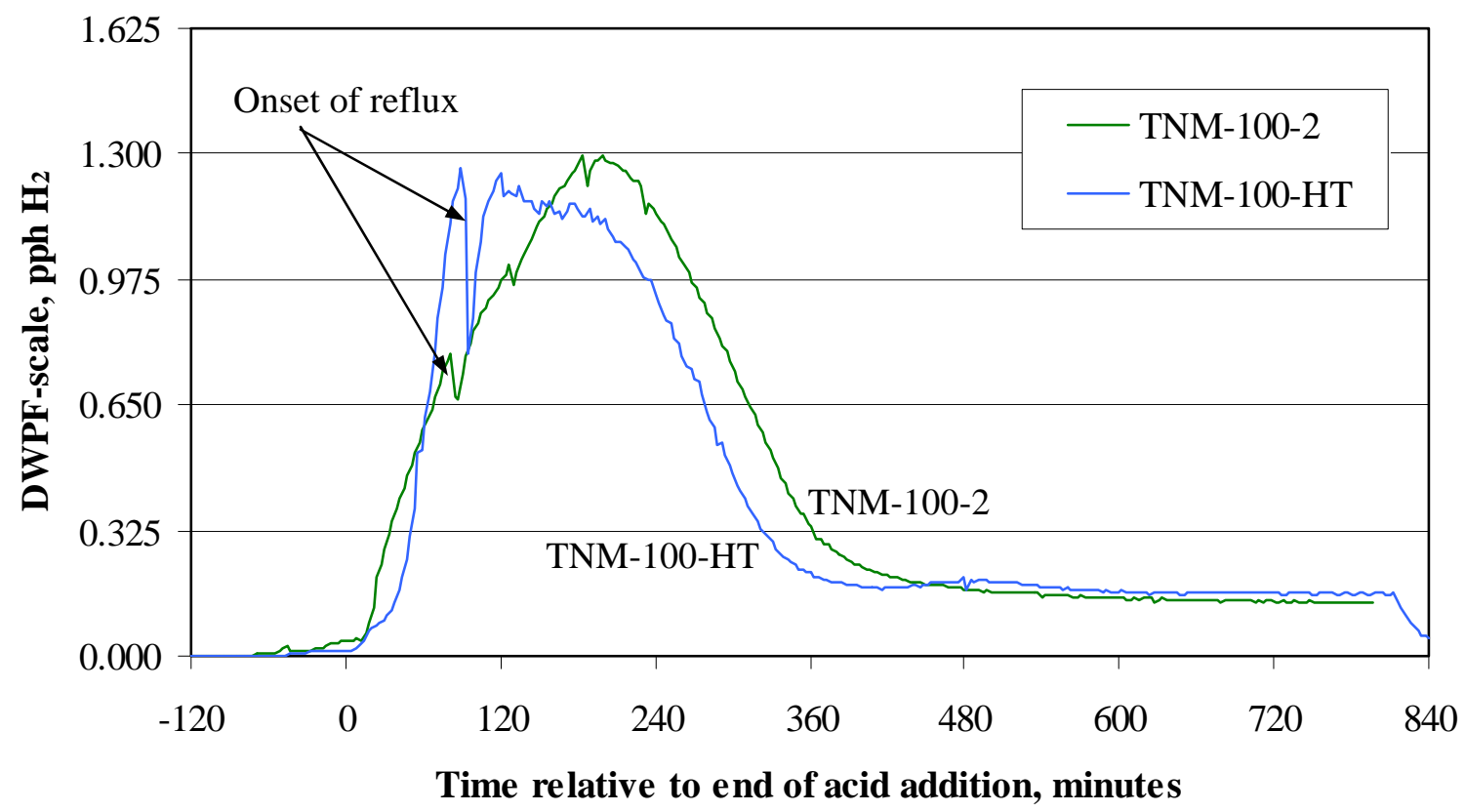

These two sets of hydrogen results are nearly identical throughout the SRAT cycle. This seems to indicate that increasing the stoichiometric factor from $172 \%$ to $176 \%$ essentially off-set the reduction in excess acid present due to the $11 \%$ lower stoichiometric acid requirement of the heat-treated sludge. Then, since the same noble metal concentrations were present, and roughly the same amount of excess acid was present, these two runs produced nearly identical hydrogen generation rate profiles. The heattreated simulant appeared to rise to its peak more steeply and also to produce slightly less total hydrogen. Both runs noted the onset of reflux by making noticeable short-term reductions in hydrogen generation. These were smaller, however, than those seen in the Phase I, Part 2 study on the impact of mercury, Koopman (2005a). This is attributed to the redesigned test equipment, Baich (2004b), which is generally performing more like the full-scale DWPF SRAT in terms of chemistry.

The rate of decline in hydrogen generation rate following the peak rate was very similar between the two tests. Apparently the primary deactivation process was not impacted by heat-treatment. The hydrogen generation rate fell to about $0.15 \mathrm{lbs} / \mathrm{hr}$ and held fairly steady through most of the reflux period (until the slurry was cooled at about 800 minutes).

The $\mathrm{pH}$ data were fairly similar between the two runs as seen in Figure 7. 
WSRC-TR-2005-00286

Revision 0

Figure 7. SRAT pH Data for $100 \%$ Trimmed Noble Metals

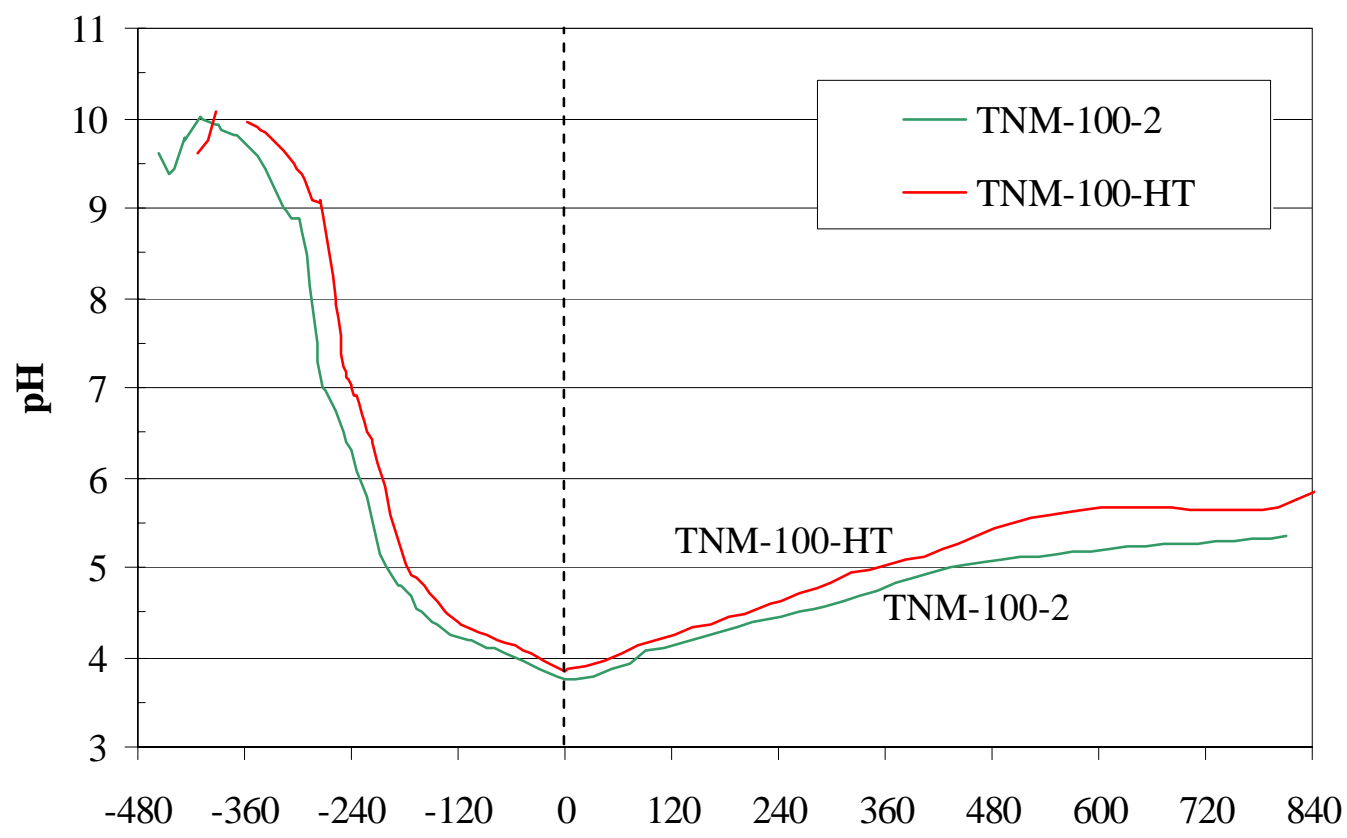

Time relative to end of acid addition, minutes

Less acid was added to TNM-100-HT. This may have produced a slightly higher $\mathrm{pH}$ at the end of acid addition as well as appearing to shift $\mathrm{pH}$ data during acid addition to the right since zero is the time of the end of acid addition, not the start of acid addition. The stoichiometric acid calculation indicated that this run needed less acid, and that seems to have been confirmed by the processing data in general. Post-run checks with $\mathrm{pH}$ buffer solutions indicated that the $\mathrm{pH}$ probe in TNM-100-2 was reading 0.2 units lower than the probe in TNM-100-HT. This likely explains part of the difference between the two data sets as the cycle progressed, and the probe bias developed. Differences in $\mathrm{pH}$ at selected times were, however, generally greater than $0.2 \mathrm{pH}$ units.

\subsubsection{Co-precipitated Noble Metal SRAT Cycle Comparison}

The same comparisons made in section 3.4.1 were made for the co-precipitated noble metal tests, CNM2 and CNM-HT. These two tests were at $171 \%$ of stoichiometry, or 2.889 moles total acid/L sludge, and at $176 \%$ of stoichiometry, or 2.765 moles of total acid/L sludge, respectively. 
WSRC-TR-2005-00286

Revision 0

Figure 8. Comparison of SRAT $\mathrm{H}_{2}$ Data in Runs with Co-Precipitated Noble Metals

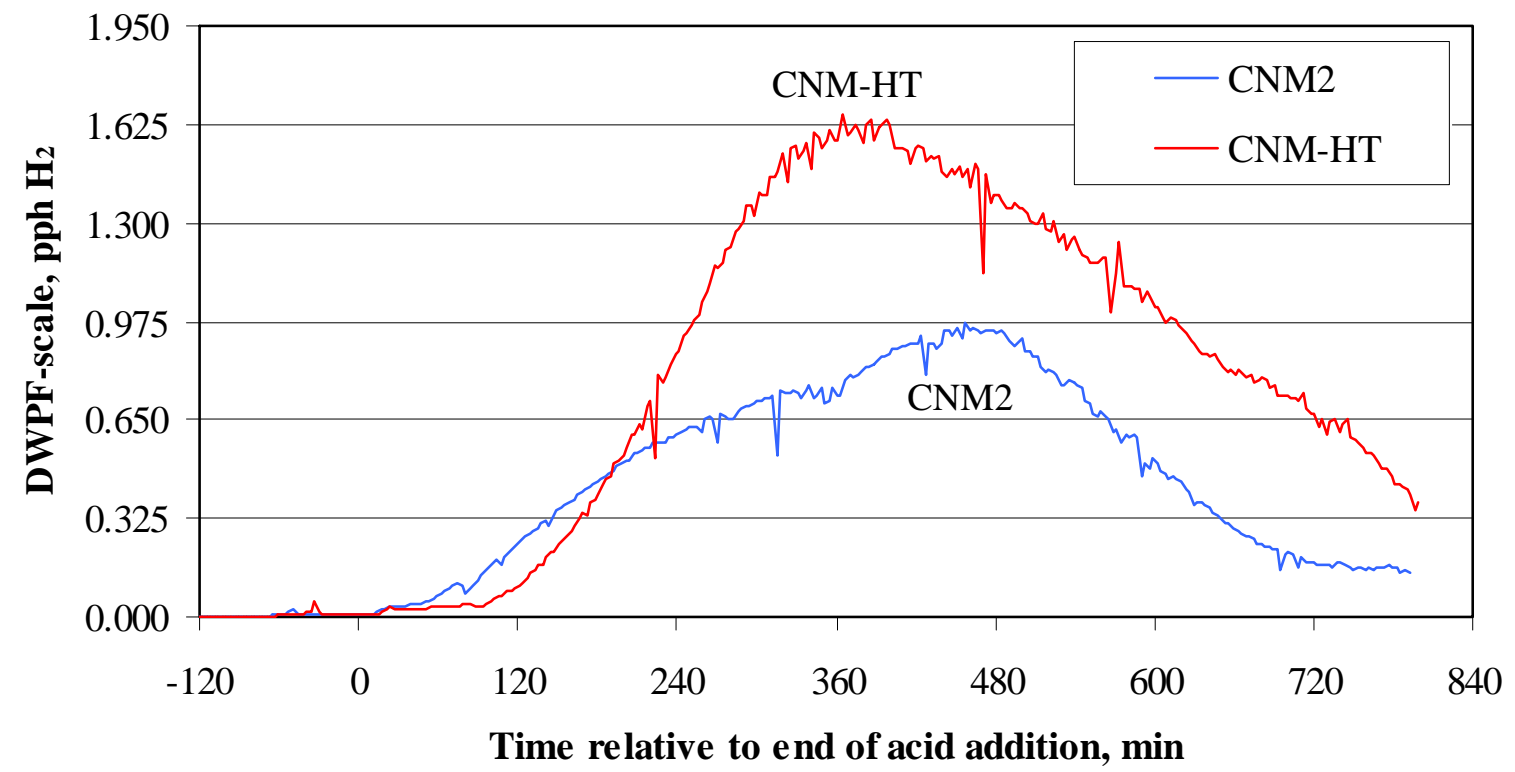

The peak hydrogen generation rate during the heat-treated simulant run was approximately $70 \%$ greater than that in CNM2. It also peaked about an hour earlier. This occurred even though CNM-HT received $3.7 \%$ less total acid per liter of starting sludge. Given the results obtained in section 3.4.1, it was expected that the acid additions in these two runs could have produced fairly comparable hydrogen generation rate results. It can be concluded that the changes in base equivalents due to heat-treatment produced a real change in the acid requirement under processing conditions. Heat-treatment may have somehow enhanced the activity of the noble metals relative to the original simulant. Peak hydrogen generation in CNM-HT also exceeded that seen in the trimmed noble metal run, TNM-100-2. It was only slightly larger than that in TNM-65.

The rates of decline in hydrogen generation rate following the peak were fairly similar. Deactivation seemed to be a little slower in CNM-HT. Because the peaks came later in the reflux period than in the runs with trimmed noble metals, it was not possible to observe the hydrogen generation rate where CNMHT would have started to level off. It was still above $0.3 \mathrm{lbs} / \mathrm{hr}$ when the SRAT cycle was concluded.

The SRAT pH data for the two SRAT simulations are given in Figure 9. 
WSRC-TR-2005-00286

Revision 0

Figure 9. SRAT pH Data with Co-Precipitated Noble Metals

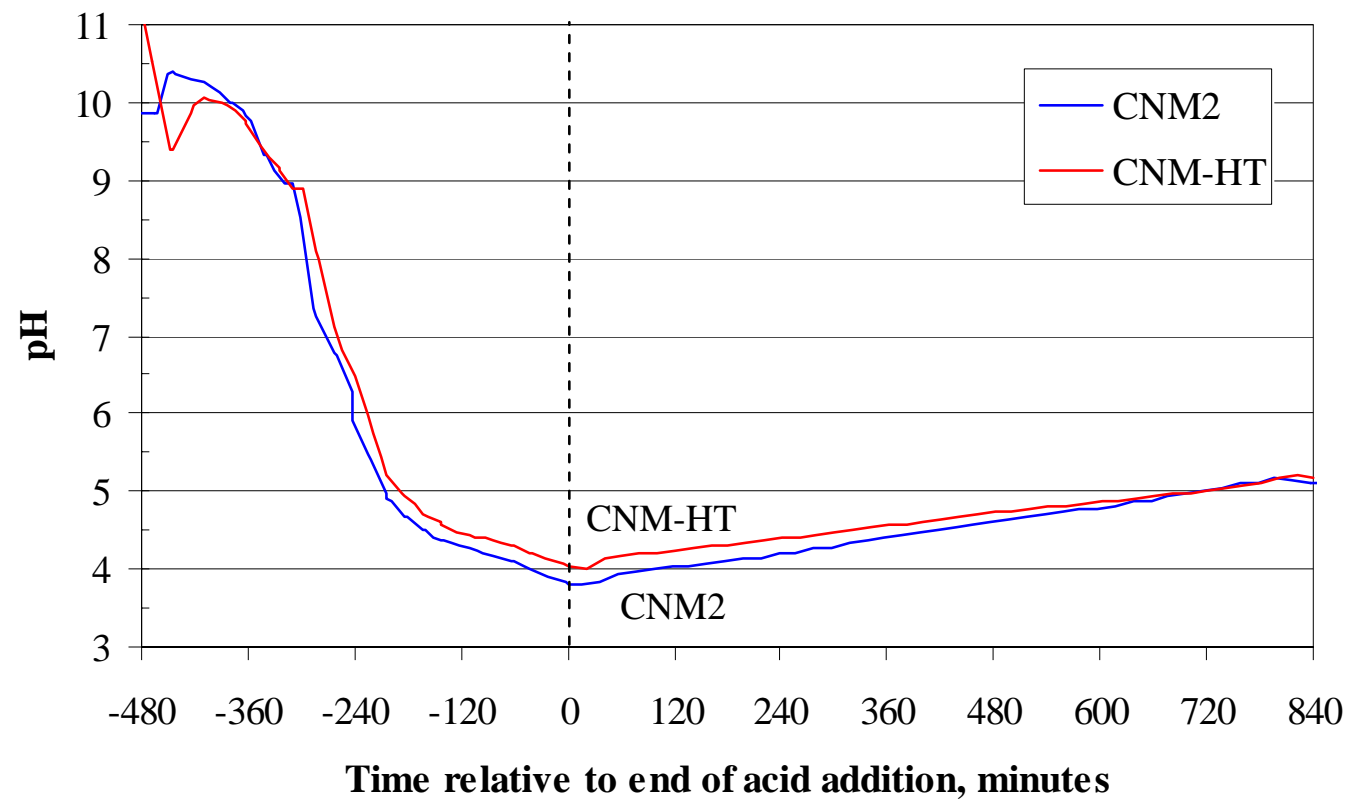

The relative positions of the two $\mathrm{pH}$ curves are similar to what was seen in Figure 7 for the trimmed noble metal case, i.e. that the heat-treated curve was above the original simulant curve. The change in $\mathrm{pH}$ during boiling, which should track formic acid destruction, was very similar. These data did not suggest an alternative explanation for the enhanced hydrogen generation in CNM-HT relative to CNM2. The slightly more rapid rate of increase in $\mathrm{pH}$ during boiling in CNM2 suggested that it was destroying formic acid faster than CNM-HT.

The carbon dioxide data was also examined to check for an explanation for the increased hydrogen generation in the heat-treated test. 
WSRC-TR-2005-00286

Revision 0

Figure 10. SRAT $\mathrm{CO}_{2}$ Data with Co-precipitated Noble Metals

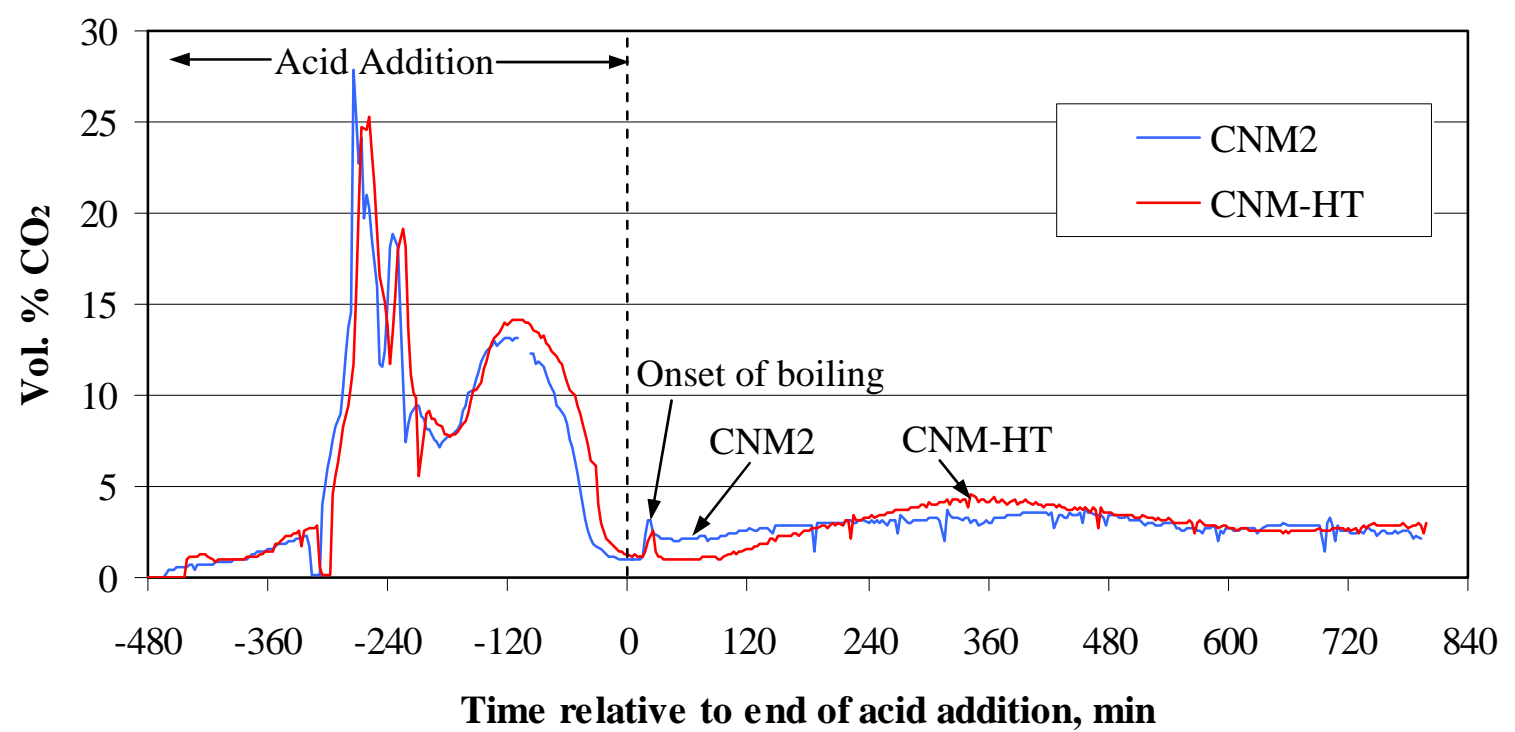

The carbon dioxide data show that CNM2 was making more $\mathrm{CO}_{2}$ than $\mathrm{CNM}-\mathrm{HT}$ after the onset of boiling. This was also observed in TNM-100-2 relative to TNM-65, with TNM-65 ultimately having the higher maximum hydrogen generation rate. Hydrogen generation immediately after the onset of boiling was also higher in CNM2 than CNM-HT, i.e. was qualitatively tracking the $\mathrm{CO}_{2}$ concentration. The $\mathrm{CO}_{2}$ concentration did not show a 70\% difference between CNM2 and CNM-HT during boiling in the SRAT cycle, and from 480 minutes until the end of the SRAT cycle the $\mathrm{CO}_{2}$ concentrations were virtually identical between the two runs, unlike hydrogen.

Apparently the proportion of consumed formate that produced hydrogen was lower in CNM2 relative to CNM-HT following acid addition. It is hard to argue that the actual proportion was the same within the slurry, but that other species in the slurry were consuming it, since that clearly did not happen in the runs with trimmed noble metals. The trimmed simulants should have similar species relative to the coprecipitated noble metal simulants except for the noble metals themselves. Therefore, it can be concluded that the form of the noble metals must be responsible for the change in relative proportions of hydrogen to carbon dioxide based on this single comparison. No evidence was found to support other plausible alternatives, such as if additional noble metals or additional acid had somehow been present.

Neither the $\mathrm{pH}$ nor the $\mathrm{CO}_{2}$ data provided the insight needed to explain the higher hydrogen generation rates seen in the heat-treated case. Aliquots of the SRAT products from the five primary runs were taken and centrifuged. The five aqueous phases were recovered. The samples were analyzed to determine the extent that Pd, Rh, and Ru were in solution, section 3.2.1. Expanded results for Rh are given in Table 10. 
Table 10. SRAT Product Rh Dissolution Levels

\begin{tabular}{|l|c|c|c|}
\hline Test & $\begin{array}{c}\text { Rh in feed } \\
\text { slurry, } g\end{array}$ & $\begin{array}{c}\text { Rh in SRAT product } \\
\text { supernate, } g\end{array}$ & $\begin{array}{c}\text { \% Rh in } \\
\text { solution }\end{array}$ \\
\hline CNM2 & 0.0343 & 0.000502 & 1.46 \\
\hline CNM-HT & 0.0343 & 0.00440 & 12.83 \\
\hline TNM-100-2 & 0.0339 & 0.000323 & 0.95 \\
\hline TNM-65 & 0.0220 & 0.000381 & 1.73 \\
\hline TNM-100-HT & 0.0339 & 0.000191 & 0.56 \\
\hline
\end{tabular}

The high Rh solubility in CNM-HT may have been related to its heightened catalytic activity. There was roughly an order of magnitude more Rh in solution in this run than in CNM2. Rh solubility may also have explained why TNM-65 had more hydrogen than TNM-100-2, section 3.3.2. The data only show the condition in the SRAT product, but if the same relative ranking held throughout the SRAT cycle, then this could be an explanation for increased hydrogen generation in CNM-HT. Data obtained by Boley and Lambert in 1996, see analysis in Koopman (2005b), support a lower catalytic activity for elemental rhodium versus the form in site waste.

\subsection{SRAT Data - Heat-Treatment Form of Noble Metal Comparison}

The two runs using heat-treated simulants, TNM-100-HT and CNM-HT, were planned to be as comparable as possible in terms of noble metals and excess acid to meet the second goal of section 1.2. They also provided another comparison between co-precipitated and trimmed noble metals similar to that in section 3.3. Both were batched at $176 \%$ of the stoichiometric acid requirement. This gave moles total acid per liter sludge additions of 2.765 and 2.552 respectively. As seen in section 3.4.1, TNM-100-HT gave results similar to TNM-100-2 in the SRAT cycle. As seen in section 3.4.2, the CNM-HT had surprisingly different results from CNM2. The two heat-treated simulant SRAT cycle results are compared to each other in this section.

\subsubsection{Hydrogen Generation Rate Data}

The onset of hydrogen generation data were examined to see if similar behavior was observed to that in the three runs without heat-treatment. The GC data were converted to DWPF-scale lbs/hr of hydrogen generation. They are given in Figure 11. 
WSRC-TR-2005-00286

Revision 0

Figure 11. Onset of Hydrogen Generation - Heat-treated Case

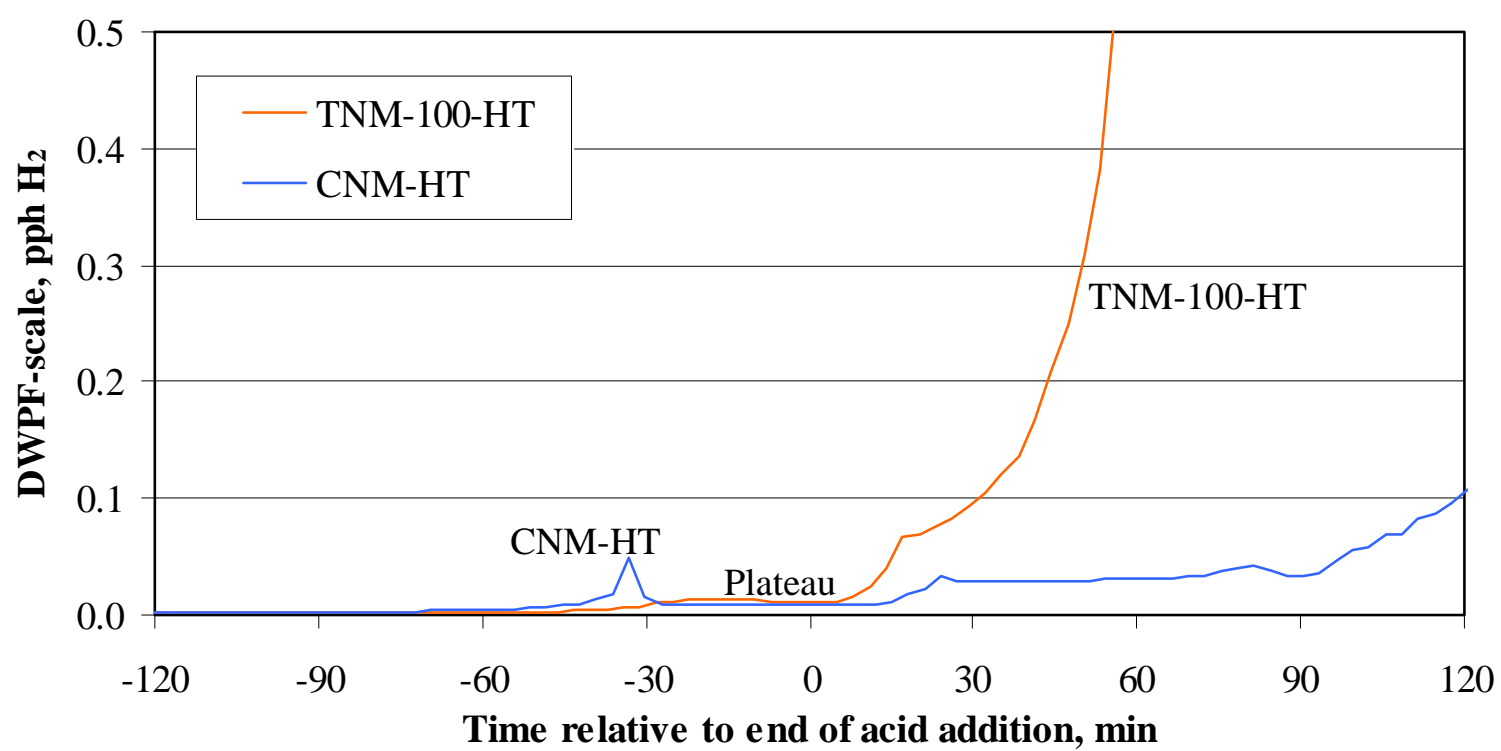

A small peak was noted during CNM-HT about 35 minutes before the end of acid addition. The location was similar to those seen in Figure 2 for the three runs that did not use heat-treated simulants, but the peak was several times larger. This peak was followed by a period of reduced hydrogen generation before the rate increased to the eventual maximum. TNM-100-HT did not produce a distinct peak by the end of acid addition, but it did reach 50\% of the small peak values in Figure 2 at the plateau level. TNM100-HT hydrogen generation became significantly more active starting about 15 minutes after acid addition, while activation from the plateau level in CNM-HT was much slower. This was similar to the difference between TNM-100-2 and CNM2.

The overall hydrogen generation profiles for the two heat-treated simulant runs are shown in Figure 12. 
WSRC-TR-2005-00286

Revision 0

Figure 12. Hydrogen Generation During the Heat-Treated Simulant Tests

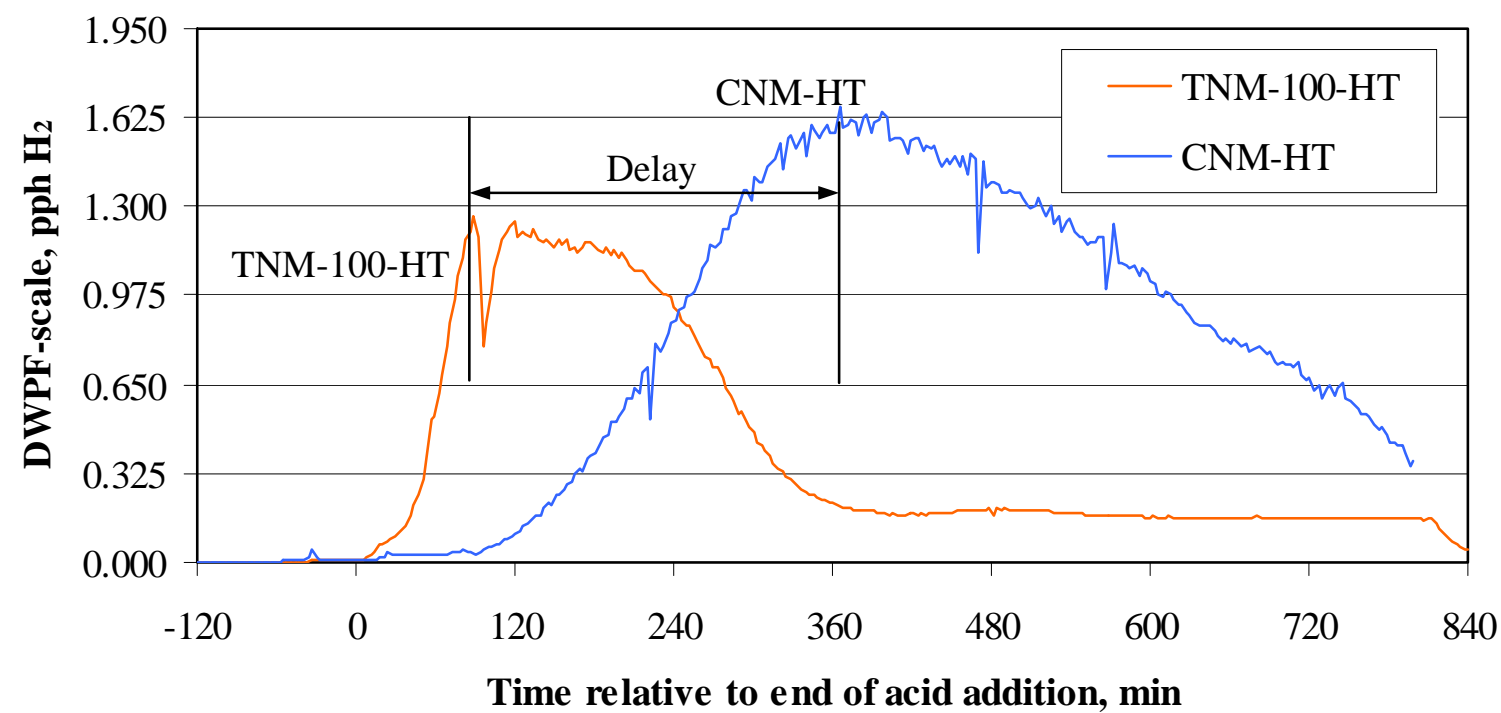

CNM-HT produced the maximum peak hydrogen generation rate of the five tests in the $171-176 \%$ of stoichiometry range, but it was only slightly more than TNM-65, 1.66 vs. $1.57 \mathrm{lbs} / \mathrm{hr}$. This peak was reached nearly five hours later than the peak in TNM-100-HT. This is another example of the coprecipitated noble metals reaching maximum activity more slowly than the trimmed noble metals. The first example was the three runs in section 3.3. A third example was found in the two preliminary runs, CNM and TNM-100, Appendix A. This pattern of slower activation for the co-precipitated noble metals was clearly established during this testing. The rate of decline in hydrogen generation rate appears to be more distinctly slower in CNM-HT than in TNM-100-HT, especially on the interval from 0.3-1.0 lbs $\mathrm{H}_{2} / \mathrm{hr}$.

\subsubsection{Examination of Differences between the Heat-treated Runs}

Other data for the two heat-treated SRAT runs were compared in an attempt to understand the hydrogen generation rates of CNM-HT. Additional comparisons were also made with the un-heat-treated simulants. Carbon dioxide behavior was examined since it is the co-product of hydrogen generation from formic acid. Figure 13 shows the $\mathrm{CO}_{2}$ data for the two runs with heat-treated simulant. 
Figure 13. Heat-Treated Simulant SRAT $\mathrm{CO}_{2}$ Data

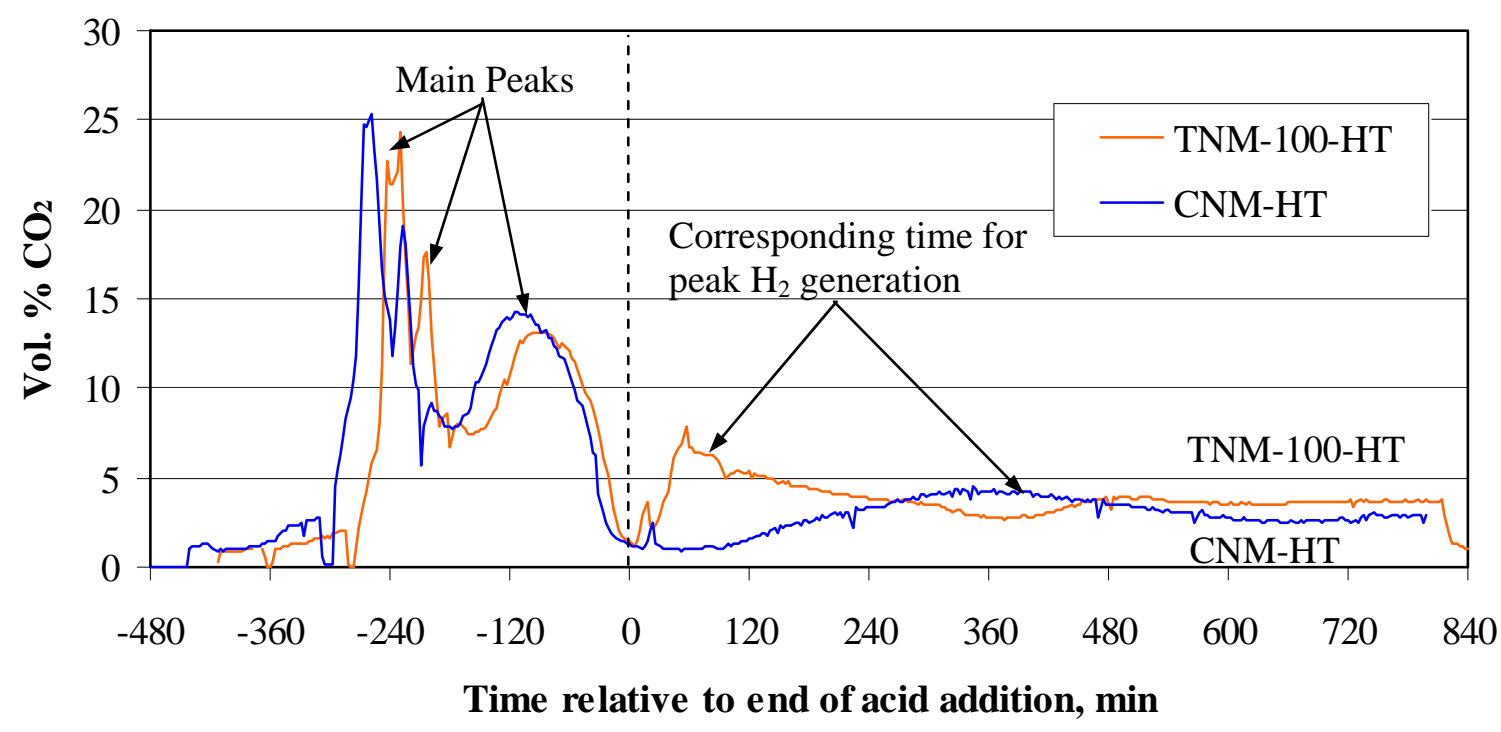

The three main $\mathrm{CO}_{2}$ peaks in CNM-HT at -260 , -230, and -130 minutes all came about 20-30 minutes sooner than in TNM-100-HT. If the acid feed to CNM-HT had been stopped sooner, then these peaks would have been shifted to the right and would have aligned more closely with those of TNM-100-HT. This could be taken to mean that CNM-HT received somewhat more excess acid than TNM-100-HT. The relative shift in acid addition due to heat-treatment of the two simulants is discussed in the next paragraph.

The difference in total acid in the two heat-treated runs was 0.20 moles acid/L sludge, or $7.5 \%$, whereas the difference between co-precipitated and trimmed noble metal acid addition in the three un-heat-treated runs was 0.12 moles acid/L sludge, or $4.2 \%$. This was primarily due to small changes in the various inputs to the stoichiometric acid calculation which could be entirely due to analytical uncertainty. A 0.08 moles acid/L sludge shift was justified by the analytical results, but may not have actually been present. This could be argued if the heat-treatment impact on both simulants was essentially the same.

If the acid addition in CNM-HT was decreased, to make this pair more like the first pair, then the $\mathrm{CO}_{2}$ data would shift about ten minutes closer together. The actual off-set was closer to 25 minutes. To test this hypothesis, another SRAT run should be completed with heat-treated, co-precipitated noble metal simulant and $\sim 0.08$ moles less acid per liter sludge. Samples of SRAT supernate could be collected to check for noble metal dissolution at the same time. There may be more than one factor responsible for the increased hydrogen generation seen in CNM-HT.

The peak $\mathrm{CO}_{2}$ generation rate for TNM-100-HT at 56 minutes was actually about 30 minutes sooner than the peak hydrogen generation rate at 90 minutes. Less than perfect correlation in the timing of the $\mathrm{CO}_{2}$ and $\mathrm{H}_{2}$ peaks was also observed in one of the three tests without heat-treatment, TNM-100-2, section 3.3. Many instances of near perfect correlation between the timing of the $\mathrm{CO}_{2}$ and $\mathrm{H}_{2}$ peaks have been observed, see for example Koopman (2005b). A peak offset seemed to be particularly likely when the peak hydrogen generation rate occurred shortly after the end of acid addition.

The maximum $\mathrm{CO}_{2}$ generation rate during boiling was higher in TNM-100-HT than in CNM-HT, i.e. the opposite direction observed for hydrogen. The $\mathrm{CO}_{2}$ generation rate corresponding to the time of the maximum peak hydrogen generation rate in Figure 12 was about 30\% larger in TNM-100-HT (less $\mathrm{H}_{2}$ ) 
than in CNM-HT (more $\mathrm{H}_{2}$ ). The reasons for this reversal of relative behavior are not presently known, but the reality of this observation was apparently supported by the formate loss data which was unusually high in TNM-100-HT. This behavior was not observed in the three tests without heat-treatment. TNM100-HT had fairly similar $\mathrm{CO}_{2}$ data to TNM-100-2, just as it did for hydrogen, Figure 14. TNM-100-HT received 5\% less formic acid than TNM-100-2, however, from which to produce the $\mathrm{CO}_{2}$ consistent with the larger percent formate loss by material balance.

Figure 14. Heat-Treatment Impact on $\mathrm{CO}_{2}$ with Trimmed Noble Metals

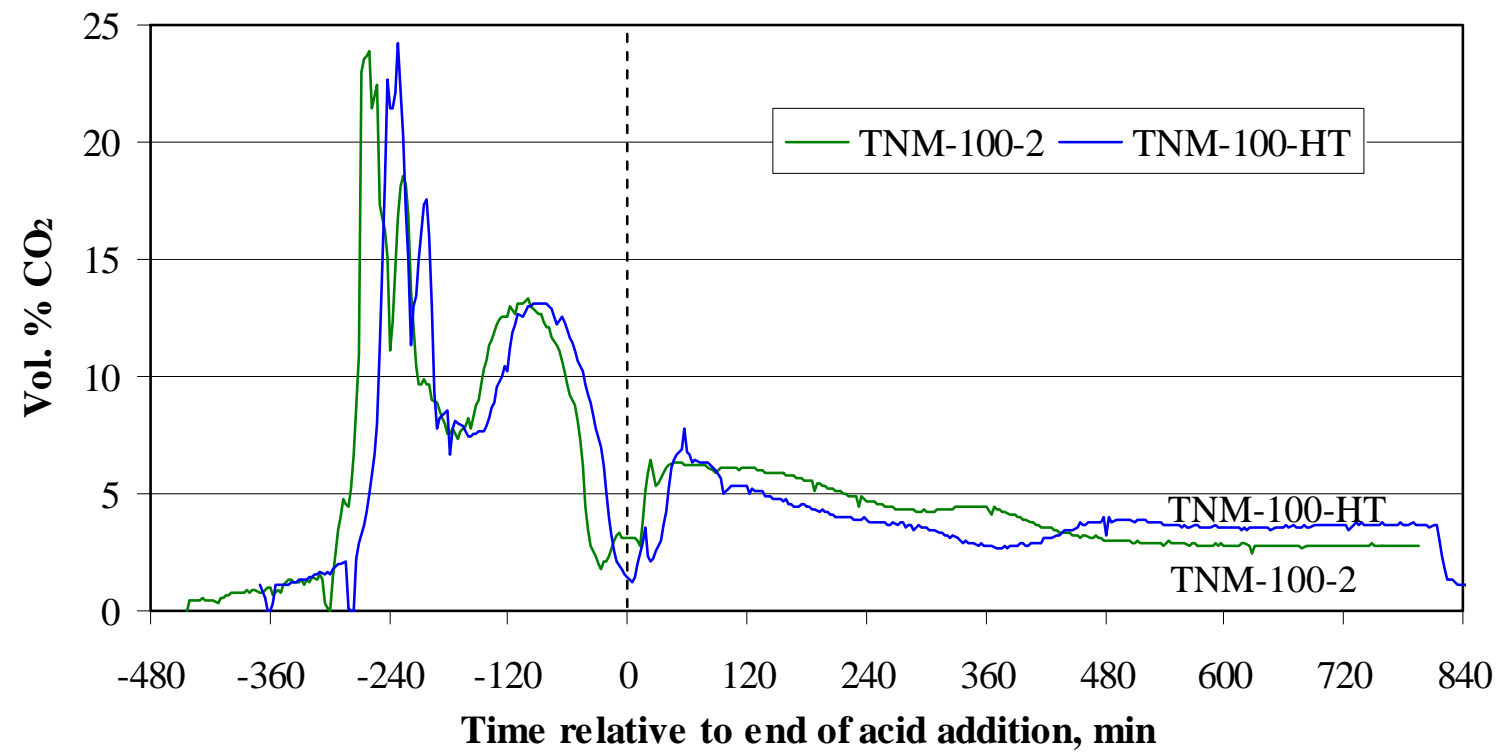

The impact of heat-treatment on the co-precipitated noble metal simulant $\mathrm{CO}_{2}$ evolution was not very pronounced, Figure 15. Although the TIC analyses were about $10 \%$ different, it was not obvious that this led to more $\mathrm{CO}_{2}$ evolution during acid addition, particularly from -480 to -240 minutes when the carbonate appears to be destroyed. CNM-HT received $96.2 \%$ as much formic acid as CNM2. It is possible that starting TIC was actually identical, since the simulant was from the same recipe preparation in both cases. The difference may have been entirely due to analytical uncertainties. 
Figure 15. Heat-Treatment Impact on $\mathrm{CO}_{2}$ with Co-Precipitated Noble Metals

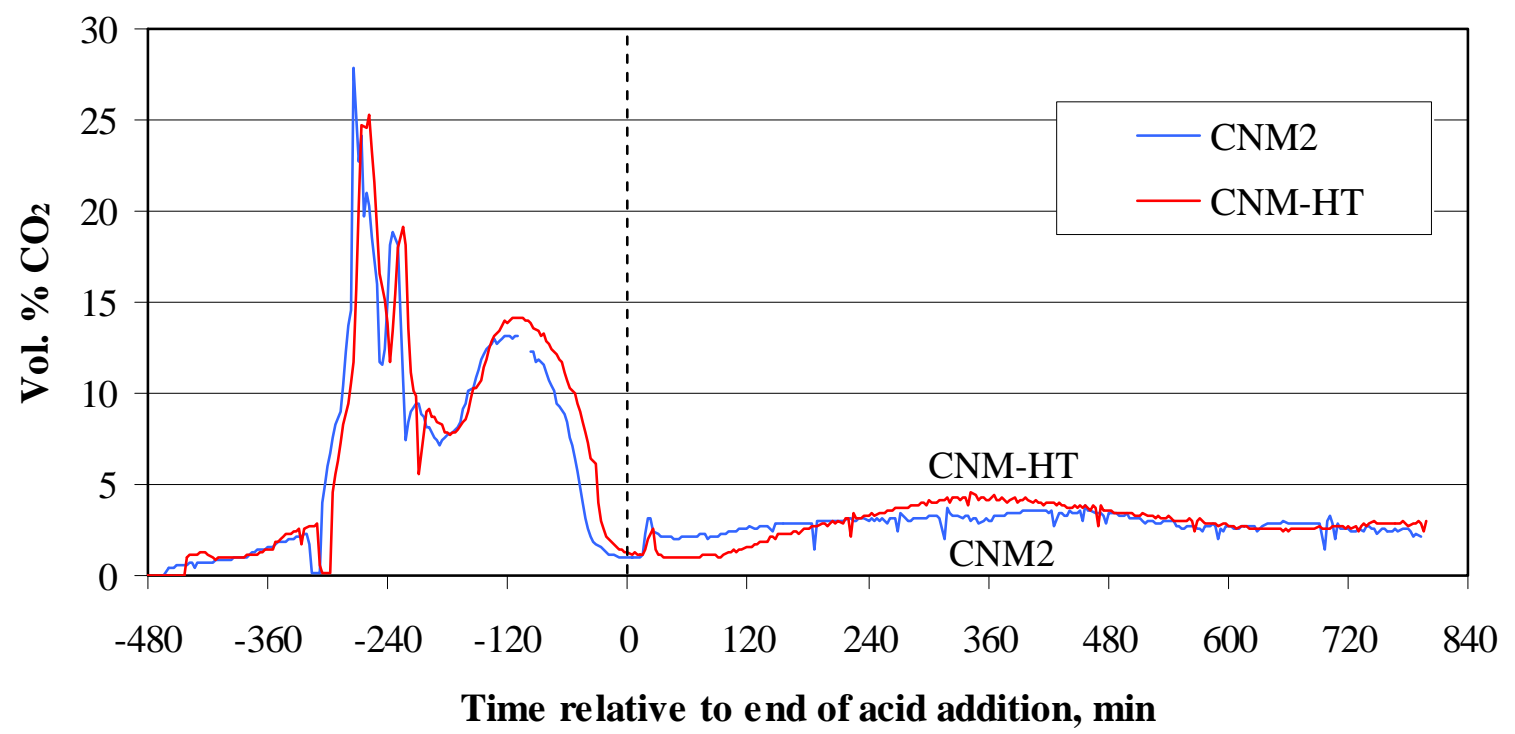

Relatively, however, the CNM-HT data for $\mathrm{CO}_{2}$ went through larger variations during boiling than CNM2, while the TNM-100-HT data for $\mathrm{CO}_{2}$ went through smaller variations during boiling than TNM100-2. This could be taken to mean that noble metals in CNM-HT went through a wider range of activity levels during processing than those in CNM2, while the trimmed noble metals in TNM-100-HT had a lower range of activity than those in TNM-100-2. This could be indicating that there was more difficulty in activating the co-precipitated noble metals.

Based on the simulant titration work in Koopman (2005c), heat-treatment did not produce the full change in base equivalents in under an hour. This is consistent with CNM2 producing less hydrogen than CNMHT, and with TNM-100-2 and TNM-100-HT producing similar peak hydrogen generation rates. If the heat-treatment impact occurred quickly relative to heat-up and early acid addition time, then there should have been more excess acid in CNM2 and TNM-100-2 than in their heat-treated counterparts following acid addition, and relatively more hydrogen would have been expected.

One thing was clear from the heat-treated simulant SRAT testing. The act of heat-treatment changed the inputs to the acid calculation toward a lower stoichiometric acid requirement. This reduction was apparently real. Consequently, both less total acid and less formic acid were fed to the two heat-treated SRAT cycles than to the corresponding runs with the un-heat-treated simulants. In spite of the lower total acid additions, the two runs with heat-treated simulant produced as much or more hydrogen than the corresponding un-heat-treated runs. The conclusion is that heat-treatment, as performed in this study, caused a significant change in processing both with co-precipitated and with trimmed noble metals.

\subsection{Summary of Preliminary SRAT Runs}

Two preliminary form of noble metal SRAT runs were completed in late 2004. Run CNM was based on co-precipitated noble metal simulant. Run TNM-100 was based on the corresponding simulant without noble metals. They were both at higher acid stoichiometries than the five main runs. The recomputed acid stoichiometries were significantly different from each other. Therefore, the two runs do not form a good basis for a direct comparison of peak generation rate such as was done for CNM2 and TNM-100-2 or for CNM-HT and TNM-100-HT. The majority of the SRAT cycle results are presented in Appendix A. The most relevant findings are summarized briefly here. Additional preliminary run data was used in section 3.7 . 
The preliminary run data provided additional support for some of the conclusions drawn so far:

- The shift to higher formate loss and lower nitrite to nitrate conversions was first noticed in the two preliminary runs. The results provided improved estimates for likely formate losses and nitrite to nitrate conversions for the acid calculations for the main runs.

- The increased difference in the wt. \% total solids in the SRAT product between prediction and measurement was seen.

- Both runs significantly exceeded the DWPF design basis of $0.65 \mathrm{lbs} / \mathrm{hr}$ hydrogen in the SRAT. This led to lower stoichiometric factors for the runs that followed.

- The two runs supported the shift to later times for the peak hydrogen generation rate when using co-precipitated noble metals.

- The two runs supported the existence and helped to explain the significance of the small hydrogen generation peak near the end of formic acid addition.

- The two runs gave insight into the sensitivity of the maximum SRAT hydrogen generation rate to potential errors in the inputs to the stoichiometric acid calculation, discussed further in section 3.7.

\subsection{Sensitivity of Peak Hydrogen Generation Results to Acid Stoichiometry Inputs}

The major source of sensitivity for the results in this report arose during comparisons of tests based on different starting simulants. This section examines whether the result from section 3.3, that coprecipitated noble metals are less active than trimmed noble metals for peak hydrogen generation, is supported by the data. This section then examines whether the result from section 3.5, that heat-treated, co-precipitated noble metals are apparently more active than trimmed noble metals in heat-treated simulant, is supported by the data.

An essentially identical recipe was followed in producing the simulants with and without co-precipitated noble metals. The recipe itself, however, can lead to variations in the outcome of multiple preparations. For example, the mass of insoluble carbonates formed prior to washing was uncertain in the recipe. Also, the precise amount of aluminum to add was set by analyses following recovery of the washed slurry, and was subject to analytical error. Identical heat-treatment procedures were followed in producing the heattreated variants of the two simulants.

\subsubsection{Un-Heat-Treated Case}

The major difference in the acid calculations for the two un-heat-treated simulants was due to TIC. A $20 \%$ error in TIC would have produced a 5.5\% difference in the total moles of acid added to either simulant. The stoichiometric factor of the co-precipitated noble metal simulant in CNM2 is $171 \pm 9 \%$ due to TIC uncertainty alone $\left(0.055^{*} 171 \% \approx 9 \%\right)$. The uncertainty of $20 \%$ is not unusual for historical ADS TIC data for waste simulant slurry samples. It was also the magnitude of the difference between the two simulants prepared in this study by an essentially identical recipe. The high sensitivity of the acid calculation, however, was partially due to the $\sim 2000 \mathrm{mg} / \mathrm{kg}$ TIC content of these simulants. TIC induced uncertainty could have shown up as $171 \pm 4 \%$ on the stoichiometric factor if TIC had been about 1000 $\mathrm{mg} / \mathrm{kg}$.

A preliminary run, CNM in Appendix A, was performed with the co-precipitated noble metal simulant at $183 \%$ stoichiometry (on the same analytical basis that CNM2 was at $171 \%$ ). Peak hydrogen generation was significantly affected by this increment of 7\% extra acid as seen in Figure 16. 
Figure 16. Hydrogen Generation at Two Stoichiometries with Co-precipitated Simulant

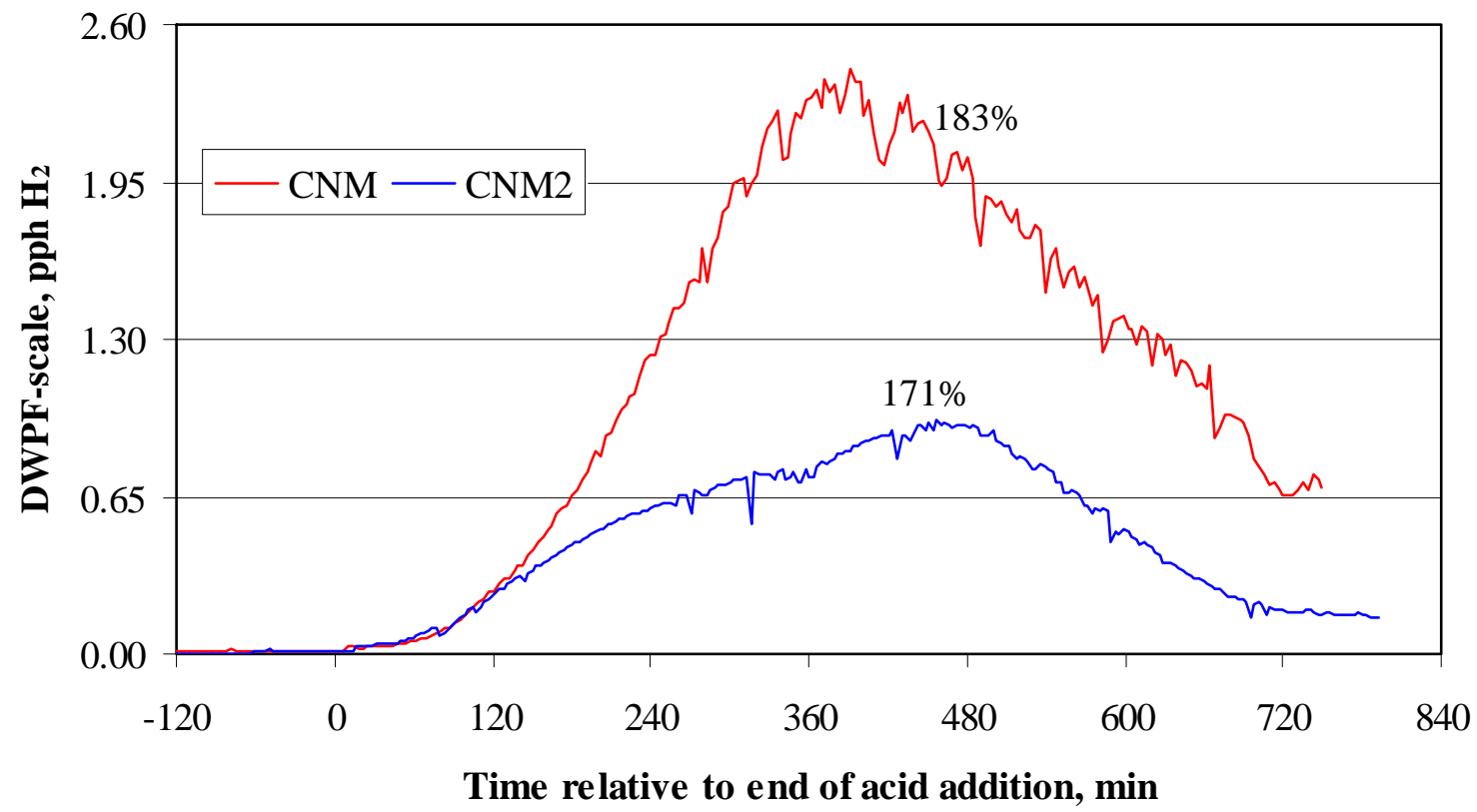

The impact of the $7 \%$ additional acid on the timing of the peak hydrogen generation rate was small, but the impact on the magnitude of the peak was an increase by a factor of 2.5 relative to the $171 \%$ case. Therefore, the observation that the peak hydrogen generation rate was lower with co-precipitated noble metals than with trimmed noble metals is potentially subject to small errors in the stoichiometric acid calculation. The observation that the timing of the peak shifted to later times with co-precipitated noble metals, however, still holds. This, in light of supporting data, was interpreted to mean that the coprecipitated noble metals were more difficult to activate.

There are potentially mitigating factors, however, to the above assessment of the uncertainty in the stoichiometric acid requirement. First, and most importantly, the simulant with co-precipitated noble metals had the higher TIC value, and so had the higher stoichiometric acid demand. This typically translates into more excess acid at stoichiometric factors much over $100 \%$. If the TIC value was artificially inflated for some reason for the co-precipitated noble metal simulant, then the expected consequence would have been greater hydrogen generation due to less acid consumption in converting TIC to $\mathrm{CO}_{2}$. The opposite was observed. The above argument becomes more complicated, however, if the simulant with the higher peak hydrogen generation rate had the lower TIC measurement, as was the case with the two heat-treated simulants.

Second, the TIC was measured on both starting simulants following preparation. It was then measured again several months later following the development of the Analytical Development Section's “ITS Acid Demand TIC" method. A distinct difference was detected at this time between the two starting simulants. All subsequent data showed the same relative ranking of the two simulants, namely that the coprecipitated noble metal simulant contained about $20 \%$ more TIC than the simulant without noble metals. Third, both simulants were subjected to a heat-treatment step, and the resulting slurries were analyzed for TIC. The same trend was seen there. It was concluded that the absolute magnitude of TIC may be in error in both simulants, but that the relative impact on the acid stoichiometry is much less than indicated by $171 \pm 9 \%$. 
The acid calculations were also based on the $\mathrm{pH} 7$ base equivalents, wt. \% total solids combined with wt.\% manganese, and the nitrite ion concentration. These three sets of values were in much closer agreement between the two simulants than was the TIC value, and were all within the normal analytical uncertainty. The analysis in Appendix A derived an approximate sensitivity of 0.11 lbs hydrogen per hour per percent stoichiometric factor at the peak in the vicinity that the testing was done. TNM-100-2 is the nominal trimmed noble metal run that should be most like traditional SRAT simulations. The difference between the CNM2 and TNM-100-2 peak hydrogen generation rates was just $0.323 \mathrm{lbs} / \mathrm{hr}$, Table 11.

Table 11. Peak Hydrogen Generation Rate Summary

\begin{tabular}{|l|c|c|}
\hline & $\begin{array}{c}\text { Peak } \mathrm{H}_{2} \text { Generation Rate, } \\
\text { DWPF-scale lbs/hr }\end{array}$ & $\begin{array}{c}\text { Difference relative to } \\
\text { TNM-100-2 }\end{array}$ \\
\hline CNM & 2.415 & 1.121 \\
\hline TNM-100 & $\sim 3.75$ & $\sim 2.46$ \\
\hline CNM2 & 0.971 & -0.323 \\
\hline TNM-100-2 & 1.294 & 0 \\
\hline TNM-65 & 1.532 & 0.238 \\
\hline CNM-HT & 1.661 & 0.367 \\
\hline TNM-100-HT & 1.249 & -0.045 \\
\hline
\end{tabular}

The difference between CNM2 and TNM-100-2 is equivalent to a 3\% change in the stoichiometric factor, which is within the generally accepted uncertainty of performing an acid calculation on two different sludges. This rate of change in hydrogen generation rate versus stoichiometric factor must be non-linear, or these simulants would go from no hydrogen to the DWPF SRAT limit with a 6\% increase in the stoichiometric factor. In the region of 2.6-2.9 moles total acid per liter with SB3 concentrations of noble metals, the hydrogen generation rate near the DWPF SRAT limit is very sensitive to small changes, e.g. $2 \%$ changes, in total acid. Future tests should attempt to move lower in peak hydrogen generation, e.g. into the $0.3-0.6 \mathrm{lbs} / \mathrm{hr}$ range if possible, to reduce the sensitivity of the peak generation rate to the uncertainties in the acid calculation. It is anticipated that the rate of change of peak hydrogen generation with stoichiometry will be much less than $0.11 \mathrm{lbs} / \mathrm{hr} / \%$ factor as the range of generation rates is lowered. Future tests not intended for direct comparison to the above seven SRAT simulations should move back toward $1000 \mathrm{mg} / \mathrm{kg}$ TIC and $0.5 \mathrm{M}$ base equivalents, i.e. away from $2200 \mathrm{mg} / \mathrm{kg}$ TIC and 0.7-0.8M base equivalents. This would drop the acid addition by about 0.6 moles/L sludge. It would also reduce the sensitivity of the stoichiometric acid demand to $20 \%$ uncertainty in TIC.

The trimmed and co-precipitated noble metal simulants were made following the same recipes except for the noble metals, the stoichiometric requirement for the co-precipitated noble metal simulant was larger, the total acid added to the co-precipitated noble metal run was larger, and the peak hydrogen generation rate was nevertheless lower. Intuitively, then, it appears that the co-precipitated noble metals were less active for the peak hydrogen generation rate, but this was not conclusively proven by a single comparison as close as the one in section 3.3.

\subsubsection{Heat-Treated Case}

Turning the un-heat-treated case arguments around for the heat-treated case does not lead to the same intuitive conclusion. The co-precipitated noble metal case had a higher stoichiometric demand, the same factor was used, this put more acid to the co-precipitated noble metal run, and this run produced a 33\% higher peak hydrogen generation rate. More acid (at constant stoichiometric factor) and more hydrogen generally go together. Prior to heat-treatment, the simulant with co-precipitated noble metals had a lower 
peak hydrogen generation rate. Heat-treatment did not impact the two simulants identically based on the analytical data.

It should be noted that the acid addition decreased by 0.23 moles/L for TNM-100-HT relative to TNM$100-2$, but only by $0.12 \mathrm{moles} / \mathrm{L}$ for CNM-HT relative to CNM2. This worked out to a net $4.2 \%$ change relative to the average acid addition of 2.6 moles/L sludge, or to a net change equivalent to $176 \pm 7 \%$ in the stoichiometric factor. The available data indicate that increasing the stoichiometric factor in one system up $7 \%$ relative to the other simulant could produce a $0.77 \mathrm{lbs} / \mathrm{hr}$ change in the peak hydrogen generation rate. This range of uncertainty is $186 \%$ of the measured difference in peak rate between the two heattreated simulant tests. Therefore, it is just as likely that the heat-treated noble metals were not unusually active, and the additional hydrogen was caused by a biased high acid addition in CNM-HT. The CNMHT noble metals may have been no more active than in the un-heat-treated, co-precipitated noble metal simulant. The data cannot conclusively support the claim that the heat-treated co-precipitated noble metals were more active than the trimmed noble metals. Repeating these tests is one way to resolve some of this uncertainty.

\subsubsection{Summary of Sensitivity Analysis}

This analysis of sensitivity was necessary to clarify the results. Clearly visible differences in peak hydrogen generation rates were seen on the graphs. These would be accepted as actual differences in other circumstances, e.g. a set of runs all starting with an identical simulant. The sensitivity analysis indicates that these differences are not necessarily significant in this type of study. This is the conclusion that can be drawn for the four simulants with their somewhat different acid calculation inputs. The five main SRAT runs at $171-176 \%$ acid peaked at approximately the same hydrogen generation rate. That is, plausible analytical uncertainties could cause larger differences between runs than the observed differences.

The difference between TNM-100-2 and CNM2 was given several paragraphs earlier as that expected from a 3\% change in the stoichiometric factor. The implication is that using co-precipitated noble metal simulants would lead to a larger acid addition window than trimmed noble metal simulants, assuming nitrite destruction is not impacted (nitrite destruction sets the other end of the acid addition window). A potentially 3\% wider window does not seem particularly significant. The testing here was done at stoichiometries that exceeded the DWPF design basis of $0.65 \mathrm{lbs} / \mathrm{hr}$ hydrogen. The rate of change of the peak hydrogen generation rate with stoichiometry appears to be much larger in the region tested than in the vicinity of $0.65 \mathrm{lbs} / \mathrm{hr}$ of hydrogen generation based on a review of previous data, Koopman (2004a and 2005b). Consequently, the potential impact on the upper end of the acid addition window is projected to get larger as the stoichiometry is reduced toward that producing $0.65 \mathrm{lbs} / \mathrm{hr}$ peak hydrogen. This would seem to indicate that using co-precipitated noble metal simulants to define the acid stoichiometry would be beneficial when the acid addition window appears to be narrow.

In addition to the significant change in the timing of the peak hydrogen generation rate, it appears that coprecipitated noble metals gave a lower peak hydrogen generation rate than trimmed noble metals for the un-heat-treated simulant case. The significant change in the timing of the peak hydrogen generation rate was seen with the heat-treated simulants. The impact of co-precipitated noble metals in heat-treated simulants needs further study to evaluate whether or not the peak generation rate was impacted. 
WSRC-TR-2005-00286

Revision 0

This page intentionally left blank. 


\subsection{CONCLUSIONS}

The primary goal of Phase II, Part 1 of the hydrogen generation program was to perform an initial evaluation of the impact of using co-precipitated noble metals in simulations compared to using trimmed noble metals. Aging effects on co-precipitated noble metals were investigated as a secondary goal of Phase II, Part 1 of the program. There were two follow-up objectives for Phase II based on changes made since the Phase I SRAT testing was completed. The first was an investigation into the inhibition of hydrogen generation associated with the onset of reflux. The second was an assessment of the impacts of lab-scale equipment modifications on SRAT processing in general, and on hydrogen generation in this and future phases.

Phase II, Part I included new experimental SRAT work on simulants with and without co-precipitated noble metals and with and without heat-treatment. Trimmed noble metals were found to be conservative with respect to peak hydrogen generation rate with these simulants. Co-precipitated noble metals would probably give a wider acid addition window than trimmed noble metals. A final choice between trimmed and co-precipitated noble metals requires comparisons to real waste processing results to ensure the SRNL conclusions remain conservative relative to DWPF processing. A preliminary comparison test is planned as part of Phase II, Part 2. Simulant will be tested for comparison to the SB3 Shielded Cells results obtained in Bannochie (2004).

The following list summarizes findings from the experimental portion of this work.

- Co-precipitated noble metal simulant processes similarly to trimmed noble metal simulant in most respects, such as nitrite to nitrate conversion, formate destruction, and $\mathrm{pH}$, but differently with respect to hydrogen generation.

- The peak hydrogen generation rate occurred three to five hours later for the regular and heattreated co-precipitated noble metal slurries than for the slurries with trimmed noble metals.

- Trimmed noble metals appear to be conservative relative to co-precipitated noble metals as long as the peak hydrogen generation rate does not occur late in the SRAT boiling period.

- Use of trimmed noble metals could lead to an expectation that the actual peak hydrogen generation rate will occur in the SRAT cycle when it might actually come in the SME cycle. It is important to have the peak hydrogen generation rate occur during the SRAT cycle, because the air purge dilution is 3.1 times greater than that in the SME cycle.

- The peak generation rate was slightly higher during processing of the heat-treated co-precipitated noble metal simulant relative to the trimmed noble metal heat-treated simulant, but this may have been caused by somewhat more excess acid being added to the co-precipitated noble metal test.

- The hydrogen generation results for the heat-treated, co-precipitated noble metal simulant suggest that the heat-treatment methodology may be producing unexpected, and potentially unrealistic, effects on the catalytic activity of the noble metals. The approach of using a $97^{\circ} \mathrm{C}$ heat-treatment step to qualitatively simulate tank farm aging may not be optimal.

- The peak hydrogen generation rate increased from about 1.3 to about $3.3 \mathrm{lbs}_{2} / \mathrm{hr}$ on the range of $170-190 \%$ stoichiometry, or about $0.1 \mathrm{lbs} . \mathrm{H}_{2} / \mathrm{hr}$ per \% change in the stoichiometric factor at DWPF scale.

- The sensitivity of the hydrogen generation rates to the acid addition uncertainty was greater than expected. This was magnified by the high TIC and base equivalents values of all of the simulants. 
- The variations in the peak hydrogen generation rate were found to generally track the quantity of dissolved rhodium in the SRAT product.

- A low activity noble metal, potentially palladium, activated and then de-activated during the final hour of formic acid addition. The peak generation rate was $<3 \%$ of the maximum rate seen in each test.

- These new simulants were more prone to foaming during acid addition at the nominal DWPF antifoam addition strategy than traditional CETL-based SB3 simulant.

- Heat-treatment of simulant significantly altered the base equivalents at $\mathrm{pH}$ 7. This complicated the control of excess acid in the heat-treated tests relative to the regular tests

- The two heat-treated simulants were able to produce hydrogen at or above the rates in the unheat-treated simulants from less acid. Therefore, it was concluded that the heat-treatment did produce real changes in the acid requirement. The approach to heat-treatment as an approximation to tank farm aging processes may need further study.

- Carbon dioxide generation data was far less sensitive than hydrogen generation data to changes in the simulants.

- The hydrogen generation results for the trimmed noble metal runs, TNM-100-2 and TNM-65, show that the role of noble metal concentration on hydrogen generation is only partially understood. TNM-65 had a higher peak hydrogen generation rate, even though it had $1 \%$ less total acid and 35\% lower noble metal concentrations. This conclusion is not sensitive to the acid calculation input uncertainty issues discussed in the report, because an identical starting sludge simulant was used in both of these runs.

The results obtained from this study should be valuable in future phases of the hydrogen generation rate program as well as to other programs performing simulations of the DWPF Chemical Processing Cell. 


\subsection{RECOMMENDATIONS/PATH FORWARD}

\subsection{Recommendations}

Additional studies are recommended on the impact of the form of noble metals on hydrogen generation. These include attempting to duplicate the results of the final SB3 Shielded Cells qualification SRAT cycle to ensure co-precipitated noble metals are conservative, evaluating the impact of co-precipitated noble metals on the acid addition window for either SB3 or SB4 baseline composition, performing a follow-up study to investigate the relationship between concentrations of dissolved noble metals in the SRAT supernate during processing and hydrogen generation, further investigating how heat-treatment may have produced more hydrogen and more dissolved rhodium than the other tests, and heat-treating some of the noble metal-free simulant with trimmed noble metals present for use in a follow-up comparison SRAT simulation.

Such tests would clarify the significance of dissolved noble metals, answer some of the outstanding questions about the impact of heat-treatment on hydrogen generation, increase the understanding about the impact of the concentration of noble metals on hydrogen generation, and begin to define conditions where co-precipitated or trimmed noble metals would be preferred in support of real waste processing. The hydrogen generation program should then move forward to study some of the other potential factors influencing hydrogen generation, such as the interactions between the individual noble metals, whether trimmed or co-precipitated, at different concentrations.

\subsection{Path Forward}

There are still many potential issues impacting hydrogen generation that should be studied. One of the most logical ones to undertake after the above work is a study designed to evaluate the impact of noble metal concentrations on hydrogen generation. Another example of what needs to be better understood was found during the form of noble metal testing. Run TNM-65 had a higher peak hydrogen generation rate than TNM-100-2, even though it had 1\% less total acid and 35\% lower noble metal concentrations. A better understanding is needed of the conditions where reducing acid and/or noble metal concentrations could lead to potentially higher peak hydrogen generation rates. A better understanding is needed of the reactions or processes that lead to deactivation of the noble metal(s) that are catalytically active at the peak in hydrogen generation.

Future work should move toward the region of lower peak hydrogen generation rates, and toward more prototypical inputs to the stoichiometric acid calculation. Hydrogen generation rates that were several times the DWPF limit were found to be overly sensitive to small changes in the acid stoichiometric factor, or equivalently to small changes, or uncertainties, in the inputs to the stoichiometric acid calculation. Reducing the stoichiometric factor, however, might create other problems, such as altering the timing of peak generation rates as seen in some of the historical SB3 data, Koopman (2005b). Base equivalents and TIC should be brought down closer to typical fresh sludge batch values found in the Shielded Cells qualification work in future work. This is especially true for TIC, which was responsible for a lot of uncertainty in the stoichiometric acid requirement at $2200 \mathrm{mg} / \mathrm{kg}$. Lowering the stoichiometric acid requirement reduces the quantity that the stoichiometric acid factor multiplies in computing the total acid to be used. A 5\% uncertainty applied to a 1 mole acid/L sludge requirement makes the quantity of excess acid for hydrogen generation half as uncertain as the same uncertainty applied to a 2 mole acid/L sludge requirement. These two changes together should improve the comparability of peak hydrogen generation rates in future tests with different starting sludges. 
WSRC-TR-2005-00286

Revision 0

This page intentionally left blank. 


\subsection{REFERENCES}

Baich, M. A., D. R. Best, T. K. Snyder, and M. F. Williams, Sludge Batch 2-3 Blend Flowsheet Simulations: Determination of the Acid Addition Window (U). WSRC-TR-2004-00042, Savannah River Site, Aiken, SC 29808 (2004a).

Baich, M. A., Modified Lab Scale SRAT Findings and Recommendations. SRNL-GPD-2004-00098, Savannah River Site, Aiken, SC 29808 (2004b).

Bannochie, C. J., J. M. Pareizs, and D. C. Koopman, Sludge Batch 2/3 Blend SRAT Cycle in the SRNL Shielded Cells. WSRC-TR-2004-00097, Savannah River Site, Aiken, SC 29808 (2004).

Eibling, R. E., Impact of Simulant Production Methods on the Physical Properties of DWPF Sludge Batch 3 Simulant. WSRC-TR-2004-00578, Savannah River Site, Aiken, SC 29808 (2005).

Fellinger, T. L., and D. C. Koopman, Hydrogen Generation for Sludge Receipt and Adjustment Tank (SRAT) and Slurry Mix Evaporator (SME), WSRC-RP-2004-0028 (TT\&QAP), Savannah River Site, Aiken, SC 29808 (2004).

Hsu, C. W. and J. A. Ritter, Study on Hydrogen Evolution During Treatment of SRS High Level Radioactive Waste Simulant with Formic Acid. WSRC-MS-92-270, Savannah River Site, Aiken, SC 29808 (1992).

Koopman, D. C., Review of Catalytic Hydrogen Generation in the Defense Waste Processing Facility (DWPF) Chemical Processing Cell (U). WSRC-TR-2002-00334, Savannah River Site, Aiken, SC 29808 (2004a).

Koopman, D. C., Analytical Study Plan for Hydrogen Generation for Sludge Receipt and Adjustment Tank (SRAT) and Slurry Mix Evaporator (SME) (U). SRNL-GPD-2004-00060, Savannah River Site, Aiken, SC 29808 (2004b).

Koopman, D. C., and M. A. Baich, Effect of Mercury-Noble Metal Interactions on SRAT Processing of SB3 Simulant (U). WSRC-TR-2004-00548, Savannah River Site, Aiken, SC 29808 (2005a).

Koopman, D. C., D. P. Lambert, and M. A Baich, Review of Catalytic Hydrogen Generation in the DWPF Chemical Processing Cell, Part II (U). WSRC-TR-2004-00206, Savannah River Site, Aiken, SC 29808 (2005b).

Koopman, D. C. and R. E. Eibling, Preparation and Heat-treatment of DWPF Simulants with and without Co-Precipitated Noble Metals (U). WSRC-TR-2004-00285, Savannah River Site, Aiken, SC 29808 (2005c).

References for SRAT Simulation Run Plans (seven total):

Koopman, D. C., SB3 Hydrogen Generation Study (Run 1). SRNL-GPD-2004-00079, Savannah River Site, Aiken, SC 29808 (12/19/2004) for “TNM-100”.

Koopman, D. C., SB3 Hydrogen Generation Study (Run 2). SRNL-GPD-2004-00080, Savannah River Site, Aiken, SC 29808 (12/19/2004) for “CNM". 
Koopman, D. C., DWPF Hydrogen Generation Study, Phase II (Run H2KB-2). SRNL-ITS-2005-00037, Savannah River Site, Aiken, SC 29808 (2/24/2005) for “CNM2”.

Koopman, D. C., DWPF Hydrogen Generation Study, Phase II (Run H2HTKB). SRNL-ITS-2005-00050, Savannah River Site, Aiken, SC 29808 (2/24/2005) for “CNM-HT”.

Koopman, D. C., DWPF Hydrogen Generation Study, Phase II (Run H2-100TNM). SRNL-ITS-200500064, Savannah River Site, Aiken, SC 29808 (3/11/2005) for “TNM-100-2”.

Koopman, D. C., DWPF Hydrogen Generation Study, Phase II (Run H2-65TNM). SRNL-ITS-200500065, Savannah River Site, Aiken, SC 29808 (3/11/2005) for “TNM-65”.

Koopman, D. C., DWPF Hydrogen Generation Study, Phase II (Run H2-HT-RE). SRNL-ITS-200500103, Savannah River Site, Aiken, SC 29808 (4/8/2005) for “TNM-100-HT”. 


\subsection{ACKNOWLEDGEMENTS}

The author is indebted to Terri Fellinger for her help in coordinating the hydrogen generation study activities, monitoring resources and spend out, and providing feedback as needed. The author acknowledges the contributions of David Best, Jennifer Jantzen, and Pat Toole for their work on sample analysis. Additional analytical support came from the Analytical Development Section under the direction of John Young (TIC), and Mike Whitaker, William Boyce, and Curtis Johnson (ICP-MS). Mark Baich oversaw the experimental preparation of the co-precipitated noble metal simulant. Mark Baich and Frances Williams are also recognized for getting the gas chromatographs baked out and calibrated before the runs, and also downloading the GC data files to computers tied into the site network. They also undertook some GC data reprocessing activities to correct for small issues in the raw analysis methods. Ned Bibler reviewed the plans and data obtained during preparation of the co-precipitated noble metal simulant, especially the ICP-MS results. Thanks are also due to Joe Wheeler and Frances Williams, along with Tony Burckhalter, Jon DuVall, Sammie King, Debbie Marsh, Irene Reamer, Vickie Williams, and Phyllis Workman for their support during the experimental phase. 
WSRC-TR-2005-00286

Revision 0

This page intentionally left blank. 
WSRC-TR-2005-00286

Revision 0

APPENDIX A. DATA FROM PRELIMINARY SRAT RUNS 
Two preliminary form of noble metal SRAT runs were completed in late 2004. Run CNM was based on co-precipitated noble metal simulant. Run TNM-100 was based on the corresponding simulant without noble metals. The two runs were both targeted at about $185 \%$ of stoichiometry based on the initial slurry analyses. The 185\% factor was taken from the SB3 acid window study, Baich (2004a). This stoichiometry had given significant hydrogen generation. It was desired to have significant hydrogen generation to distinguish between the effects of co-precipitated and trimmed noble metals. Noble metals in TNM-100 were trimmed at $100 \%$ of the adjusted targets for the co-precipitated noble metal simulant recipe. Adjustments to the target concentrations were made to reflect the actual progress of the coprecipitated noble metal simulant preparation, e.g. mass changes during washing, decanting, etc.

Complications occurred during and following the two preliminary SRAT simulations. TNM-100 had to be put on hold during nitric acid addition for several hours after the SRAT lid cracked at one of the large ports. This had the potential to allow the slurry inside to heat-treat while repairs were made. Koopman (2005c) described how heat-treatment lowered the base-equivalent molarity of the two simulants. The expected consequence of heat-treatment to TNM-100 was that the effective stoichiometric factor for the acid calculation would drift upwards as the slurry heat-treated. This potentially put TNM-100 at a net higher stoichiometry than CNM.

A second complication occurred later in the runs that impacted both SRAT simulations. A natural gas relief valve opened outside ACTL where the work was being done. The two tests were shut down, and the laboratory was evacuated for several hours. This disrupts hydrogen generation, since both tests were at boiling and producing hydrogen at the time the odor of natural gas was noticed.

A third complication arose in early 2005. ADS, working with ITS, developed a more reliable TIC measurement. The new method debuted in early 2005 and was called "ITS Acid Demand TIC". The sample protocol calls for submitting two samples of simulant slurry along with one sample diluted with de-ionized water such that TIC is probably in the range of 50-75 mg/L. The two primary slurries were reanalyzed following the debut of the new method. TIC in the co-precipitated noble metal simulant increased from $2106 \mathrm{mg} / \mathrm{kg}$ to $2436 \mathrm{mg} / \mathrm{kg}$. TIC in the other simulant increased from $2062 \mathrm{mg} / \mathrm{kg}$ to 2206 $\mathrm{mg} / \mathrm{kg}$. Analysis of heat-treated co-precipitated noble metal simulant produced a value of $2516 \mathrm{mg} / \mathrm{kg}$. Analysis of the other heat-treated simulant produced a value of $1942 \mathrm{mg} / \mathrm{kg}$. The 2004 data indicated that the co-precipitated simulant had 2\% more TIC than the other simulant. Averaging all of the data indicates that the co-precipitated noble metal simulant probably had about $2423 \mathrm{mg} / \mathrm{kg}$ TIC, or $17 \%$ more TIC, than the other simulant which had about $2072 \mathrm{mg} / \mathrm{kg}$.

Recomputing the stoichiometric factor with the average TIC values led to a change from $185 \%$ to $194.25 \%$ for the factor in TNM-100. Recomputing the stoichiometric factor for run CNM led to a change from $185 \%$ to $183.1 \%$. The revised input data indicate that the two runs were not at about the same stoichiometric factor, but were instead $11.1 \%$ different in their factors. A compounding issue was that this occurred in a region where peak hydrogen generation rate is very sensitive to the amount of excess acid added. Added to this was the potential impact of the broken lid on the base equivalents of TNM-100, via unintended heat-treatment, which would tend to increase the effective factor above $194.25 \%$.

Because of these complications, it was decided to not attempt a direct comparison of CNM and TNM-100 for the purposes of evaluating co-precipitated versus trimmed noble metals. A second pair of runs, CNM2 and TNM-100-2, was performed. These two runs were summarized in section 3.3. These runs had the benefit of the improved TIC measurements before preparing their acid calculations. The factor for the stoichiometric acid addition was also reduced based on the amount of hydrogen made in CNM and TNM-100. The two preliminary runs, CNM and TNM-100, do provide additional hydrogen generation 
data. This was especially true for CNM, which did not have the broken lid, and which had peaked in hydrogen generation before the natural gas event caused the run to be put on stand-by.

Many of the analytical results for the starting sludges and SRAT products have been included in tables earlier in this report and will not be repeated here. Figure 16 showed the impact of increasing the stoichiometric factor from $171 \%$ to $183 \%$ for the simulant with co-precipitated noble metals on the pounds per hour, pph, of hydrogen generation at DWPF scale. The natural gas outage time at +576 minutes was removed from the "processing time" in Figure 16. The higher acid addition in CNM caused the first peak to occur about an hour sooner. This was still much later than the peak times observed in the tests with comparable concentrations of trimmed noble metals. The initial noble metal activation period from zero to two hours after acid addition was nearly identical in terms of hydrogen generation. The average increase in peak hydrogen generation was $0.12 \mathrm{lbs} / \mathrm{hr}$ per $1 \%$ increment in the stoichiometric factor.

Hydrogen generation was detected fairly early in both of the tests with co-precipitated noble metals, Figure 17. This is not the typical hydrogen generation behavior.

Figure 17. Onset of Hydrogen Generation in Co-ppt Testing

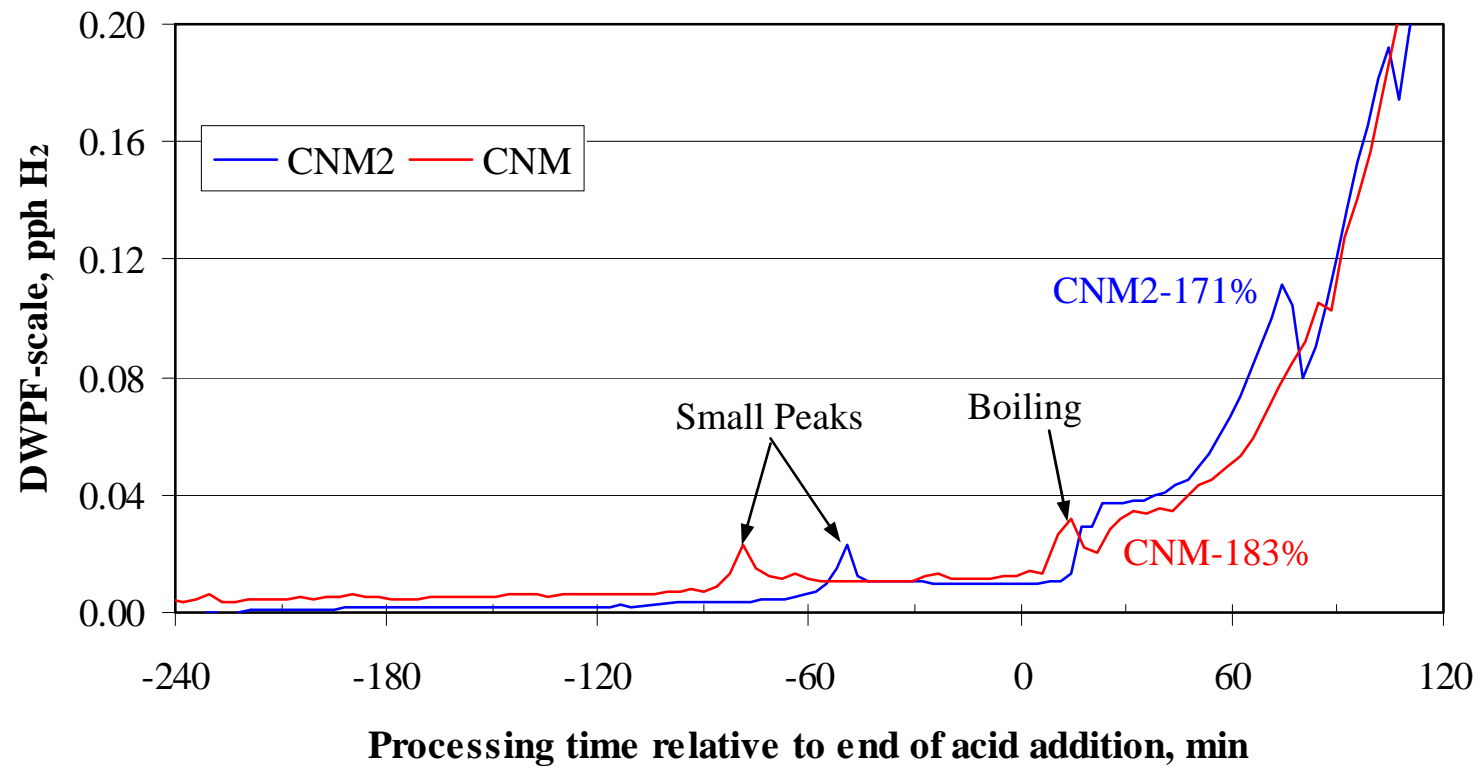

The two small peaks before the end of acid addition at -60 minutes nearly lined up in the sense that they almost occurred after the same amount of total acid had been added. It seems certain that this peak was caused by the same phenomenon in both runs, and that it occurred after essentially the same quantity of total acid had been added. The two peak magnitudes were nearly identical. If this small peak was due to palladium, as the literature suggests that it might be, then palladium apparently is much less active than rhodium and/or ruthenium. (The hydrogen generation review report, Koopman (2004b), discussed the relative induction periods and activity data found in the literature.)

A generally similar comparison was made between TNM-100 and TNM-100-2 to assess the impact of stoichiometry on hydrogen generation. The stoichiometry for TNM-100 has not been as well defined, however, as that of CNM. This was due to the potential heat-treatment impact on base equivalent 
molarity while the lid was being replaced. Post-run calculations put the stoichiometric factor for TNM-

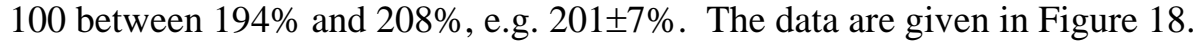

Figure 18. Impact of Stoichiometry on Hydrogen Generation (trimmed noble metals)

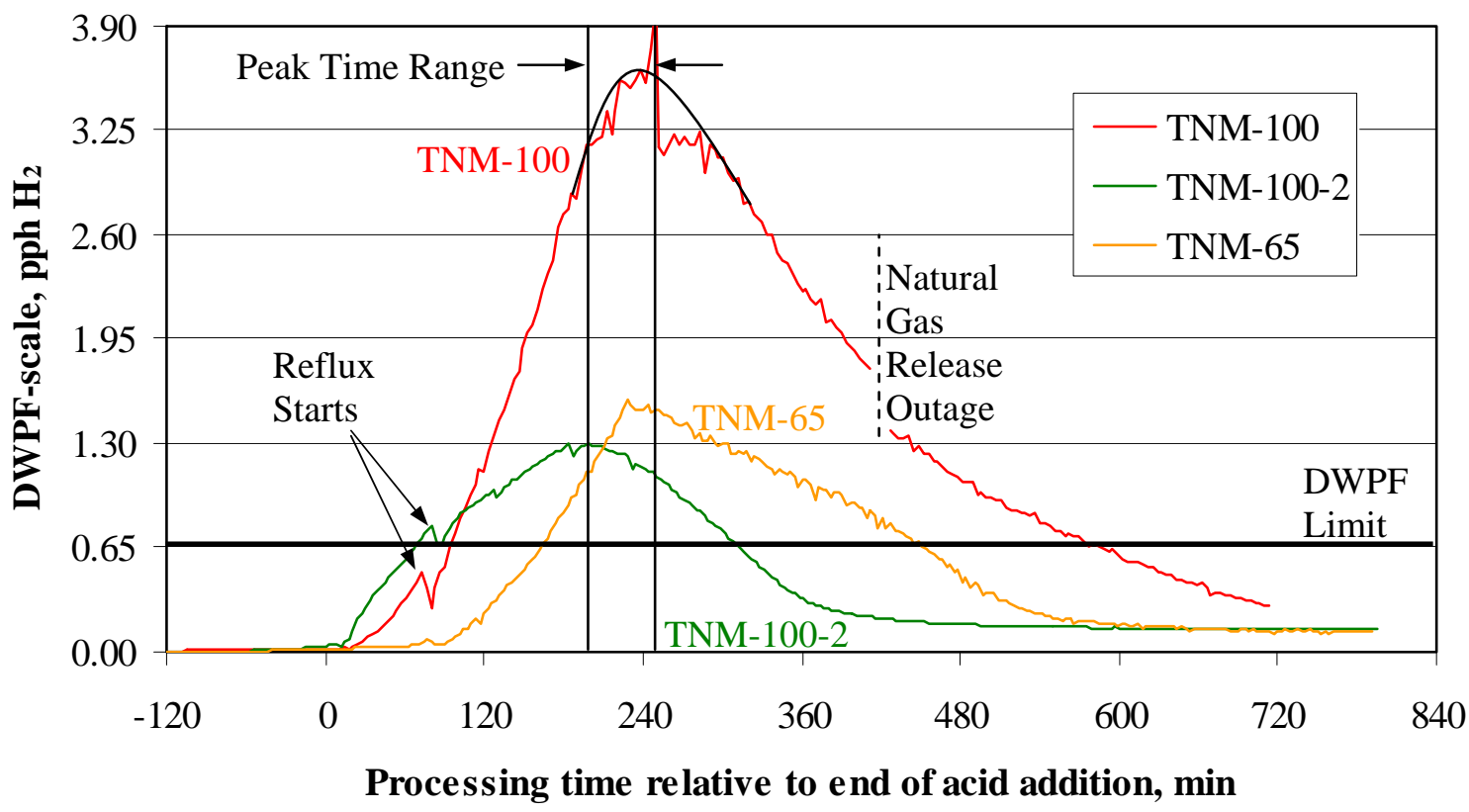

Clearly, there was an enormous amount of hydrogen generation in TNM-100 compared to the DWPF design basis SRAT limit of $0.65 \mathrm{lbs} / \mathrm{hr}$ (highlighted by the choice of axis scaling). Data for TNM-100 were adjusted to take out the time when the test was on hold during the natural gas release. This occurred at +412 minutes. The flow rate calculation for TNM-100 was complicated by another factor. The volume \% hydrogen peak became so large that there were integration problems and separation problems with the adjacent helium peak on the GC. The TA's were also under instructions to increase the air purge when the hydrogen concentration got to 2\%. At 256 minutes, the helium flow was turned off, so that there would only be a single hydrogen peak to analyze in that retention time range. Nitrogen was used to compute the hydrogen flow while the helium was off, i.e. until 480 minutes. A hypothetical smoothed hydrogen generation rate curve has been superimposed over the data around 240 minutes that might indicate what the peak would have looked like if there had been fewer process changes going on.

The TNM-100 peak hydrogen generation rate apparently occurred slightly later than both the TNM-100-2 peak rate and the TNM-65 peak rate. This may have occurred simply because it took considerably longer for the hydrogen generation rate to rise to its maximum value. The three peak rates occurred in a fairly narrow range of times that were 3-5 hours earlier relative to the peak rate times of the co-precipitated noble metal tests, Figure 16. TNM-100 produced about $3.7 \mathrm{lbs} / \mathrm{hr}$ hydrogen at its peak (smoothed curve) compared to $1.3 \mathrm{lbs} / \mathrm{hr}$ in TNM-100-2. This was an average increase of $0.083 \pm 0.026 \mathrm{lbs} / \mathrm{hr}$ per $1 \%$ increase in the stoichiometric factor (roughly $0.1 \mathrm{lbs} / \mathrm{hr} / \%$ change in factor). The uncertainty covers the uncertainty in the stoichiometric factor of TNM-100. This is probably slightly less than was seen for the co-precipitated noble metal data, unless heat-treatment actually had no different impact on TNM-100 than it had on any of the other four runs with un-heat-treated simulants.

Heat-treatment effects may occur simultaneously with acid addition during SRAT processing, but the two effects have not been separated yet. If they did occur simultaneously, then the change in peak hydrogen 
generation rate averaged about $0.11 \mathrm{lbs} / \mathrm{hr}$ per percent factor for both the co-precipitated noble metal simulant and the trimmed simulant. This factor was useful in evaluating the impact of uncertainties in the inputs to the acid calculations on the peak hydrogen generation, see section 3.7.

Small peaks were seen near the end of formic acid addition in the tests with the trimmed noble metals similar to those seen in the tests with the co-precipitated noble metals.

Figure 19. Early Hydrogen Generation in Trimmed Noble Metal Testing

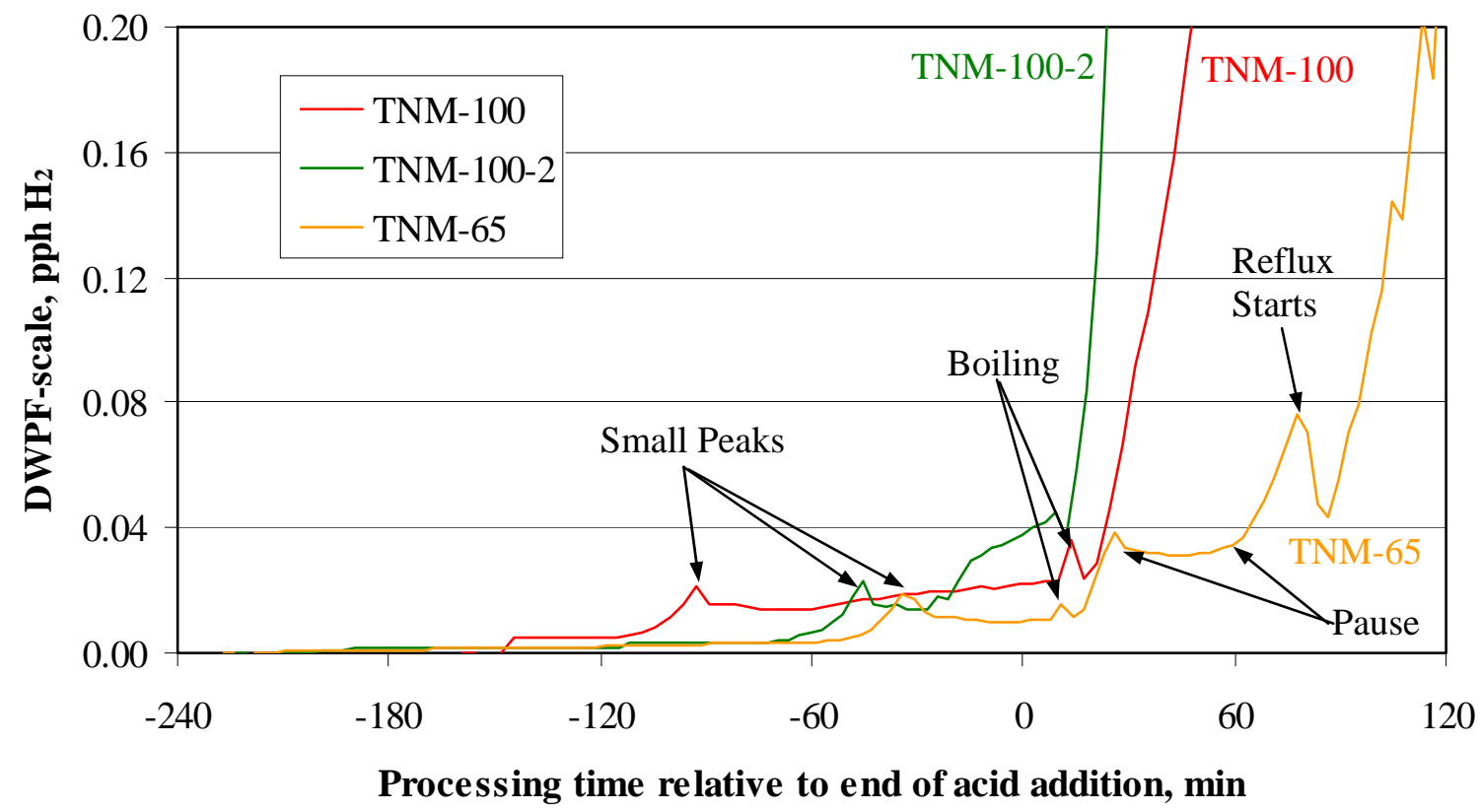

Spacing between the TNM-100 and TNM-100-2 small peaks during acid addition was 48 minutes, which was consistent with the moles of acid added up to that point being the same. This confirms that these peaks are being driven by the same process and occur after approximately the same quantity of acid has been added to the sludge. The peak heights for TNM-100 and TNM-100-2 were the same, as was the case for CNM and CNM2. The peak in TNM-65 was only about $80 \%$ as high as the other two peaks and somewhat later. This suggested that a noble metal was responsible, since the sludge was identical to TNM-100 and TNM-100-2 except for the 35\% lower noble metal concentrations.

The onset of reflux produced dips in the hydrogen generation rate. The largest percent drop was in TNM65 , which was producing the least amount of hydrogen at the time. None of the drops were as severe as those seen in the Phase I, Part 2 hydrogen generation program testing with the larger MWWT. The onset of boiling seemed to trigger increased hydrogen generation in the three trimmed noble metal cases, but the TNM-65 run seemed to pause for about 45 minutes in its rise just short of reaching $0.04 \mathrm{lbs} / \mathrm{hr}$. TNM65 managed to catch up about half of that lag by the time it peaked relative to TNM-100-2.

Some of the other preliminary run data were examined to see if they would help to better constrain the acid stoichiometry of TNM-100. This related to the uncertainty introduced by the effect of heat-treatment on base equivalents that gave rise to a range of $201 \pm 7 \%$ for the TNM-100 stoichiometric factor. One such comparison, the carbon dioxide data for CNM and TNM-100, is given in Figure 20. Another for $\mathrm{pH}$ is given in Figure 21. 
WSRC-TR-2005-00286

Revision 0

Figure 20. Preliminary Run Carbon Dioxide Data

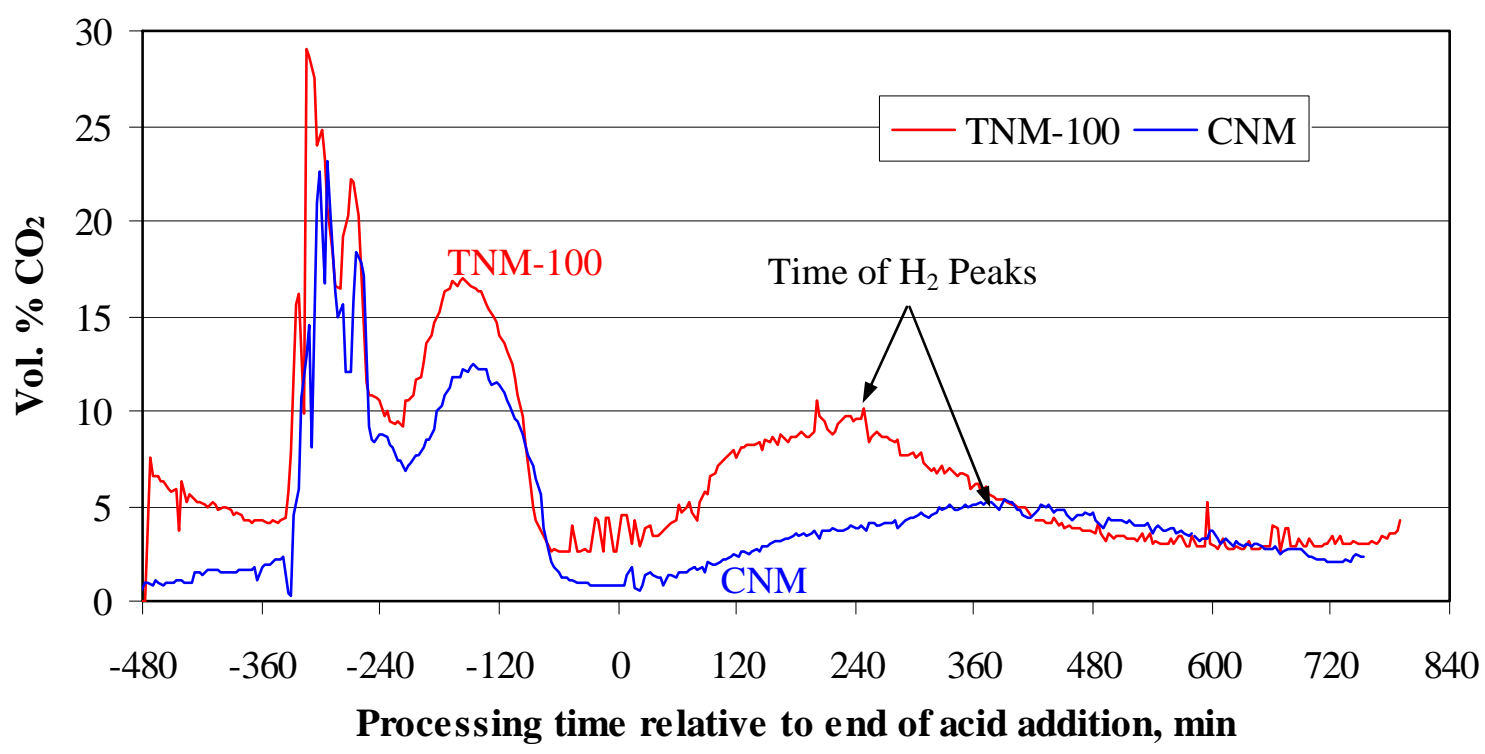

It is difficult to explain the larger $\mathrm{CO}_{2}$ peaks in TNM-100 during acid addition. There was less TIC and the same amount of nitrite to destroy as CNM. There is a possibility that they are due to integration routine issues with the $\mathrm{GC}$ used during this test. The $\mathrm{CO}_{2}$ peaks during acid addition occur at fairly similar times for the two runs. The TNM-100 peaks precede the CNM peaks in general, but not by as much as might be expected if CNM was at $183 \%$ and TNM-100 was at $208 \%$ stoichiometry. It seems more likely that TNM-100 actually processed closer to $194 \%$ than to $208 \%$ based on this data.

The $\mathrm{CO}_{2}$ peaks during boiling aligned with the corresponding primary hydrogen peaks. $\mathrm{CO}_{2}$ production was roughly double hydrogen production at the peak during boiling. This ratio is closer than it typically is in runs with lower hydrogen generation rates. Ratios of 5-10 have been obtained in many runs with traditional simulants that peaked with 0.2-0.8 lbs/hr hydrogen, Koopman (2005b). The implication may be that the source of the extra $\mathrm{CO}_{2}$ beyond that associated with hydrogen generation was less impacted by the increased acid, and consequently fell in relative importance. 
Figure 21. Preliminary SRAT Run pH Data

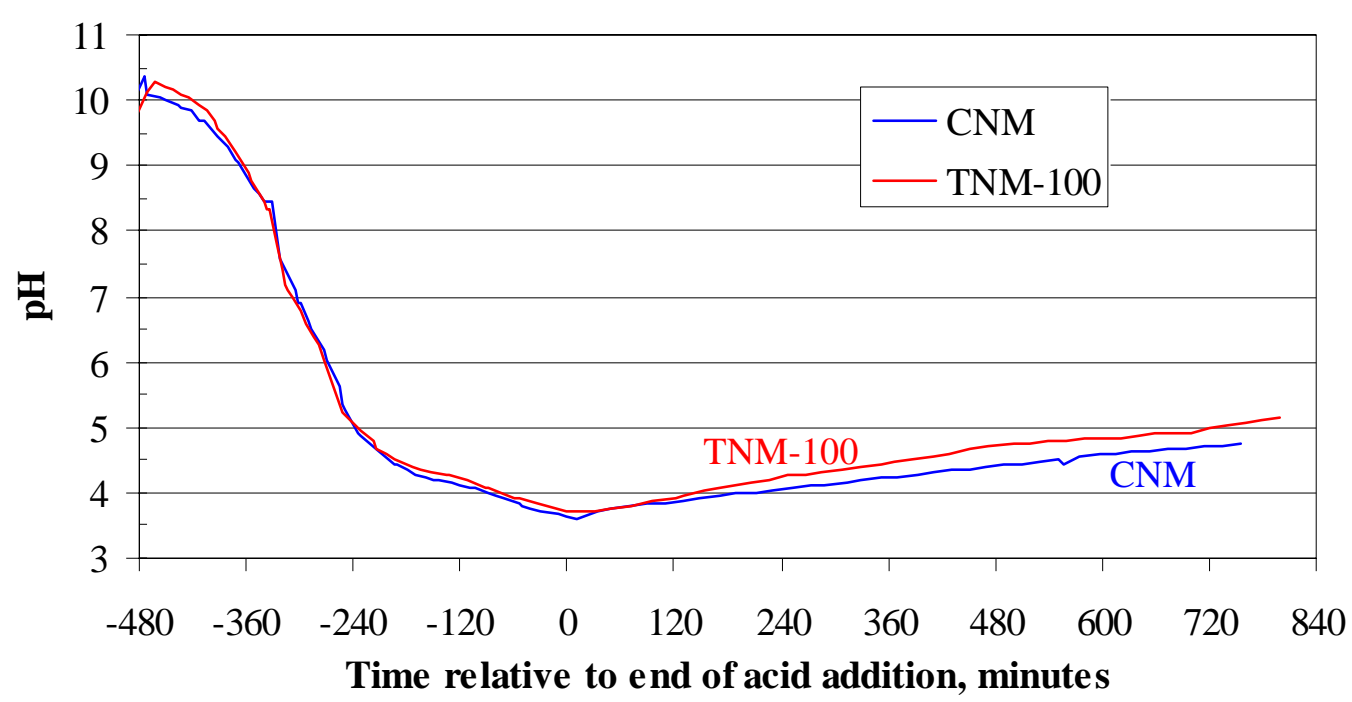

The two $\mathrm{pH}$ traces are remarkably similar during acid addition given the potential differences in stoichiometry between the two runs. This may be an indication that the loss of base equivalents seen during heat-treatment at least partially occurs during acid addition in parallel with acid-base neutralizations and carbonate to bicarbonate conversions. This would support the case that the stoichiometric factor for TNM-100 was closer to $194 \%$ than to $208 \%$. The somewhat more rapid pH rise during boiling for TNM-100 is consistent with greater formic acid destruction, e.g. that destruction that occurs during hydrogen generation. TNM-100 had the largest total mass loss of any of the seven SRAT runs, consistent with more formate loss and a greater loss of acid during processing.

There was an issue of perspective in this discussion of the appropriate value of the stoichiometric acid factor for each run. It may be that the proper end state for the two in-house simulants is the one that they move toward during heat-treatment. In that case, it would be fair to claim that the stoichiometric factors for CNM, CNM2, TNM-100-2, and TNM-65 were all understated, since inflated values were used for the base equivalents. The discussion assumed that the base equivalents measured for the two un-heat-treated slurries were the proper bases for computing the stoichiometric factors. Further information is needed to choose between the two possibilities. The best source would be radioactive sludge titration data taken before and after a heat-treatment. Perhaps there would be a change, or perhaps there would be no change. Given the unusual rhodium dissolution that occurred in the heat-treated, co-precipitated noble metal SRAT product there is an issue with the current heat-treatment methodology itself that is still to be resolved. Perhaps this was not a suitable method to qualitatively approximate aging effects during storage. 
WSRC-TR-2005-00286

Revision 0

This page intentionally left blank. 
WSRC-TR-2005-00286

Revision 0

APPENDIX B. MATERIAL BALANCE RESULTS 
Overall and anion material balances were constructed for all seven of the form of noble metals testing SRAT simulations. The results of these are given in this appendix. Mass inputs included sludge, rinse water, noble metals, nitric and formic acids, and antifoam solution. Mass outputs included SRAT product, four removals from the MWWT, and the condensate in the FAVC. Mass loss to the off-gas purge can not be measured with the current equipment.

The gross material balance closure on the slurry and condensate streams is given in Table 12. This compares the mass predicted for the SRAT product in the absence of gas generation to the measured mass of the SRAT product. All numbers are in grams.

Table 12. Phase II Overall Mass Balance Agreement

\begin{tabular}{|l|r|r|r|r|r|r|c||}
\hline & CNM & CNM2 & CNM-HT & TNM-100 & TNM-100- & TNM-65 & $\begin{array}{c}\text { TNM-100- } \\
\text { HT }\end{array}$ \\
\hline Predicted & 2505 & 2336 & 2311 & 2520 & 2302 & 2315 & 2262 \\
\hline Measured & 2376 & 2210 & 2192 & 2319 & 2185 & 2191 & 2110 \\
\hline Delta & 129 & 126 & 119 & 201 & 117 & 124 & 152 \\
\hline
\end{tabular}

Approximately 5-10 grams of the individual deltas are due to lost slurry mass on the $\mathrm{pH}$ probe, left in the SRAT vessel, stuck on the agitator blades, etc. The measured mass difference ran about $130 \mathrm{~g}$, which is fairly typical of runs at this scale. The similarity gives a first order confirmation that the runs were generally similar, and that computations on formate loss and nitrite to nitrate conversion will not be unduly biased by errors in the SRAT product mass. TNM-100 clearly had the largest mass loss, but this run made much more off-gas during reflux than the other six runs. This may be sufficient to account for the higher delta in Table 12 for this run. TNM-100-HT had a distinctly higher formate loss and smaller nitrite to nitrate conversion than the other six tests, which is consistent with it having the second largest mass loss.

Condensate and SRAT product anions were analyzed fairly thoroughly, Appendix C and D. Formate ion balances were prepared for all seven simulations. These are given in Table 13. Two measures of formate loss were prepared. The first tracked formate proceeding into the SME cycle in the SRAT product only. This excluded formate lost to the MWWT and FAVC. This was the calculation needed to help predict the redox of the eventual SME product. The second balance tracked all measured formate. This balance gave a truer indication of the formate destruction chemistry occurring in the SRAT vessel. The \% loss calculations were based on formate that would have been present in the SRAT product if none were destroyed, i.e. it took the formate added less that removed in samples as its basis.

Table 13. Phase II SRAT Formate Balances

\begin{tabular}{||l|c|c|c|c|c|c|c||}
\hline & CNM & CNM2 & $\begin{array}{c}\text { CNM- } \\
\text { HT }\end{array}$ & $\begin{array}{c}\text { TNM- } \\
100\end{array}$ & $\begin{array}{c}\text { TNM- } \\
100-2\end{array}$ & $\begin{array}{c}\text { TNM- } \\
65\end{array}$ & $\begin{array}{c}\text { TNM- } \\
100-H T\end{array}$ \\
\hline Formate added, g & 254.34 & 227.20 & 218.65 & 255.68 & 221.10 & 218.58 & 210.45 \\
\hline MWWT +FAVC, g & $4.06+$ & 3.88 & 3.59 & $5.21+$ & 4.59 & 4.22 & 3.76 \\
\hline SRAT product, g & 198.1 & 173.7 & 168.3 & 186.2 & 164.1 & 167.2 & 140.9 \\
\hline $\begin{array}{l}\text { \% added formate not in } \\
\text { SRAT product }\end{array}$ & 22.1 & 23.6 & 23.0 & 27.2 & 25.8 & 23.5 & 33.1 \\
\hline Formate destroyed, g & 52.2 & 49.6 & 46.8 & 64.3 & 52.4 & 47.2 & 65.8 \\
\hline$\%$ added formate destroyed & 20.9 & 21.8 & 21.4 & 25.7 & 23.7 & 21.6 & 31.3 \\
\hline
\end{tabular}

“+” result has MWWT samples, but does not have the FAVC component, which would increase it 
Results for the \% formate destroyed were fairly consistent except for TNM-100-HT. The largest loss, otherwise, was for TNM-100. TNM-100 made the most hydrogen and carbon dioxide during boiling. (The formate content of the FAVC was typically less than $0.1 \mathrm{~g}$. CNM and TNM-100 FAVC anions were not analyzed and factored into the actual loss calculation. Those two results were slightly overstated relative to the five main tests, assuming that they would have had similar formate contents in the FAVC.)

A $\pm 10 \%$ analytical uncertainty equated to about $\pm 20 \mathrm{~g}$ of formate in the SRAT product. The difference in the extremes for $\mathrm{g}$ formate lost was only $19 \mathrm{~g}$. Similar limits are put on the carbon dioxide loss check of formate loss. The raw material data did not permit a claim that a significant change in formate loss was seen between the seven runs. The TNM-100-HT sample was analyzed multiple times, however, which should have reduced the uncertainty in the mean SRAT product formate concentration sufficiently to set it apart from the other six tests.

Similar balances were made on nitrate to determine nitrate formation and the fraction of destroyed nitrite converted to nitrate, Table 14. Nitrite destruction was indicated to be essentially complete in all seven tests ( $>99 \%)$. Two balances on nitrate were prepared here as was done with formate. The first looked at nitrate going to the SME, and was the relevant calculation for predicting the SME product redox in the acid calculation. The second looked at all nitrate, and this actual species mass balance gave the truer accounting of SRAT chemistry.

Table 14. Phase II SRAT Nitrate Balance Calculations

\begin{tabular}{|l|c|c|c|c|c|c|c||}
\hline & CNM & CNM2 & $\begin{array}{c}\text { CNM- } \\
\text { HT }\end{array}$ & $\begin{array}{c}\text { TNM- } \\
100\end{array}$ & $\begin{array}{c}\text { TNM- } \\
100-2\end{array}$ & $\begin{array}{c}\text { TNM- } \\
65\end{array}$ & $\begin{array}{c}\text { TNM- } \\
100-H T\end{array}$ \\
\hline Nitrate in feed, g & 27.13 & 25.51 & 25.29 & 24.90 & 25.66 & 25.66 & 24.98 \\
\hline Nitrate added, g & 77.70 & 64.04 & 59.64 & 80.44 & 61.62 & 60.70 & 55.25 \\
\hline MWWT +FAVC, g & $3.84+$ & 7.01 & 5.89 & $3.61+$ & 11.32 & 4.76 & 7.00 \\
\hline SRAT product nitrate, g & 112.4 & 91.4 & 91.3 & 111.6 & 89.0 & 91.0 & 76.3 \\
\hline SRAT product nitrate gain, g & 7.57 & 1.85 & 6.37 & 6.26 & 1.72 & 4.64 & -3.9 \\
\hline \% nitrite to nitrate-acid calc & 16 & 4 & 13 & 13 & 4 & 10 & -8 \\
\hline \% nitrite to nitrate-actual & 24 & 20 & 25 & 21 & 28 & 20 & 6 \\
\hline
\end{tabular}

"+” result has MWWT samples, but does not have the FAVC component, which would increase it

The calculation of the change in the SRAT product nitrate directly impacted the redox prediction. The seemingly large variations in nitrite to nitrate conversion (molar basis) were primarily due to analytical errors and the small difference of large numbers effect. Uncertainties on the \% conversions were probably of order $\pm 10 \%$ or more, e.g. $16 \%$ is $16 \pm 10 \%$. The actual nitrite to nitrate conversion calculation took into account nitrate formed and lost in condensate streams. These amounts varied over a fairly small range from run to run except for TNM-100-HT. The two calculations also did not track each other due to accumulated uncertainties.

The result for TNM-100-HT nitrite to nitrate conversion was unusual. The results were different enough from the other six tests to suggest that they were not simply due to analytical uncertainty. This run actually showed a net nitrate loss within the SRAT slurry. This may have related to the higher formate loss somehow. The TNM-100-HT SRAT product sample was rechecked to confirm these results. A second sample of the bulk SRAT product was pulled for analysis, and this sample also confirmed the formate and nitrate concentrations. $\mathrm{CO}_{2}$ generation was as high as in runs with more added formic acid, which was consistent with the higher formate loss as well. The overall mass balance indicated more mass loss than five of the other six runs. All these observations are mutually consistent. Since this was the 
only run that used heat-treated simulant and trimmed noble metals, there is insufficient data to say that this would be the typical response of such a system.

The four dewatering samples from the MWWT during each SRAT run contained about 3-4 grams of nitrate. The FAVC had anywhere from one to seven grams of nitrate in the condensate accumulated during a run. The mass of condensate collected has been relatively variable historically. The reason for this has not been determined. The five Phase II FAVC samples that were analyzed had between 200,000 and $420,000 \mathrm{mg} / \mathrm{kg}$ nitrate, i.e. these were very concentrated in nitrate. (The calculations for CNM and TNM-100 do not account for nitrate in the FAVC. The plus signs following the MWWT+FAVC, $g$ values in these two columns are to indicate that the actual nitrate mass out in condensate would have been higher if these had been measured.) 
WSRC-TR-2005-00286

Revision 0

\section{APPENDIX C. SRAT PRODUCT ANALYTICAL RESULTS}


Additional SRAT product sample analytical results are presented in this appendix. The seven form of noble metal testing SRAT product slurries were characterized by ICP-AES, Table 15. This was necessary for material balance calculations, and it was also the only check on possible issues in batching the sludge into the SRAT vessel. The analysis of low concentration insoluble elementals was less critical than in the sludge simulants, since these species presumably tracked with the major elementals.

Table 15. Calcined Elementals in the Phase II SRAT Products

\begin{tabular}{|c|c|c|c|c|c|c|c|}
\hline $\begin{array}{l}\text { Calcined \% } \\
\text { elementals }\end{array}$ & CNM & CNM2 & $\begin{array}{c}\text { CNM- } \\
\text { HT }\end{array}$ & $\begin{array}{c}\text { TNM- } \\
100 \\
\end{array}$ & $\begin{array}{l}\text { TNM- } \\
100-2 \\
\end{array}$ & $\begin{array}{c}\text { TNM- } \\
65 \\
\end{array}$ & $\begin{array}{c}\text { TNM- } \\
100-H T\end{array}$ \\
\hline $\mathrm{Ag}$ & 0.012 & n.a. & n.a. & 0.017 & n.a. & n.a. & n.a. \\
\hline $\mathrm{Al}$ & 8.00 & 8.33 & 8.23 & 8.99 & 9.10 & 9.01 & 8.96 \\
\hline $\mathrm{Ba}$ & 0.049 & 0.050 & 0.051 & 0.050 & 0.061 & 0.060 & 0.059 \\
\hline $\mathrm{Ca}$ & 2.28 & 2.29 & 2.29 & 2.26 & 2.49 & 2.33 & 2.29 \\
\hline $\mathrm{Cd}$ & 0.061 & 0.098 & 0.088 & 0.060 & 0.078 & 0.066 & 0.115 \\
\hline $\mathrm{Ce}$ & 0.128 & 0.121 & 0.123 & 0.132 & 0.114 & 0.113 & 0.120 \\
\hline $\mathrm{Cr}$ & 0.235 & 0.234 & 0.229 & 0.224 & 0.217 & 0.217 & 0.191 \\
\hline $\mathrm{Cu}$ & 0.031 & 0.011 & 0.032 & 0.037 & 0.021 & 0.019 & 0.014 \\
\hline $\mathrm{Fe}$ & 24.2 & 23.1 & 23.6 & 23.9 & 23.4 & 23.4 & 24.1 \\
\hline Gd & 0.063 & 0.062 & 0.063 & 0.064 & 0.063 & 0.063 & 0.066 \\
\hline $\mathrm{K}$ & 0.311 & 0.392 & 0.385 & 0.264 & 0.296 & 0.277 & 0.327 \\
\hline $\mathrm{La}$ & 0.053 & 0.054 & 0.055 & 0.047 & 0.049 & 0.049 & 0.051 \\
\hline $\mathrm{Li}$ & n.a. & 0.134 & 0.133 & n.a. & $<0.10$ & $<0.10$ & $<0.10$ \\
\hline $\mathrm{Mg}$ & 1.77 & 1.73 & 1.75 & 1.75 & 2.03 & 2.06 & 2.07 \\
\hline $\mathrm{Mn}$ & 5.24 & 4.99 & 5.08 & 5.23 & 4.97 & 5.00 & 4.48 \\
\hline Mo & 0.072 & 0.070 & 0.069 & 0.069 & 0.061 & 0.061 & 0.065 \\
\hline $\mathrm{Na}$ & 20.0 & 20.2 & 19.7 & 19.2 & 18.8 & 18.7 & 18.4 \\
\hline $\mathrm{Ni}$ & 1.33 & 1.29 & 1.29 & 1.33 & 1.27 & 1.28 & 1.27 \\
\hline $\mathrm{P}$ & 0.606 & 0.580 & 0.580 & 0.578 & 0.564 & 0.564 & 0.534 \\
\hline $\mathrm{Pb}$ & $<0.01$ & $<0.01$ & $<0.01$ & $<0.01$ & $<0.01$ & $<0.01$ & $<0.01$ \\
\hline$S$ & 0.402 & 0.400 & 0.395 & 0.216 & 0.200 & 0.205 & 0.178 \\
\hline $\mathrm{Sb}$ & 0.076 & 0.078 & 0.078 & 0.083 & $<0.10$ & $<0.10$ & 0.108 \\
\hline $\mathrm{Si}$ & 0.605 & 0.611 & 1.01 & 0.72 & 0.671 & 0.668 & 0.938 \\
\hline Sn & 0.117 & 0.146 & 0.142 & 0.115 & 0.099 & 0.099 & 0.072 \\
\hline $\mathrm{Sr}$ & 0.501 & 0.482 & 0.483 & 0.497 & 0.490 & 0.490 & 0.504 \\
\hline $\mathrm{Ti}$ & 0.024 & 0.024 & 0.024 & 0.027 & 0.028 & 0.027 & 0.023 \\
\hline $\mathrm{Zn}$ & 0.045 & 0.042 & 0.050 & 0.058 & 0.046 & 0.050 & 0.056 \\
\hline $\mathrm{Zr}$ & $<0.01$ & $<0.01$ & $<0.01$ & $<0.01$ & 0.012 & 0.008 & $<0.01$ \\
\hline$\sum$ oxides & 97.4 & 96.5 & 97.4 & 97.3 & 96.1 & 95.9 & 96.2 \\
\hline
\end{tabular}

n.a. $=$ not analyzed

Results are generally consistent within each of the two groups (with and without co-precipitated noble metals). Results also are consistent with those for the starting sludges in Table 1, page 4, and in Koopman (2005c). 
Table 16 summarizes the SRAT product slurry IC anion data. IC anion analysis of the SRAT product focused on nitrite, nitrate, and formate, since these relate to the material balance and to the predicted redox.

Table 16. Phase II SRAT Product Slurry Anions

\begin{tabular}{|l|c|r|r|r|r|r|c||}
\hline & CNM & CNM2 & $\begin{array}{c}\text { CNM- } \\
\text { HT }\end{array}$ & $\begin{array}{c}\text { TNM- } \\
100\end{array}$ & $\begin{array}{c}\text { TNM- } \\
100-2\end{array}$ & $\begin{array}{c}\text { TNM- } \\
65\end{array}$ & $\begin{array}{c}\text { TNM- } \\
100-H T\end{array}$ \\
\hline Nitrite, $\mathrm{mg} / \mathrm{kg}$ & $<100$ & $<100$ & $<100$ & $<100$ & $<100$ & $<100$ & $<100$ \\
\hline Nitrate, $\mathrm{mg} / \mathrm{kg}$ & 47,200 & 40,900 & 41,200 & 47,600 & 40,300 & 41,100 & 34,750 \\
\hline Formate, $\mathrm{mg} / \mathrm{kg}$ & 83,100 & 77,700 & 76,000 & 79,300 & 74,300 & 75,500 & 64,750 \\
\hline Chloride, $\mathrm{mg} / \mathrm{kg}$ & 210 & 206 & 206 & 242 & 242 & 218 & 250 \\
\hline
\end{tabular}

Table 17 gives the corresponding wt. \%, pH, and density data for the SRAT product slurries.

Table 17. Other Phase II SRAT Product Properties

\begin{tabular}{|l|r|r|r|r|r|r|r|}
\hline & CNM & CNM2 & $\begin{array}{c}\text { CNM- } \\
\text { HT }\end{array}$ & $\begin{array}{c}\text { TNM- } \\
100\end{array}$ & $\begin{array}{c}\text { TNM- } \\
100-2\end{array}$ & $\begin{array}{c}\text { TNM- } \\
65\end{array}$ & $\begin{array}{c}\text { TNM- } \\
100-H T\end{array}$ \\
\hline Wt.\% TS & 23.63 & 23.04 & 23.52 & 23.80 & 23.44 & 23.38 & 23.55 \\
\hline Wt.\% IS & 9.79 & 9.36 & 10.10 & 9.80 & 9.89 & 9.76 & 9.24 \\
\hline Wt.\% SS & 13.85 & 13.68 & 13.42 & 14.00 & 13.56 & 13.62 & 14.31 \\
\hline Wt.\% CS & 14.74 & 14.53 & 14.88 & 15.15 & 15.05 & 14.99 & 15.27 \\
\hline pH & 4.20 & 6.23 & 4.81 & 5.03 & 5.67 & 5.14 & 5.41 \\
\hline Density & 1.18 & 1.15 & 1.20 & 1.20 & 1.22 & 1.21 & 1.14 \\
\hline
\end{tabular}

TS=total solids, IS=insoluble solids, $S S=$ soluble solids, $C S=$ calcined solids

Solids and density results were consistent from run to run. Variations in SRAT product sample pH are not unusual.

The measured SRAT product total solids were lower than expected from the acid calculation spreadsheet. This spreadsheet takes into account the destruction of nitrite, the conversion of nitrite into nitrate, the loss of formate, the destruction of carbonate to carbon dioxide, and the neutralization of titrated base by acid to water plus salt. The destruction of nitrite mass loss calculation is only approximate, because it assumes an intermediate consumption of acid from the three identified parallel paths for this reaction.

Table 18. Phase II SRAT Product Total Solids

\begin{tabular}{|l|r|r|r|r|r|r|c||}
\hline & CNM & CNM2 & $\begin{array}{c}\text { CNM- } \\
\text { HT }\end{array}$ & $\begin{array}{c}\text { TNM- } \\
100\end{array}$ & $\begin{array}{c}\text { TNM- } \\
100-2\end{array}$ & $\begin{array}{c}\text { TNM- } \\
65\end{array}$ & $\begin{array}{c}\text { TNM- } \\
100-H T\end{array}$ \\
\hline Wt.\% measured & 23.63 & 23.04 & 23.52 & 23.80 & 23.44 & 23.38 & 23.55 \\
\hline Wt.\% predicted & 27.01 & 25.89 & 26.02 & 26.90 & 25.92 & 25.94 & 24.92 \\
\hline Difference & 3.38 & 2.85 & 2.48 & 3.10 & 2.48 & 2.56 & 1.37 \\
\hline
\end{tabular}

The average difference between predicted and measured solids was $2.6 \%$. The difference was smallest for both heat-treated cases in their respective groups. The inference would be that some of the lost base equivalents molarity accompanying heat-treatment was at the expense of some insoluble hydroxide solids that were reacting to form water in the un-heat-treated SRAT cycles. The more important feature to the 
hydrogen generation program was that all seven SRAT products were within 0.45 wt. \% of the mean SRAT product wt. \% of 23.48. This means that the reactants and catalysts for hydrogen generation were about equally concentrated in all of the tests.

Similar data from the Phase I study on mercury-noble metal interactions are shown in Table 19 for comparison. Details concerning Tests 1-6 from Phase I can be found in Koopman (2005a).

Table 19. SRAT Product Total Solids in Phase I Tests

\begin{tabular}{|l|r|r|r|r|r|r||}
\hline & \multicolumn{1}{|c|}{ Test 1 } & \multicolumn{1}{|c|}{ Test 2 } & \multicolumn{1}{|c|}{ Test 3 } & \multicolumn{1}{|c|}{ Test 4 } & \multicolumn{1}{|c|}{ Test 5 } & Test 6 \\
\hline Wt.\% measured & 28.10 & 28.22 & 28.26 & 28.15 & 28.28 & 28.20 \\
\hline Wt.\% predicted & 29.23 & 29.92 & 29.27 & 30.05 & 30.18 & 29.33 \\
\hline Difference & 1.13 & 1.70 & 1.01 & 1.90 & 1.90 & 1.13 \\
\hline
\end{tabular}

The average difference between measured and predicted total solids in this set of six runs was only $1.46 \%$ or nearly half of the Phase II average. In these and other cases using traditional simulants, the projected total solids and measured total solids have been fairly close (within 1-2\%). The most likely explanation for the difference in Phase II testing is that more of the insoluble co-precipitated simulant hydroxides were susceptible to neutralization than the traditional simulants used in Phase I. Neutralization of insoluble hydroxides converts solid mass to water mass. A reliable means of estimating the extent of neutralization of insoluble solids during SRAT processing was not available, but this may be part of the explanation as to why the stoichiometric acid calculation needs a significant correction factor.

There also was about a $\%$ drop in insoluble solids wt. \% from the sludge to the SRAT product in both Phase I and Phase II. This suggests that the explanation from the preceding paragraph needs further investigation. It is also possible that the difference might be related to changes made in the experimental equipment between Phase I and Phase II. These have altered nitrite to nitrate conversion and formate loss. They may have also impacted the prediction of total solids in the SRAT product. 
WSRC-TR-2005-00286

Revision 0

\section{APPENDIX D. ADDITIONAL SRAT RUN DATA}


Additional data beyond those presented to this point were obtained during each SRAT simulation. This included off-gas data for species other than $\mathrm{H}_{2}$ and $\mathrm{CO}_{2}$ such as $\mathrm{NO}$ and $\mathrm{N}_{2} \mathrm{O}$. Samples of condensate from the MWWT and FAVC were taken to investigate condensable species in the system that might impact hydrogen generation during refluxing, Koopman (2005a). This section presents the balance of the SRAT data, except for some data from the two preliminary runs which were presented in Appendix A.

A sampling program was initiated to track concentrations in the dewatering samples. Each run produced four samples. Each sample was a composite of material passing through the MWWT. It should be recalled, however, that the MWWT is not mixed. The first two samples in each set were approximately $125 \mathrm{~g}$ each. These are denoted by -MWWT-1 and -MWWT-2 in Table 20 and Table 21. The initial sample, -MWWT-1, was working against a pre-run charge of $50 \mathrm{~g}$ of de-ionized water used to fill the MWWT, i.e. there was a dilution effect. The sample accumulated from start-up through nitric acid addition and through about one hour into formic acid addition. The CNM-MWWT-1 sample, however, was completed at nearly the same time as the start of formic acid addition. The -MWWT-2 samples started immediately following the -MWWT-1 samples, and they were typically completed $1 / 2$ to $2-1 / 2$ hours before the end of formic acid addition. The third samples were larger than -MWWT-1 and - 2 . They were typically 200-250 g, depending on the precise dewater mass targeted. They were completed just before the start of reflux. These three samples each covered about the same length of processing time. The final samples, -MWWT-4, were the entire contents of the MWWT at the end of the SRAT cycle, or about $50 \mathrm{~g}$.

Anions in these samples were tracked in species material balances, Appendix B. Other properties were checked as well. This included $\mathrm{pH}$ and density. Elementals were run on two sets of the samples. Density was only checked on the final five runs, not the two preliminary runs. This measurement was started when the analyses were expanded to include the FAVC condensate. This condensate was more concentrated than any of the MWWT condensates. Its density was not essentially that of water.

IC anions failed to detect nitrite, chloride, sulfate, phosphate, or oxalate at the detection limit of $100 \mathrm{mg} / \mathrm{L}$ in any of the seven sets of samples. Table 20 gives the four MWWT results for each of the three runs based on the co-precipitated noble metal simulant.

Table 20. MWWT Analyses - Co-precipitated Noble Metal Tests

\begin{tabular}{|l|c|c|c|c|}
\hline & Nitrate, $\mathrm{mg} / \mathrm{L}$ & Formate, $\mathrm{mg} / \mathrm{L}$ & $\mathrm{pH}$ & Density, g/mL \\
\hline CNM-MWWT-1 & 2645 & $<100$ & 1.00 & n.a. \\
\hline CNM-MWWT-2 & 3945 & 5130 & 0.83 & n.a. \\
\hline CNM-MWWT-3 & 13,100 & 13,550 & 0.32 & n.a. \\
\hline CNM-MWWT-4 & 192 & 5235 & 1.60 & n.a. \\
\hline CNM2-MWWT-1 & 2185 & 589 & 1.56 & 1.01 \\
\hline CNM2-MWWT-2 & 12,150 & 5630 & 0.72 & 1.01 \\
\hline CNM2-MWWT-3 & 4430 & 13,450 & 1.05 & 1.01 \\
\hline CNM2-MWWT-4 & $<100$ & 1750 & 2.32 & 1.00 \\
\hline CNM-HT-MWWT-1 & 2520 & 1385 & 1.00 & 1.00 \\
\hline CNM-HT-MWWT-2 & 14,800 & 5000 & 0.60 & 1.01 \\
\hline CNM-HT-MWWT-3 & 4225 & 11,200 & 0.90 & 1.00 \\
\hline CNM-HT-MWWT-4 & 211 & 2040 & 1.74 & 1.00 \\
\hline
\end{tabular}

n.a. = not analyzed (presumably between 1.00-1.01) 
CNM-MWWT-2 completed two-and-a-half hours before the end of formic acid addition, which may explain why the nitrate peak was found in CNM-MWWT-3 instead of CNM-MWWT-2. Most of the -MWWT-2 samples collected material from later in acid addition, i.e. during the primary period of nitrite destruction.

The corresponding data for the four runs with trimmed noble metals are given in Table 21.

Table 21. MWWT Analyses - Trimmed Noble Metal Tests

\begin{tabular}{|l|r|r|c|c||}
\hline & Nitrate, $\mathrm{mg} / \mathrm{L}$ & Formate, $\mathrm{mg} / \mathrm{L}$ & $\mathrm{pH}$ & Density, g/mL \\
\hline TNM-100-MWWT-1 & 2365 & 186 & 1.12 & n.a. \\
\hline TNM-100-MWWT-2 & 14,700 & 4810 & 0.28 & n.a. \\
\hline TNM-100-MWWT-3 & 6195 & 19,100 & 0.51 & n.a. \\
\hline TNM-100-MWWT-4 & 100 & 2400 & 1.73 & n.a. \\
\hline TNM-100-2-MWWT-1 & 2480 & 755 & 0.64 & 1.01 \\
\hline TNM-100-2-MWWT-2 & 17,000 & 8560 & 2.74 & 1.01 \\
\hline TNM-100-2-MWWT-3 & 6385 & 14,500 & 3.08 & 1.01 \\
\hline TNM-100-2-MWWT-4 & 514 & 1455 & 1.12 & 1.01 \\
\hline TNM-65-MWWT-1 & 1900 & 691 & 0.45 & 1.01 \\
\hline TNM-65-MWWT-2 & 14,850 & 5370 & 2.66 & 1.01 \\
\hline TNM-65-MWWT-3 & 5865 & 14,550 & 3.04 & 1.00 \\
\hline TNM-65-MWWT-4 & 186 & 803 & 1.35 & 1.01 \\
\hline TNM-100-HT-MWWT-1 & 2200 & 1560 & 1.81 & 1.00 \\
\hline TNM-100-HT-MWWT-2 & 14,500 & 7845 & 0.80 & 1.01 \\
\hline TNM-100-HT-MWWT-3 & 2070 & 10,350 & 1.82 & 1.01 \\
\hline TNM-100-HT-MWWT-4 & 151 & 339 & 2.85 & 1.01 \\
\hline
\end{tabular}

n.a. $=$ not analyzed (presumably between 1.00-1.01)

There are issues with $\mathrm{pH}$ measurement at these low values, such as choice of standards, etc. Measurements were often made many days apart on the different sets. This increased the likelihood that different probes would be used. It was unlikely that the samples TNM-100-MWWT-3 and TNM-65MWWT-3 actually had higher pHs than CNM2-MWWT-3, since they both had more formate and nitrate than CNM2-MWWT-3. Also, the expected trend was for the fourth samples, e.g. TNM-100-MWWT-4, to have a higher $\mathrm{pH}$ than any of the second and third samples, but this was not always observed. It was observed that nitrate and formate were always at lower concentrations in the fourth samples than in the third, however, which should have correlated with a higher $\mathrm{pH}$.

There was a tendency for nitrate to peak in the second sample, while formate tended to peak in the third sample. This was related to the timing of the samples relative to nitrite destruction and the end of formic acid addition. Formate tended to be more persistent than nitrate toward the end of the SRAT (the fourth samples). This seems logical. Formic acid is both more volatile and more concentrated than molecular nitric acid in the SRAT during reflux. Formate in the fourth samples may be tracking the SRAT pH. Higher formate in the fourth samples seemed to correlate with lower pH's in the SRAT slurries late in the reflux period and in the SRAT product samples. This would indicate that the evaporated formate species is probably molecular formic acid. The concentration of molecular formic acid in the SRAT increases as $\mathrm{pH}$ decreases, when the concentration of formate ion is relatively constant as was the case in these runs. A higher formic acid concentration is consistent with an increased evaporation rate for formic acid when SRAT pH is lower, e.g. standard vapor-liquid equilibrium calculations would indicate this. 
The MWWT seemed to be transitioning between the third and fourth samples, i.e. at the time that the reflux was initiated. This was the point of interest to hydrogen generation from the standpoint of how reflux impacted hydrogen generation. There was probably some nitrate present, but the main anion was formate. Nitrite was negligible in all of the samples from the MWWT. Nevertheless, there was a brief renewal of $\mathrm{N}_{2} \mathrm{O}$ and $\mathrm{NO}$ generation associated with the onset of reflux.

The timing of the $\mathrm{NO}$ and $\mathrm{N}_{2} \mathrm{O}$ generation is best illustrated with figures. Figure 22 and Figure 23 show NO generation profiles for the five non-preliminary SRAT runs in Phase II.

Figure 22. NO Generation in Normal Simulant Tests

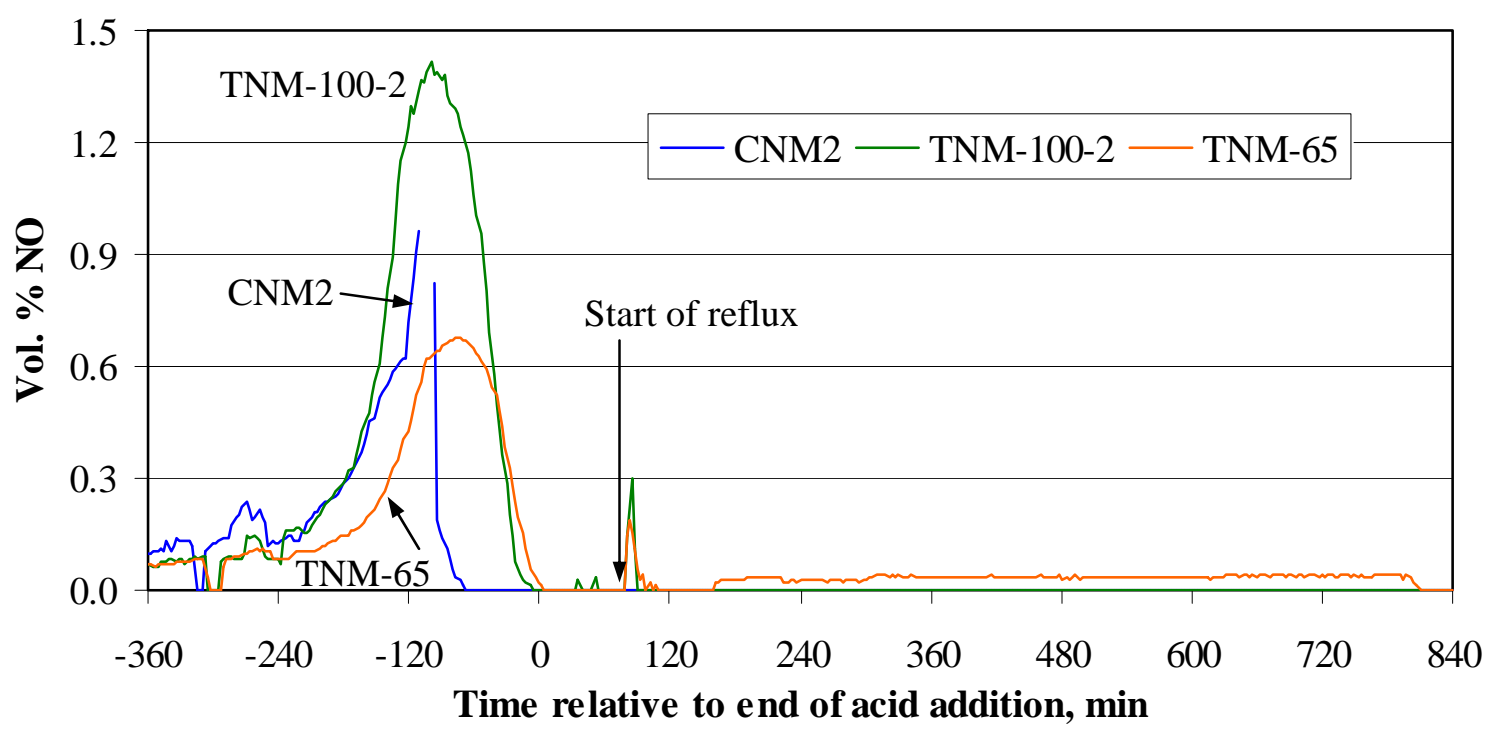

Figure 23. NO Generation in Heat-treated Simulant Tests

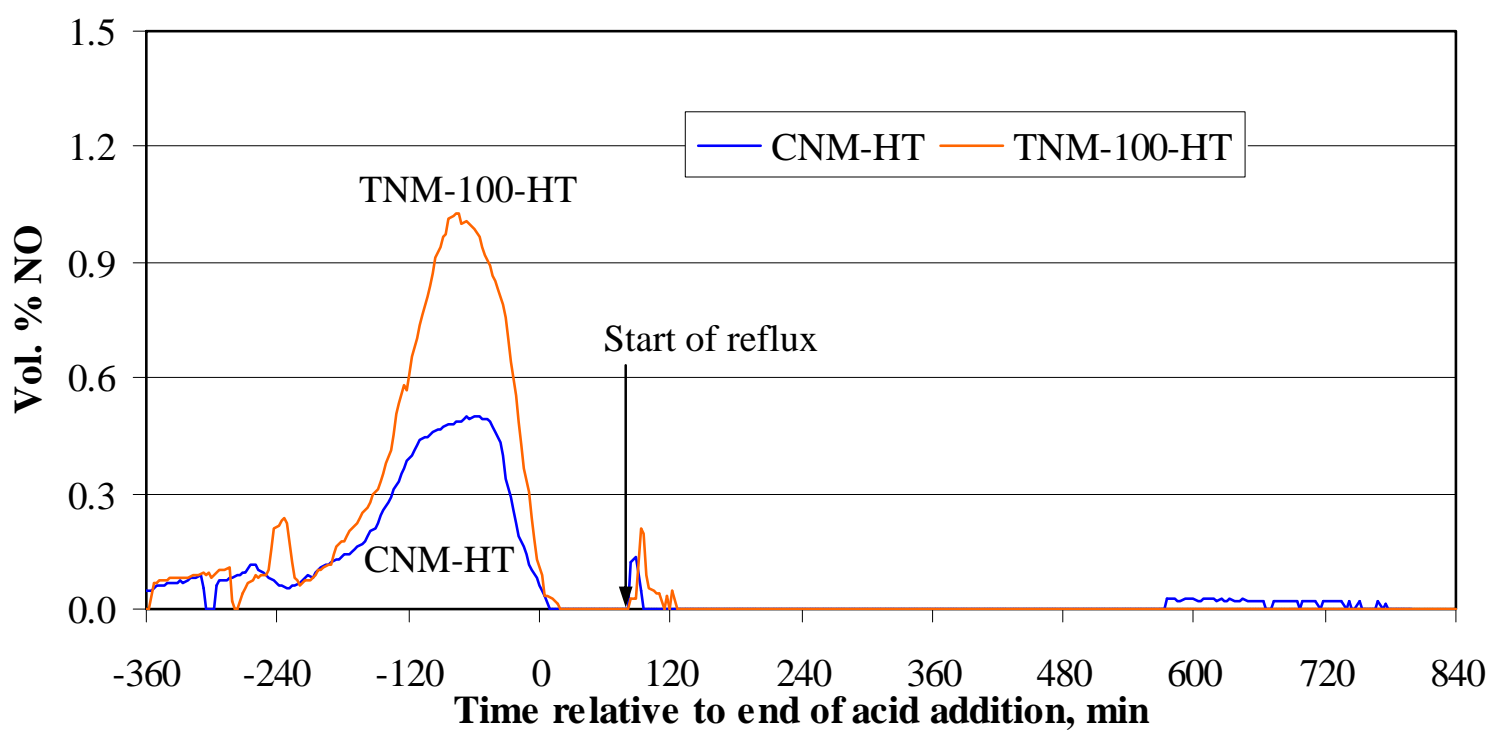


The small bursts of NO generation immediately following the start of reflux are clearly seen in the data about 90 minutes after the end of acid addition. Figure 24 and Figure 25 show the corresponding $\mathrm{N}_{2} \mathrm{O}$ data for the five non-preliminary runs of Phase II.

Figure 24. $\mathrm{N}_{2} \mathrm{O}$ Generation in Normal Simulant Tests

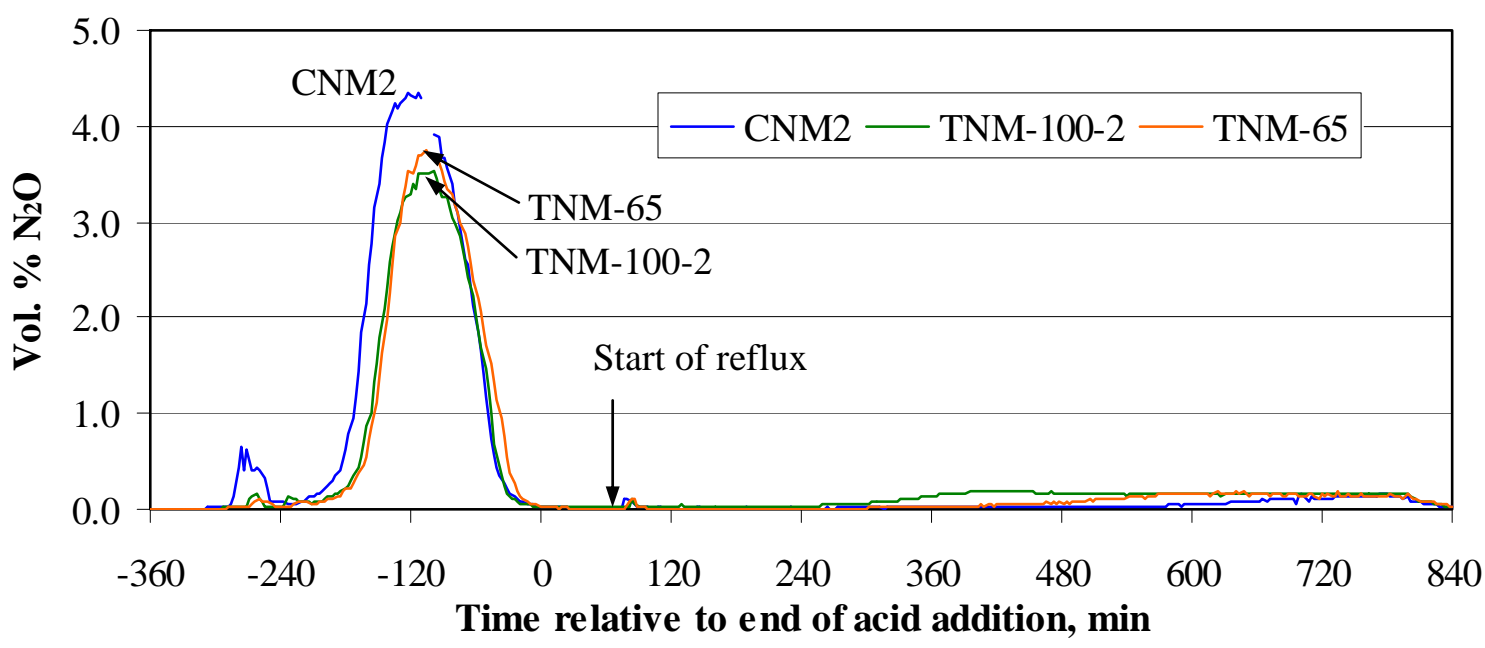

Figure 25. $\mathrm{N}_{2} \mathrm{O}$ Generation in Heat-treated Simulant Tests

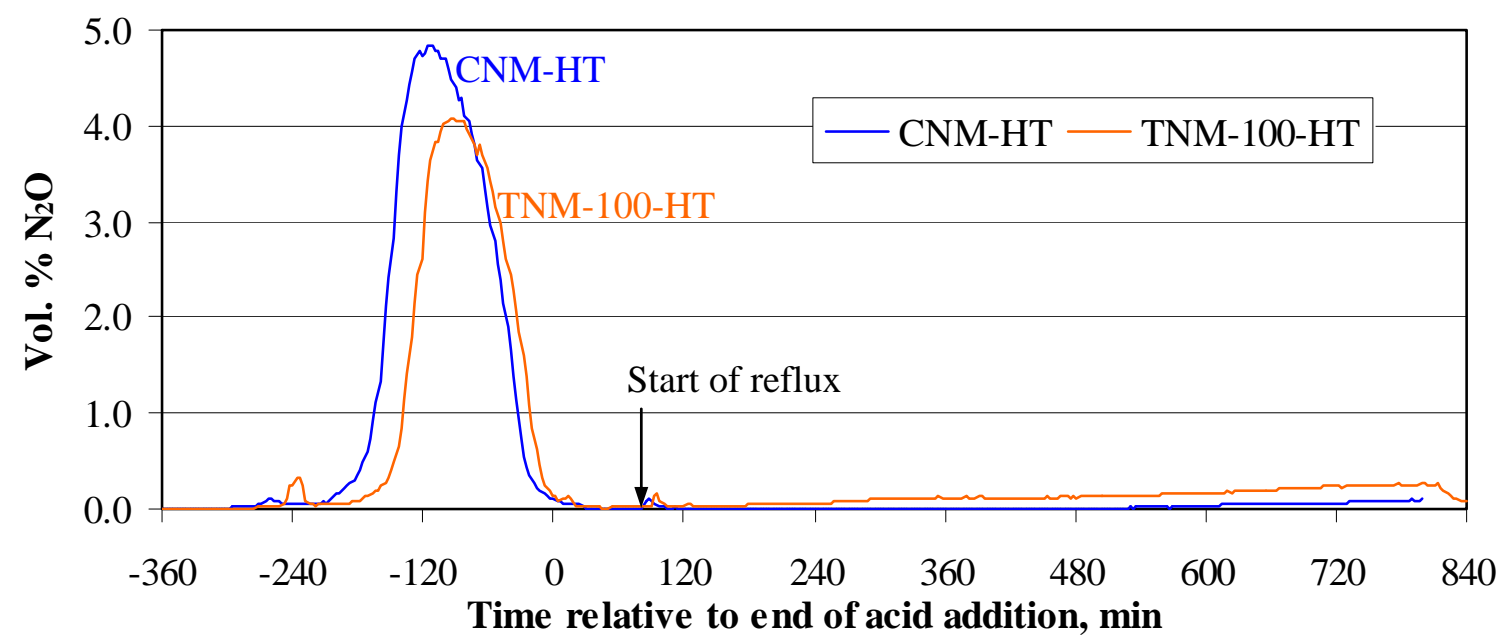

The $\mathrm{N}_{2} \mathrm{O}$ generation at the start of reflux was less evident than for the NO data. One reason was the 3.3 times larger range on the vol. \% axis of the $\mathrm{N}_{2} \mathrm{O}$ graphs. Most of the -MWWT-2 samples covered the period from -360 minutes through about -30 to -90 minutes when $\mathrm{NO}$ and $\mathrm{N}_{2} \mathrm{O}$ were peaking. Most of the -MWWT-3 samples captured the tail end of the $\mathrm{NO}$ and $\mathrm{N}_{2} \mathrm{O}$ peaks plus the end of formic acid addition and all of dewatering. The end of formic acid addition is the period where the excess acid is accumulated and where the $\mathrm{pH}$ is lowest. These are the conditions most favorable to the evaporation of molecular formic acid (maximum concentration of molecular formic acid occurs around this time).

Precise numerical comparisons of the MWWT sample results between the seven runs are complicated by the existing experimental controls. Refluxing is stopped periodically for about four to five minutes to check the boil-up rate. During these tests, condensate is accumulated in the MWWT. Following each 
test, refluxing resumed, and the MWWT volume returned to normal. These boil-up rate checks tended to churn the contents of the MWWT more than simple refluxing. (Boil-up rate is controlled close to the equivalent of $5000 \mathrm{lbs} / \mathrm{hr}$, but there are variations from run to run as well as during a run.)

Selected elemental data were obtained on the condensate samples from the two runs with $100 \%$ noble metals that were not heat-treated. These data are given in Table 22.

Table 22. Elemental Composition of MWWT Condensate Samples

\begin{tabular}{|l|c|c|c|c|c|c|c|c|c|c|c||}
\hline & $\mathrm{Al}$ & $\mathrm{Ca}$ & $\mathrm{Fe}$ & $\mathrm{Gd}$ & $\mathrm{K}$ & $\mathrm{Mg}$ & $\mathrm{Mn}$ & $\mathrm{Na}$ & $\mathrm{Ni}$ & $\mathrm{Si}$ & $\mathrm{Zn}$ \\
\hline & $\mathrm{mg} / \mathrm{L}$ & $\mathrm{mg} / \mathrm{L}$ & $\mathrm{mg} / \mathrm{L}$ & $\mathrm{mg} / \mathrm{L}$ & $\mathrm{mg} / \mathrm{L}$ & $\mathrm{mg} / \mathrm{L}$ & $\mathrm{mg} / \mathrm{L}$ & $\mathrm{mg} / \mathrm{L}$ & $\mathrm{mg} / \mathrm{L}$ & $\mathrm{mg} / \mathrm{L}$ & $\mathrm{mg} / \mathrm{L}$ \\
\hline TNM-100-2 & & & & & & & & & & & \\
\hline MWWT-1 & 0.104 & 0.107 & 0.056 & $<0.01$ & 0.268 & $<0.01$ & 0.014 & $<0.50$ & $<0.01$ & 232 & $<0.01$ \\
\hline MWWT-2 & 0.090 & 0.116 & 0.106 & $<0.01$ & 0.269 & $<0.01$ & 0.031 & $<0.50$ & $<0.01$ & 77.5 & $<0.01$ \\
\hline MWWT-3 & 0.094 & 0.073 & $<0.04$ & $<0.01$ & 0.225 & $<0.01$ & $<0.01$ & $<0.50$ & $<0.01$ & 321 & $<0.01$ \\
\hline MWWT-4 & 0.087 & 0.060 & $<0.04$ & $<0.01$ & 0.258 & $<0.01$ & $<0.01$ & $<0.50$ & $<0.01$ & 190 & $<0.01$ \\
\hline CNM2 & & & & & & & & & & & \\
\hline MWWT-1 & 0.098 & 0.073 & 0.121 & $<0.01$ & 0.291 & $<0.01$ & 0.026 & 0.456 & $<0.01$ & 243 & $<0.01$ \\
\hline MWWT-2 & 0.132 & 0.118 & 0.176 & $<0.01$ & 0.234 & 0.026 & 0.126 & 1.33 & $<0.01$ & 68.3 & $<0.01$ \\
\hline MWWT-3 & 0.128 & 0.053 & $<0.04$ & $<0.01$ & 0.193 & $<0.01$ & 0.051 & $<0.50$ & $<0.01$ & 314 & $<0.01$ \\
\hline MWWT-4 & 0.085 & 0.548 & $<0.04$ & $<0.01$ & 0.253 & $<0.01$ & $<0.01$ & $<0.50$ & $<0.01$ & 131 & $<0.01$ \\
\hline
\end{tabular}

Silicon is the only major element in these samples. It is over a hundred times more abundant than sodium, potassium, calcium, aluminum, iron, magnesium, and manganese combined. Gadolinium, nickel, and zinc never reached detectable concentrations. Silicon approached 0.01M. Silicon could come from $\mathrm{SiO}_{2}$ in the sludge and/or from decomposition products of the 747 antifoam. Peak nitrate and formate concentrations were in the vicinity of $0.3 \mathrm{M}$. This confirms that the nitrate and formate are primarily present as nitric and formic acids in the condensate samples.

Samples of the FAVC were analyzed for the five main runs. It took an entire SRAT simulation to produce about ten grams of condensate in the FAVC. It was not possible to run all desired dilutions due to the limited amount of sample.

Table 23. FAVC Condensate Analyses

\begin{tabular}{||l|c|c|c|c|c||}
\hline & Nitrate, $\mathrm{mg} / \mathrm{L}$ & Formate, $\mathrm{mg} / \mathrm{L}$ & Silicon, $\mathrm{mg} / \mathrm{L}$ & $\mathrm{pH}$ & Density, g/mL \\
\hline TNM-100-2 & 419,000 & 1100 & 337 & 0.82 & 1.22 \\
\hline TNM-65 & 228,000 & 1025 & n.a. & 1.09 & 1.13 \\
\hline TNM-100-HT & 182,000 & 1185 & n.a. & 2.24 & 1.10 \\
\hline CNM2 & 241,000 & 1535 & 307 & 2.28 & 1.13 \\
\hline CNM-HT & 318,000 & 1295 & n.a. & 2.30 & 1.15 \\
\hline
\end{tabular}

n.a. - not analyzed

The TNM-65 sample was 3.68M in nitrate. $3.74 \mathrm{M}$ nitric acid solution has a density of $1.12 \mathrm{~g} / \mathrm{mL}$ at $20^{\circ} \mathrm{C}$. The CNM2 sample was $5.13 \mathrm{M}$ in nitrate. $5.18 \mathrm{M}$ nitric acid solution has a density of $1.167 \mathrm{~g} / \mathrm{mL}$ at $20^{\circ} \mathrm{C}$. Both sample results were consistent with the condensates being essentially nitric acid solutions plus minor impurities. The $\mathrm{pH}$ readings in Table 23 are likely too high. The true $\mathrm{pH}$ values of most samples were probably less than 1.0. The results indicated that a net enrichment of nitrate relative to formate had occurred in the two stage condensation of the SRAT off-gas. 


\section{Distribution:}

E. W. Holtzscheiter, SRNL

D. A. Crowley, 999-W

S. L. Marra, 999-W

T. B. Calloway, 999-W

N. E. Bibler, SRNL

C. M. Jantzen, SRNL

G. C. Wicks, SRNL

J. R. Harbour, 773-42A

C. A. Langton, 773-43A

T. L. Fellinger, SRNL

C. C. Herman, 773-42A

C. J. Bannochie, 773-42A

M. E. Stone, 999-W

R. E. Eibling, 999-W

J. M. Pareizs, SRNL

M. J. Barnes, SRNL

M. S. Miller, 704-S

J. E. Occhipinti, 704-S

R. M. Hoeppel, 704-27S

H. H. Elder, 766-H

J. F. Iaukea, 704-30S

J. W. Ray, 704-S

F. A. Washburn, 704-27S

P. M. Patel, 704-27S

R. N. Mahannah, 704-28S

A. B. Sanders, 704-27S

W. B. Van-Pelt, 704-S 